\title{
Global macroeconomic scenarios of the COVID-19 pandemic
}

\section{CAMA Working Paper 62/2020 June 2020}

\author{
Warwick McKibbin \\ Centre for Applied Macroeconomic Analysis, ANU \\ The Brookings Institution \\ Centre of Excellence in Population Ageing Research (CEPAR)

\section{Roshen Fernando} \\ Centre for Applied Macroeconomic Analysis, ANU \\ Centre of Excellence in Population Ageing Research (CEPAR)
}

\section{Abstract}

The COVID-19 global pandemic has caused significant global economic and social disruption. In McKibbin and Fernando (2020), we used data from historical pandemics to explore seven plausible scenarios of the economic consequences if COVID-19 were to become a global pandemic. In this paper, we use currently observed epidemiological outcomes across countries and recent data on sectoral shutdowns and economic shocks to estimate the likely impact of COVID-19 pandemic on the global economy in coming years under six new scenarios. The first scenario explores the outcomes if the current course of COVID-19 is successfully controlled, and there is only a mild recurrence in 2021. We then explore scenarios where the opening of economies results in recurrent outbreaks of various magnitudes and countries respond with and without economic shutdowns. We also explore the impact if no vaccine becomes available and the world must adapt to living with COVID-19 in coming decades. The final scenario is the case where a given country is in the most optimistic scenario (scenario 1), but the rest of the world is in the most pessimistic scenario.

The scenarios in this paper demonstrate that even a contained outbreak (which is optimistic), will significantly impact the global economy in the coming years. The economic consequences of the COVID-19 pandemic under plausible scenarios are substantial and the ongoing economic adjustment is far from over. 


\title{
Keywords
}

Pandemics, infectious diseases, risk, macroeconomics, DSGE, CGE, G-Cubed

\author{
JEL Classification
}

C54, C68, F41

\section{Address for correspondence:}

(E) cama.admin@anu.edu.au

ISSN 2206-0332

The Centre for Applied Macroeconomic Analysis in the Crawford School of Public Policy has been established to build strong links between professional macroeconomists. It provides a forum for quality macroeconomic research and discussion of policy issues between academia, government and the private sector.

The Crawford School of Public Policy is the Australian National University's public policy school, serving and influencing Australia, Asia and the Pacific through advanced policy research, graduate and executive education, and policy impact. 


\title{
Global Macroeconomic Scenarios of the COVID-19 Pandemic
}

\author{
Warwick McKibbin ${ }^{1} \&$ Roshen Fernando ${ }^{2}$
}

24 June 2020

\begin{abstract}
The COVID-19 global pandemic has caused significant global economic and social disruption. In McKibbin and Fernando (2020), we used data from historical pandemics to explore seven plausible scenarios of the economic consequences if COVID-19 were to become a global pandemic. In this paper, we use currently observed epidemiological outcomes across countries and recent data on sectoral shutdowns and economic shocks to estimate the likely impact of COVID-19 pandemic on the global economy in coming years under six new scenarios. The first scenario explores the outcomes if the current course of COVID-19 is successfully controlled, and there is only a mild recurrence in 2021. We then explore scenarios where the opening of economies results in recurrent outbreaks of various magnitudes and countries respond with and without economic shutdowns. We also explore the impact if no vaccine becomes available and the world must adapt to living with COVID-19 in coming decades. The final scenario is the case where a given country is in the most optimistic scenario (scenario 1), but the rest of the world is in the most pessimistic scenario.
\end{abstract}

The scenarios in this paper demonstrate that even a contained outbreak (which is optimistic), will significantly impact the global economy in the coming years. The economic consequences of the COVID-19 pandemic under plausible scenarios are substantial and the ongoing economic adjustment is far from over.

Keywords: Pandemics, infectious diseases, risk, macroeconomics, DSGE, CGE, G-Cubed

JEL Codes: C54, C68, F41

We gratefully acknowledge financial support from the Australia Research Council Centre of Excellence in Population Ageing Research (CE170100005). We thank Renee Fry-McKibbin, Jeff Oughton, Louise Sheiner and David Wessel and participants at a CAMA webinar for helpful comments. We thank Ausgrid for providing electricity use data that assisted in the calibration of shocks and Peter Wilcoxen and Larry Weifeng Liu for their research collaboration on the G-Cubed model. We also acknowledge the contributions to earlier research on modelling of pandemics with Jong-Wha Lee and Alexandra Sidorenko.

${ }^{1}$ Australian National University; the Brookings Institution; and Centre of Excellence in Population Ageing Research (CEPAR)

${ }^{2}$ Australian National University and Centre of Excellence in Population Ageing Research (CEPAR) 


\section{Introduction}

In late 2019, a novel coronavirus was causing infections in China. The virus had close virological characteristics to the coronavirus that caused SARS (SARS-CoV) and was named SARS-CoV-2. Even though the SARS-CoV-2 has been less fatal than SARS-CoV, SARSCoV-2 has been much more infectious. Shortly after the Chinese outbreak, other countries also began reporting cases. The evolving epidemic was officially declared a pandemic by the World Health Organization (WHO) on 11 March 2020.

In early February 2020, we undertook a study that applied data from historical pandemics, information on the evolving epidemic in China and our experience from modelling SARS and Bird Flu to explore the potential global economic implications of COVID-19 under seven

plausible scenarios in a global economic model. "The global macroeconomic impacts of COVID-19: seven scenarios" was released on 2 March 2020. Early results were made available to policymakers in major economies and international institutions. At the time the paper was written, it was still uncertain whether the outbreak would translate into a pandemic. Thus, to estimate what could be the likely costs of a pandemic, three of the seven scenarios explored the economic costs to the world if the outbreak only occurred in China and four of the scenarios explored the global economic costs if a global pandemic occurred but at varying degrees of attack rates and case fatality rates.

The evolution of the pandemic and the economic implications continue to be highly uncertain. However, as new information emerges, notably greater understanding through scientifically based interventions in some countries and outright failure in others, the nature of the uncertainty has changed. Initially, uncertainty was about how close COVID-19 would be to the historical experience of pandemics. After six months, the concern is now about how frequently the pandemic might recur and how high the economic costs of responding or not responding in some countries might be. Policy in many countries initially was designed to contain the virus and to minimise economic disruption, particularly in the labour market. The focus now is how to open economies hit with a massive economic shock and how economies will adapt to the post-COVID-19 world. It is uncertain whether a vaccine will be available in time to prevent more pandemic waves and, if not, what would be the least costly option of managing them. It is an open question of whether lockdowns are the right option for managing recurring waves or if it will be possible for people to adapt to long-term social distancing and improved hygiene practices. 
In this paper, we attempt to guide policymakers determine how different responses might change possible economic futures. In addition to our previous experience in modelling pandemics and particularly COVID-19, we capitalise on the novel, yet imperfect, information on cases and responses to the pandemic worldwide.

The paper is structured as follows. The next section places the current study in the context of our previous study and other recent studies conducted by the International Monetary Fund (IMF), the Organization for Economic Cooperation and Development (OECD) and the World Bank on economic repercussions of COVID-19. Section 3 summarises the G-Cubed model used in the study. Section 4 explains in depth how and why different scenarios and shocks were constructed. The results from the simulations are presented in Section 5 before we conclude and present possible policy implications arising from the study in the final section.

\section{Studies on Global Macroeconomics of COVID-19}

When we conducted our first study, it was still uncertain whether the outbreak in China would spread to the rest of the world. Thus, our study included three scenarios where the outbreak was contained in China, still varying the proportion of people getting infected (the attack rate). We also varied the mortality rates using the case-fatality rate for SARS as a benchmark. The remaining four scenarios explored the economic implications if the outbreak were to translate into a global pandemic. Similar to the first three scenarios, we had three attack rates with varying degrees of mortality, resembling those of SARS and flu. The seventh scenario was a recurring pandemic at a moderate attack rate and case-fatality rate. Table 1 summarises these scenarios.

A handful of countries from East Asia and the Middle East had some previous experience with coronavirus outbreaks. However, the vast majority of the countries had limited experience. Thus, when formulating the shocks in the original study, including the mortality and morbidity, impact on productivity and consumption as well as changes in sector risk premia and government expenditure, the formulation of shocks for other countries used China as a benchmark. In the study, the susceptibility to a coronavirus outbreak for other countries relative to China was modelled using an Index of Vulnerability. This index considered population density within a given country, openness to tourism and health and sanitation standards of the country. 
Table 1 - Scenario assumptions in The Global Macroeconomic Impacts of COVID-19: Seven Scenarios

\begin{tabular}{|c|c|c|c|c|c|c|c|}
\hline \multirow{2}{*}{ Scenario } & \multirow{2}{*}{$\begin{array}{l}\text { Countries } \\
\text { Affected }\end{array}$} & \multirow{2}{*}{ Severity } & \multirow{2}{*}{$\begin{array}{l}\text { Attack Rate } \\
\text { for China }\end{array}$} & \multirow{2}{*}{$\begin{array}{c}\text { Case } \\
\text { Fatality Rate } \\
\text { China }\end{array}$} & \multirow{2}{*}{$\begin{array}{l}\text { Nature of } \\
\text { Shocks }\end{array}$} & \multirow{2}{*}{$\begin{array}{c}\begin{array}{c}\text { Shocks } \\
\text { Activated }\end{array} \\
\text { China }\end{array}$} & \multirow{2}{*}{$\begin{array}{c}\begin{array}{c}\text { Shocks } \\
\text { Activated }\end{array} \\
\begin{array}{c}\text { Other } \\
\text { countries }\end{array} \\
\end{array}$} \\
\hline & & & & & & & \\
\hline 1 & China & Low & $1.0 \%$ & $2.0 \%$ & Temporary & All & Risk \\
\hline 2 & China & Mid & $10.0 \%$ & $2.5 \%$ & Temporary & All & Risk \\
\hline 3 & China & High & $30.0 \%$ & $3.0 \%$ & Temporary & All & Risk \\
\hline 4 & Global & Low & $10.0 \%$ & $2.0 \%$ & Temporary & All & All \\
\hline 5 & Global & Mid & $20.0 \%$ & $2.5 \%$ & Temporary & All & All \\
\hline 6 & Global & High & $30.0 \%$ & $3.0 \%$ & Temporary & All & All \\
\hline 7 & Global & Low & $10.0 \%$ & $2.0 \%$ & Permanent & All & All \\
\hline
\end{tabular}

Source: McKibbin and Fernando (2020a)

With the gradual evolution of the outbreak, more information has become available specifically regarding the cases, deaths and policy responses by governments to manage the pandemic. Nevertheless, as observed in the World Bank's Global Economic Prospects report (2020b), released on 8 June 2020, there have been very few studies exploring global economic consequences of the COVID-19 pandemic to date. The studies by the World Trade Organization (2020), Maliszewska et al. (2020) and the World Bank (2020a) utilise Computable General Equilibrium (CGE) models and mainly focus on the impact of mortality, morbidity and increased production costs on the economies. A study by the International Monetary Fund [IMF] (2020c), which utilises a semi-structural Dynamic Stochastic General Equilibrium (DSGE) model, also includes disruptions to financial markets.

The OECD (2020) released Global Economic Outlook on 10 June 2020, in which it explores two scenarios focusing on the recurrence of COVID-19 and presents its expectations about global economic repercussions. Table 2 summarises the current expectations about the global economic consequences of the pandemic set out in the recent reports by the IMF (2020a), World Bank (2020b) and OECD (2020), segregated by the countries and the regions that we focus on in this study.

The range of estimates across countries and studies are diverse. Still, all studies show a substantial negative shock to the global economy in 2020 with an expected rebound in 2021 but not back to the levels of GDP in most countries experienced in 2019. These are consistent with the analysis in this paper. 
Table 2 - GDP forecasts by the international financial institutions

\begin{tabular}{|c|c|c|c|c|c|c|c|c|}
\hline Source & \multicolumn{4}{|c|}{ OECD (June 2020) } & \multicolumn{2}{|c|}{ IMF (April 2020) } & \multicolumn{2}{|c|}{ World Bank (June 2020) } \\
\hline Country/Region & $\begin{array}{c}\text { Single-hit } \\
\text { Scenario } \\
2020\end{array}$ & $\begin{array}{c}\text { Single-hit } \\
\text { Scenario } \\
2021\end{array}$ & $\begin{array}{c}\text { Double-hit } \\
\text { Scenario } \\
2020\end{array}$ & $\begin{array}{c}\text { Double-hit } \\
\text { Scenario } \\
2021\end{array}$ & 2020 & 2021 & 2020 & 2021 \\
\hline Unit & \multicolumn{4}{|c|}{$\begin{array}{l}\text { Average of Quarterly GDP Deviations from November } \\
2019 \text { Projections }\end{array}$} & \multicolumn{2}{|c|}{$\begin{array}{l}\text { Difference from January } \\
2020 \text { GDP Projections }\end{array}$} & \multicolumn{2}{|c|}{ Real GDP Growth } \\
\hline Argentina & $\mathrm{N} / \mathrm{A}$ & $\mathrm{N} / \mathrm{A}$ & $\mathrm{N} / \mathrm{A}$ & $\mathrm{N} / \mathrm{A}$ & $-6.30 \%$ & $2.40 \%$ & $-7.30 \%$ & $2.10 \%$ \\
\hline Australia & $-0.78 \%$ & $3.58 \%$ & $-6.35 \%$ & $5.35 \%$ & $-7.70 \%$ & $2.90 \%$ & $-7.00 \%$ & $3.90 \%$ \\
\hline Brazil & $\mathrm{N} / \mathrm{A}$ & $\mathrm{N} / \mathrm{A}$ & $\mathrm{N} / \mathrm{A}$ & $\mathrm{N} / \mathrm{A}$ & $-7.50 \%$ & $0.60 \%$ & $-8.00 \%$ & $2.20 \%$ \\
\hline Canada & $-5.38 \%$ & $4.63 \%$ & $-11.80 \%$ & $8.18 \%$ & $-8.00 \%$ & $2.40 \%$ & $-7.00 \%$ & $3.90 \%$ \\
\hline China & $\mathrm{N} / \mathrm{A}$ & $\mathrm{N} / \mathrm{A}$ & $\mathrm{N} / \mathrm{A}$ & N/A & $-4.80 \%$ & $3.40 \%$ & $1.00 \%$ & $6.90 \%$ \\
\hline France & $4.40 \%$ & $3.18 \%$ & $-7.38 \%$ & $12.75 \%$ & $-8.50 \%$ & $3.20 \%$ & $-7.00 \%$ & $3.90 \%$ \\
\hline Germany & $2.83 \%$ & $2.30 \%$ & $-6.25 \%$ & $6.65 \%$ & $-8.10 \%$ & $3.80 \%$ & $-7.00 \%$ & $3.90 \%$ \\
\hline India & $\mathrm{N} / \mathrm{A}$ & N/A & $\mathrm{N} / \mathrm{A}$ & $\mathrm{N} / \mathrm{A}$ & $-3.90 \%$ & $0 . .9 \%$ & $-3.20 \%$ & $3.10 \%$ \\
\hline Indonesia & $\mathrm{N} / \mathrm{A}$ & $\mathrm{N} / \mathrm{A}$ & $\mathrm{N} / \mathrm{A}$ & $\mathrm{N} / \mathrm{A}$ & $-5.40 \%$ & $2.70 \%$ & $0.00 \%$ & $4.80 \%$ \\
\hline Italy & $2.25 \%$ & $3.73 \%$ & $-9.50 \%$ & $13.68 \%$ & $-9.60 \%$ & $4.10 \%$ & $-7.00 \%$ & $3.90 \%$ \\
\hline Japan & $-0.60 \%$ & $0.58 \%$ & $-5.88 \%$ & $2.10 \%$ & $-5.90 \%$ & $2.50 \%$ & $-6.10 \%$ & $2.50 \%$ \\
\hline Mexico & $\mathrm{N} / \mathrm{A}$ & $\mathrm{N} / \mathrm{A}$ & $\mathrm{N} / \mathrm{A}$ & $\mathrm{N} / \mathrm{A}$ & $-7.60 \%$ & $1.40 \%$ & $-7.50 \%$ & $3.00 \%$ \\
\hline Other Asia & $\mathrm{N} / \mathrm{A}$ & $\mathrm{N} / \mathrm{A}$ & $\mathrm{N} / \mathrm{A}$ & $\mathrm{N} / \mathrm{A}$ & $-5.40 \%$ & $2.70 \%$ & $0.50 \%$ & $6.60 \%$ \\
\hline Other oil producing countries & $\mathrm{N} / \mathrm{A}$ & $\mathrm{N} / \mathrm{A}$ & $\mathrm{N} / \mathrm{A}$ & N/A & $-5.60 \%$ & $0.80 \%$ & $-4.20 \%$ & $30.00 \%$ \\
\hline Republic of Korea & $-0.48 \%$ & $2.28 \%$ & $-5.45 \%$ & $4.73 \%$ & $-7.70 \%$ & $2.90 \%$ & $-7.00 \%$ & $3.90 \%$ \\
\hline Rest of Euro Zone & $1.88 \%$ & $3.20 \%$ & $-8.38 \%$ & $10.25 \%$ & $-8.70 \%$ & $3.10 \%$ & $-9.10 \%$ & $4.50 \%$ \\
\hline Rest of OECD & $-1.78 \%$ & $3.73 \%$ & $-9.35 \%$ & $8.50 \%$ & $-7.70 \%$ & $2.90 \%$ & $-7.00 \%$ & $3.90 \%$ \\
\hline Rest of the World & $\mathrm{N} / \mathrm{A}$ & $\mathrm{N} / \mathrm{A}$ & $\mathrm{N} / \mathrm{A}$ & $\mathrm{N} / \mathrm{A}$ & $-6.30 \%$ & $2.40 \%$ & $-5.20 \%$ & $4.20 \%$ \\
\hline Russia & $\mathrm{N} / \mathrm{A}$ & $\mathrm{N} / \mathrm{A}$ & $\mathrm{N} / \mathrm{A}$ & $\mathrm{N} / \mathrm{A}$ & $-7.40 \%$ & $1.50 \%$ & $-6.00 \%$ & $2.70 \%$ \\
\hline Saudi Arabia & $\mathrm{N} / \mathrm{A}$ & $\mathrm{N} / \mathrm{A}$ & $\mathrm{N} / \mathrm{A}$ & N/A & $-4.20 \%$ & $0.70 \%$ & $-3.80 \%$ & $2.50 \%$ \\
\hline South Africa & $\mathrm{N} / \mathrm{A}$ & $\mathrm{N} / \mathrm{A}$ & $\mathrm{N} / \mathrm{A}$ & N/A & $-6.60 \%$ & $3.00 \%$ & $-7.10 \%$ & $2.90 \%$ \\
\hline Turkey & $\mathrm{N} / \mathrm{A}$ & $\mathrm{N} / \mathrm{A}$ & $\mathrm{N} / \mathrm{A}$ & $\mathrm{N} / \mathrm{A}$ & $-8.70 \%$ & $3.10 \%$ & $-3.80 \%$ & $5.00 \%$ \\
\hline United Kingdom & $-1.45 \%$ & $7.73 \%$ & $-13.03 \%$ & $16.10 \%$ & $-7.90 \%$ & $2.50 \%$ & $-7.00 \%$ & $3.90 \%$ \\
\hline United States of America & $-4.05 \%$ & $4.60 \%$ & $-9.48 \%$ & $7.53 \%$ & $-7.90 \%$ & $3.00 \%$ & $-6.10 \%$ & $4.00 \%$ \\
\hline
\end{tabular}

4 | P a g e 


\section{The Hybrid DSGE/CGE Global Model}

In this paper, we apply a global intertemporal general equilibrium model with heterogeneous agents called the G-Cubed Multi-Country Model. This model is a hybrid of Dynamic Stochastic General Equilibrium (DSGE) Models and Computable General Equilibrium (CGE) Models developed by McKibbin and Wilcoxen $(1999,2013)$.

\section{The G-Cubed Model}

The version of the G-Cubed (G20) model used in this paper can be found in McKibbin and Triggs (2018) who extended the original model documented in McKibbin and Wilcoxen (1999, 2013). The model has six sectors and twenty four countries and regions. Table 3 presents all the regions and sectors in the model. Some of the data inputs include the I/O tables found in the Global Trade Analysis Project (GTAP) database (Aguiar et al. 2019), which enables us to differentiate sectors by country of production within a DSGE framework. Firms in each sector in each country produce output using the primary factor inputs of capital (K) and labour (L) as well as the intermediate or production chains of inputs in energy (E) and materials (M). These linkages are both within a country and across countries.

McKibbin and Wilcoxen $(1999,2013)$ document the approach embodied in the G-Cubed model. Several key features of the standard G-Cubed model are worth highlighting here.

First, the model completely accounts for stocks and flows of physical and financial assets. For example, budget deficits accumulate into government debt, and current account deficits accumulate into foreign debt. The model imposes an intertemporal budget constraint on all households, firms, governments, and countries. Thus, a long-run stock equilibrium obtains through the adjustment of asset prices, such as the interest rate for government fiscal positions or real exchange rates for the balance of payments. However, the adjustment towards the longrun equilibrium of each economy can be slow, occurring over much of a century.

Second, firms and households in G-Cubed must use money issued by central banks for all transactions. Thus, central banks in the model set short term nominal interest rates to target macroeconomic outcomes (such as inflation, unemployment, exchange rates, etc.) based on Henderson-McKibbin-Taylor monetary rules. These rules are designed to approximate actual monetary regimes in each country or region in the model. These monetary rules tie down the long-run inflation rates in each country as well as allowing short term adjustment of policy to smooth fluctuations in the real economy. 
Table 3 - Overview of the G-Cubed (G20) model

\section{Countries (20)}

Argentina

Australia

Brazil

Canada

China

Rest of Eurozone

France

Germany

Indonesia

India

Italy

Japan

Korea

Mexico

Russia

Saudi Arabia

South Africa

Turkey

United Kingdom

United States
Regions (4)

Rest of the OECD

Rest of Asia

Other oil-producing countries

Rest of the world

\section{Sectors (6)}

Energy

Mining

Agriculture (including fishing and hunting)

Durable manufacturing

Non-durable manufacturing

Services

\section{Economic Agents in each Country (3)}

A representative household

A representative firm (in each of the 6 production sectors)

Government

Third, nominal wages are sticky and adjust over time based on country-specific labour contracting assumptions. Firms hire labour in each sector up to the points that the marginal product of labour equals the real wage defined in terms of the output price level of that sector. Any excess labour enters the unemployed pool of workers. Unemployment or the presence of excess demand for labour causes the nominal wage to adjust to clear the labour market in the long run. In the short-run, unemployment can arise due to structural supply shocks or changes in aggregate demand in the economy.

Fourth, rigidities prevent the economy from moving quickly from one equilibrium to another. These rigidities include nominal stickiness caused by wage rigidities, costs of adjustment in investment by firms with physical capital being sector-specific in the short-run. The adjustment path is also affected by a lack of complete foresight in the formation of expectations and by monetary and fiscal authorities following particular monetary and fiscal rules. Short-term adjustment to economic shocks can be very different from the long-run equilibrium outcomes. The focus on short-run rigidities is essential for assessing the impact over the first decades of a major shock. 
Fifth, we incorporate heterogeneous households and firms. Firms are modelled separately within each sector. We assume two types of consumers and two types of firms within each sector, within each country. One group of consumers and firms base their decisions on forwardlooking expectations. The other group follow simple rules of thumb which are optimal in the long-run.

\section{Modelling Economic Impacts of COVID-19}

\subsection{Modelling Scenarios}

A pandemic directly affects an economy via its impacts on humans due to infections which lead to morbidity (unable to work temporarily) and mortality (death). There are also likely to be significant changes in the behaviour of households and firms to avoid contracting or transmitting the disease. Also, due to the substantial transmissibility of the SARS-CoV-2, governments across the world responded with direct policy changes, to varying degrees, to reduce transmission. These responses included restricting movements across as well as within borders, banning public gatherings, closing educational institutions and non-essential businesses. While some countries adopted these measures at very early stages of the outbreak, some countries were late to respond. In general, early responders have witnessed lower levels of transmission, resulting in lower levels of infections and deaths. While controlling the transmission will significantly help the countries to return to the normality sooner and mitigate the long-term economic impacts emanating from the loss of human resources, the change in human behaviour and the industrial shutdowns are causing significant short- and medium-term economic consequences.

At the same time, it is currently uncertain whether the SARS-CoV-2 could be eliminated after the current wave. According to a wide range of medical opinion, the virus may join the other existing coronaviruses and is unlikely to disappear in the immediate future. Thus, until a vaccine for the disease is produced and is widely available for distribution, the COVID-19 pandemic could recur in the future.

In the case of continuous waves, it is unlikely that people and firms would continue to respond to the future potential outbreaks the same way most have responded to the current pandemic, i.e. by changing personal behaviour and by adopting economic shutdowns. In these cases, households and firms would need to select more permanent behavioural changes, including 
adopting better hygiene practices (see Levine \& McKibbin (2020)) and implementing social distancing measures.

Given the uncertainty outlined above, we develop six alternative scenarios. Table 4 summarises these scenarios focussing on the number of pandemic waves in each year and whether or not countries respond with lockdowns. The extent of lockdown response is not the same across countries but reflects policies in place as of May 2020.

Table 4 - Modelling Scenarios

\begin{tabular}{|c|c|c|c|c|c|}
\hline \multirow[t]{2}{*}{ Scenario } & \multicolumn{2}{|c|}{$\begin{array}{l}\text { Number of Waves \& } \\
\text { Government-imposed } \\
\text { Lockdowns in } 2020\end{array}$} & \multicolumn{2}{|c|}{$\begin{array}{c}\text { Number of Waves \& } \\
\text { Government-imposed } \\
\text { Lockdowns in } 2021 \\
\end{array}$} & \multirow{2}{*}{$\begin{array}{c}\text { Recurrence } \\
\text { after } 2021\end{array}$} \\
\hline & $\begin{array}{c}\text { Number of } \\
\text { Waves }\end{array}$ & $\begin{array}{l}\text { Existence of } \\
\text { Lockdowns } \\
\end{array}$ & $\begin{array}{c}\text { Number of } \\
\text { Waves }\end{array}$ & $\begin{array}{l}\text { Existence of } \\
\text { Lockdowns }\end{array}$ & \\
\hline 1 & 1 & Yes & 1 & Yes & No \\
\hline 2 & 1 & Yes & 1 & Yes & Yes \\
\hline 3 & 2 & Yes & 1 & Yes & No \\
\hline 4 & 2 & Yes & 2 & Yes & No \\
\hline \multirow{3}{*}{5} & 1 & Yes & \multirow{3}{*}{1} & \multirow{3}{*}{ No } & \multirow{3}{*}{ Yes } \\
\hline & & & & & \\
\hline & 1 & No & & & \\
\hline \multirow{2}{*}{6} & $\begin{array}{l}\text { Country of } \\
\text { Interest - } 1\end{array}$ & Yes & $\begin{array}{l}\text { Country of } \\
\text { Interest }-0\end{array}$ & - & No \\
\hline & $\begin{array}{l}\text { Rest of the } \\
\text { World }-2\end{array}$ & Yes & $\begin{array}{l}\text { Rest of the } \\
\text { World }-2\end{array}$ & Yes & No \\
\hline
\end{tabular}

The first scenario assumes all countries experience only a single wave in early 2020 consistent with their experience as of 20 May. For countries that have not peaked by 20 May, we project the epidemiological outcome given the experience of other countries with similar characteristics. Countries are assumed to implement the lockdown measures announced up to 20 May, although the countries differ in the duration of the lockdowns depending on when the outbreak reached the respective country and the management of the severity of the pandemic. After the first wave, as a vaccine is yet to be developed, we assume that a milder outbreak occurs again in early 2021. We assume that infections in the second wave are limited to half of the infections that have emerged during the current wave. We assume that the shocks to households and firms are half of that experienced in 2020 and countries adopt half of the current 
lockdown durations. This scenario is an optimistic assessment that the current pandemic is at its worst today and will eventually improve, and a vaccine will eliminate future waves after 2021.

The second scenario allows for more persistence in the re-emergence of COVID-19. The first year of the second scenario is as same as the first year of the first scenario. However, the second scenario assumes that the pandemic will recur annually with an exponential decay in the number of infections. The countries are assumed to adopt lockdowns to manage the pandemic at the same rate as the pandemic emerges over time.

The third scenario assumes that countries, who have managed the pandemic with lockdowns, begin to relax the movement restrictions. The third scenario explores the possibility of a second wave emerging again in 2020 because the timing of easing restrictions turns out to be too early. However, the countries manage the second wave better with only half of the infections and lockdown durations compared to the first wave. A third wave, similar to the second wave, also emerges in 2021.

The fourth scenario is the same as the third scenario but with a fourth wave in the second half of 2021. This fourth wave is half of the size of the first wave in 2021 compared to the number of infections and the length of the lockdowns.

The fifth scenario assumes after the first wave, there is no vaccine developed, and the pandemic continues to emerge in subsequent years. The countries that followed lockdown discard that policy in future outbreaks after the first wave. In all countries, the pandemic eventually dies out due to herd immunity. In this case, we assume the increase in equity risk premia do not return to baseline so that there is a permanent change in global risk.

The sixth scenario consists of twenty-four simulations. We assume each country alone experiences scenario 01 while all other countries experience scenario 04. Comparing the first scenario with the sixth scenario shows how much economic impact there is on each country because of worsening global pandemic outcomes even if that country has the pandemic under control.

The shocks and how their magnitudes vary according to the scenarios are discussed next in section 4.2. 


\subsection{Shock Formulation}

One of the issues that we need to accommodate is the fact that the waves of infections are assumed to be waves over four months rather than over a year. Since the G-Cubed model is an annual model, we adjust the shocks to fit the periodicity of the model.

A flowchart outlining how we calculate each shock is contained in Appendix A. Further details can also be found on the results dashboard available via https://cama.crawford.anu.edu.au/covid-19-macroeconomic-modelling-results-dashboard and the discussion that follows.

\subsubsection{Shocks to Labour Supply}

There are three shocks to labour supply. Economic agents die due to the infection (mortality shock). Workers are also not able to work during their recovery if they catch the disease. People caring for infected children also cannot work and we assume the carers are female workers.

In formulating the mortality component of the labour supply shock, first, we used the number of COVID-19 cases reported across the world from Our World in Data [OWID] (2020) up to 20 May 2020. After 20 May, as the pandemic is continuing in many countries, we modelled how the pandemic would likely develop given the interventions governments had already implemented and behavioural changes experienced by 20 May 2020. In modelling the case numbers, we utilised a logistic regression model, which is more effective in demonstrating the short-term behaviour of the pandemic compared to compartmental models, and less data demanding compared to agent-based models (Almeshal et al 2020; Batista 2020). The modelling assumes that the momentum the pandemic had demonstrated by 20 May 2020 would continue until the pandemic is controlled within that country. The actual number of reported cases for a given country could change from our extrapolations depending on the responses by the country to the pandemic after 20 May 2020.

Once we obtained the number of cases for each country, we distributed the total cases across three main age groups: 0-19 years, 20-59 years and 60+ years, based on data available from various national and international resources including the European Centre for Disease Prevention and Control [ECDC] (2020). For those countries and regions where the cases are broken down by age group could not be found, we approximated this distribution using data for a country with a similar general infection rate and for which the data was available. We 
then used the case-fatality rates for respective countries as at 20 May 2020 to obtain the overall mortality rates.

While for the first year of the first scenario we used the epidemiological projections based on the current data, the second wave in the first scenario and the waves in following scenarios have either the same number of infections or a proportion of the infections as in the first year of the first scenario. Table 5 summarises the total number of infections under each scenario for 2020 and 2021, and Table 6 presents the estimated number of deaths under each scenario.

We do not list scenario 6 in these tables because scenario 6 is different for each country. Scenario 6 is constructed individually for each country, using scenario 1 for a focus country and scenario 4 for all other countries. Thus, twenty-four individual simulations are generated, rotating a new focus country for each simulation. For example, in the case of Argentina, the deaths for scenario 6 are those from scenario 1, while the deaths for all other countries are from scenario 4.

The second component of the labour supply shock utilised the number of infections arising among the working-age population, the 20-59 years old population group, to obtain the number of working days lost due to the incubation after getting infected. We assumed the incubation period is 14 days. Table 7 presents the magnitude of the morbidity shock emanating from the working-age population catching the infection for the first two years under each scenario.

The loss of productive work time among the female workers due to caregiving for children is the third component of the shock to labour supply. When estimating this, we utilised the number of cases among the children, i.e. the age group below 20 years, and the average female labour force participation. We also assumed only 70 per cent of the female labour force would spend time on caregiving for dependent children. Table 8 presents the magnitude of the morbidity shock for the first two years feeding into simulations arising from the caregiving time spent by the female workers with infected children. This shock is small because few children are infected. 
Table 5 - Number of Infections under each Scenario

\begin{tabular}{|c|c|c|c|c|c|c|c|c|c|c|}
\hline \multirow{2}{*}{ Country/Region } & \multicolumn{2}{|c|}{ Scenario 01} & \multicolumn{2}{|c|}{ Scenario 02} & \multicolumn{2}{|c|}{ Scenario 03} & \multicolumn{2}{|c|}{ Scenario 04} & \multicolumn{2}{|c|}{ Scenario 05} \\
\hline & Year 01 & Year 02 & Year 01 & Year 02 & Year 01 & Year 02 & Year 01 & Year 02 & Year 01 & Year 02 \\
\hline Argentina & 12,969 & 6,485 & 12,969 & 6,485 & 19,454 & 6,485 & 19,454 & 9,727 & 45,392 & 64,845 \\
\hline Australia & 7,397 & 3,699 & 7,397 & 3,699 & 11,096 & 3,699 & 11,096 & 5,548 & 25,890 & 36,985 \\
\hline Brazil & 612,254 & 306,127 & 612,254 & 306,127 & 918,380 & 306,127 & 918,380 & 459,190 & $2,142,888$ & $3,061,268$ \\
\hline Canada & 85,010 & 42,505 & 85,010 & 42,505 & 127,514 & 42,505 & 127,514 & 63,757 & 297,533 & 425,048 \\
\hline China & 84,062 & 42,031 & 84,062 & 42,031 & 126,094 & 42,031 & 126,094 & 63,047 & 294,218 & 420,312 \\
\hline France & 143,530 & 71,765 & 143,530 & 71,765 & 215,294 & 71,765 & 215,294 & 107,647 & 502,354 & 717,648 \\
\hline Germany & 175,747 & 87,873 & 175,747 & 87,873 & 263,620 & 87,873 & 263,620 & 131,810 & 615,114 & 878,734 \\
\hline India & 190,089 & 95,044 & 190,089 & 95,044 & 285,133 & 95,044 & 285,133 & 142,567 & 665,311 & 950,444 \\
\hline Indonesia & 22,012 & 11,006 & 22,012 & 11,006 & 33,018 & 11,006 & 33,018 & 16,509 & 77,041 & 110,059 \\
\hline Italy & 227,777 & 113,888 & 227,777 & 113,888 & 341,665 & 113,888 & 341,665 & 170,833 & 797,218 & $1,138,884$ \\
\hline Japan & 16,567 & 8,283 & 16,567 & 8,283 & 24,850 & 8,283 & 24,850 & 12,425 & 57,983 & 82,833 \\
\hline Mexico & 85,105 & 42,552 & 85,105 & 42,552 & 127,657 & 42,552 & 127,657 & 63,829 & 297,866 & 425,523 \\
\hline Other Asia & 60,596 & 30,298 & 60,596 & 30,298 & 90,893 & 30,298 & 90,893 & 45,447 & 212,084 & 302,978 \\
\hline Other oil producing countries & 334,765 & 167,382 & 334,765 & 167,382 & 502,147 & 167,382 & 502,147 & 251,074 & $1,171,676$ & $1,673,823$ \\
\hline Republic of Korea & 11,079 & 5,540 & 11,079 & 5,540 & 16,619 & 5,540 & 16,619 & 8,309 & 38,777 & 55,396 \\
\hline Rest of Euro Zone & 521,439 & 260,719 & 521,439 & 260,719 & 782,158 & 260,719 & 782,158 & 391,079 & $1,825,036$ & $2,607,194$ \\
\hline Rest of OECD & 108,994 & 54,497 & 108,994 & 54,497 & 163,490 & 54,497 & 163,490 & 81,745 & 381,477 & 544,968 \\
\hline Rest of the World & 588,833 & 294,416 & 588,833 & 294,416 & 883,249 & 294,416 & 883,249 & 441,624 & $2,060,914$ & $2,944,163$ \\
\hline Russia & 380,110 & 190,055 & 380,110 & 190,055 & 570,165 & 190,055 & 570,165 & 285,082 & $1,330,384$ & $1,900,549$ \\
\hline Saudi Arabia & 84,628 & 42,314 & 84,628 & 42,314 & 126,942 & 42,314 & 126,942 & 63,471 & 296,197 & 423,138 \\
\hline South Africa & 697,561 & 348,780 & 697,561 & 348,780 & $1,046,341$ & 348,780 & $1,046,341$ & 523,170 & $2,441,462$ & $3,487,803$ \\
\hline Turkey & 152,857 & 76,428 & 152,857 & 76,428 & 229,285 & 76,428 & 229,285 & 114,643 & 534,998 & 764,283 \\
\hline United Kingdom & 260,776 & 130,388 & 260,776 & 130,388 & 391,163 & 130,388 & 391,163 & 195,582 & 912,715 & $1,303,878$ \\
\hline United States of America & $1,601,664$ & 800,832 & $1,601,664$ & 800,832 & $2,402,495$ & 800,832 & $2,402,495$ & $1,201,248$ & $5,605,823$ & $8,008,318$ \\
\hline
\end{tabular}

12|P a g e 
Table 6 - Number of Deaths Under Each Scenario

\begin{tabular}{|c|c|c|c|c|c|c|c|c|c|c|}
\hline \multirow{2}{*}{ Country/Region } & \multicolumn{2}{|c|}{ Scenario 01} & \multicolumn{2}{|c|}{ Scenario 02} & \multicolumn{2}{|c|}{ Scenario 03} & \multicolumn{2}{|c|}{ Scenario 04} & \multicolumn{2}{|c|}{ Scenario 05} \\
\hline & Year 01 & Year 02 & Year 01 & Year 02 & Year 01 & Year 02 & Year 01 & Year 02 & Year 01 & Year 02 \\
\hline Argentina & 593 & 296 & 593 & 296 & 889 & 296 & 889 & 445 & 2,075 & 2,964 \\
\hline Australia & 104 & 52 & 104 & 52 & 156 & 52 & 156 & 78 & 363 & 519 \\
\hline Brazil & 40,441 & 20,221 & 40,441 & 20,221 & 60,662 & 20,221 & 60,662 & 30,331 & 141,544 & 202,206 \\
\hline Canada & 6,362 & 3,181 & 6,362 & 3,181 & 9,543 & 3,181 & 9,543 & 4,772 & 22,267 & 31,810 \\
\hline China & 4,638 & 2,319 & 4,638 & 2,319 & 6,957 & 2,319 & 6,957 & 3,478 & 16,233 & 23,190 \\
\hline France & 28,363 & 14,181 & 28,363 & 14,181 & 42,544 & 14,181 & 42,544 & 21,272 & 99,270 & 141,814 \\
\hline Germany & 8,032 & 4,016 & 8,032 & 4,016 & 12,047 & 4,016 & 12,047 & 6,024 & 28,110 & 40,158 \\
\hline India & 5,945 & 2,972 & 5,945 & 2,972 & 8,917 & 2,972 & 8,917 & 4,459 & 20,807 & 29,724 \\
\hline Indonesia & 1,456 & 728 & 1,456 & 728 & 2,183 & 728 & 2,183 & 1,092 & 5,095 & 7,278 \\
\hline Italy & 32,275 & 16,137 & 32,275 & 16,137 & 48,412 & 16,137 & 48,412 & 24,206 & 112,962 & 161,375 \\
\hline Japan & 772 & 386 & 772 & 386 & 1,159 & 386 & 1,159 & 579 & 2,703 & 3,862 \\
\hline Mexico & 8,789 & 4,394 & 8,789 & 4,394 & 13,183 & 4,394 & 13,183 & 6,591 & 30,760 & 43,943 \\
\hline Other Asia & 1,204 & 602 & 1,204 & 602 & 1,806 & 602 & 1,806 & 903 & 4,213 & 6,019 \\
\hline Other oil producing countries & 14,283 & 7,142 & 14,283 & 7,142 & 21,425 & 7,142 & 21,425 & 10,712 & 49,992 & 71,416 \\
\hline Republic of Korea & 263 & 132 & 263 & 132 & 395 & 132 & 395 & 197 & 921 & 1,315 \\
\hline Rest of Euro Zone & 54,511 & 27,256 & 54,511 & 27,256 & 81,767 & 27,256 & 81,767 & 40,884 & 190,790 & 272,557 \\
\hline Rest of OECD & 2,730 & 1,365 & 2,730 & 1,365 & 4,095 & 1,365 & 4,095 & 2,048 & 9,555 & 13,650 \\
\hline Rest of the World & 15,163 & 7,582 & 15,163 & 7,582 & 22,745 & 7,582 & 22,745 & 11,372 & 53,071 & 75,815 \\
\hline Russia & 3,559 & 1,780 & 3,559 & 1,780 & 5,339 & 1,780 & 5,339 & 2,670 & 12,458 & 17,797 \\
\hline Saudi Arabia & 472 & 236 & 472 & 236 & 708 & 236 & 708 & 354 & 1,653 & 2,361 \\
\hline South Africa & 12,140 & 6,070 & 12,140 & 6,070 & 18,211 & 6,070 & 18,211 & 9,105 & 42,491 & 60,702 \\
\hline Turkey & 4,234 & 2,117 & 4,234 & 2,117 & 6,351 & 2,117 & 6,351 & 3,175 & 14,818 & 21,168 \\
\hline United Kingdom & 36,825 & 18,413 & 36,825 & 18,413 & 55,238 & 18,413 & 55,238 & 27,619 & 128,888 & 184,126 \\
\hline United States of America & 95,927 & 47,963 & 95,927 & 47,963 & 143,890 & 47,963 & 143,890 & 71,945 & 335,744 & 479,634 \\
\hline
\end{tabular}

13 | P a g e 
Table 7 - Morbidity Shock due to Workers Catching the Infection for each Scenario (Proportion of lost days compared to the total workforce working days)

\begin{tabular}{|c|c|c|c|c|c|c|c|c|c|c|}
\hline \multirow{2}{*}{ Country/Region } & \multicolumn{2}{|c|}{ Scenario 01} & \multicolumn{2}{|c|}{ Scenario 02} & \multicolumn{2}{|c|}{ Scenario 03} & \multicolumn{2}{|c|}{ Scenario 04} & \multicolumn{2}{|c|}{ Scenario 05} \\
\hline & Year 01 & Year 02 & Year 01 & Year 02 & Year 01 & Year 02 & Year 01 & Year 02 & Year 01 & Year 02 \\
\hline Argentina & 0.0027 & 0.0013 & 0.0027 & 0.0013 & 0.0040 & 0.0013 & 0.0040 & 0.0020 & 0.0093 & 0.0133 \\
\hline Australia & 0.0020 & 0.0010 & 0.0020 & 0.0010 & 0.0030 & 0.0010 & 0.0030 & 0.0015 & 0.0071 & 0.0102 \\
\hline Brazil & 0.0241 & 0.0121 & 0.0241 & 0.0121 & 0.0362 & 0.0121 & 0.0362 & 0.0181 & 0.0844 & 0.1205 \\
\hline Canada & 0.0135 & 0.0067 & 0.0135 & 0.0067 & 0.0202 & 0.0067 & 0.0202 & 0.0101 & 0.0472 & 0.0674 \\
\hline China & 0.0004 & 0.0002 & 0.0004 & 0.0002 & 0.0006 & 0.0002 & 0.0006 & 0.0003 & 0.0014 & 0.0020 \\
\hline France & 0.0100 & 0.0050 & 0.0100 & 0.0050 & 0.0150 & 0.0050 & 0.0150 & 0.0075 & 0.0351 & 0.0501 \\
\hline Germany & 0.0086 & 0.0043 & 0.0086 & 0.0043 & 0.0129 & 0.0043 & 0.0129 & 0.0065 & 0.0301 & 0.0430 \\
\hline India & 0.0015 & 0.0008 & 0.0015 & 0.0008 & 0.0023 & 0.0008 & 0.0023 & 0.0011 & 0.0054 & 0.0077 \\
\hline Indonesia & 0.0007 & 0.0003 & 0.0007 & 0.0003 & 0.0010 & 0.0003 & 0.0010 & 0.0005 & 0.0024 & 0.0034 \\
\hline Italy & 0.0304 & 0.0152 & 0.0304 & 0.0152 & 0.0456 & 0.0152 & 0.0456 & 0.0228 & 0.1064 & 0.1520 \\
\hline Japan & 0.0009 & 0.0005 & 0.0009 & 0.0005 & 0.0014 & 0.0005 & 0.0014 & 0.0007 & 0.0033 & 0.0047 \\
\hline Mexico & 0.0062 & 0.0031 & 0.0062 & 0.0031 & 0.0093 & 0.0031 & 0.0093 & 0.0046 & 0.0217 & 0.0309 \\
\hline Other Asia & 0.0014 & 0.0007 & 0.0014 & 0.0007 & 0.0021 & 0.0007 & 0.0021 & 0.0011 & 0.0050 & 0.0071 \\
\hline Other oil producing countries & 0.0038 & 0.0019 & 0.0038 & 0.0019 & 0.0057 & 0.0019 & 0.0057 & 0.0029 & 0.0134 & 0.0191 \\
\hline Republic of Korea & 0.0015 & 0.0008 & 0.0015 & 0.0008 & 0.0023 & 0.0008 & 0.0023 & 0.0011 & 0.0053 & 0.0076 \\
\hline Rest of Euro Zone & 0.0095 & 0.0048 & 0.0095 & 0.0048 & 0.0143 & 0.0048 & 0.0143 & 0.0072 & 0.0334 & 0.0477 \\
\hline Rest of OECD & 0.0094 & 0.0047 & 0.0094 & 0.0047 & 0.0141 & 0.0047 & 0.0141 & 0.0071 & 0.0330 & 0.0471 \\
\hline Rest of the World & 0.0031 & 0.0016 & 0.0031 & 0.0016 & 0.0047 & 0.0016 & 0.0047 & 0.0023 & 0.0109 & 0.0156 \\
\hline Russia & 0.0111 & 0.0055 & 0.0111 & 0.0055 & 0.0166 & 0.0055 & 0.0166 & 0.0083 & 0.0387 & 0.0553 \\
\hline Saudi Arabia & 0.0122 & 0.0061 & 0.0122 & 0.0061 & 0.0184 & 0.0061 & 0.0184 & 0.0092 & 0.0429 & 0.0612 \\
\hline South Africa & 0.1338 & 0.0669 & 0.1338 & 0.0669 & 0.2007 & 0.0669 & 0.2007 & 0.1004 & 0.4684 & 0.6691 \\
\hline Turkey & 0.0098 & 0.0049 & 0.0098 & 0.0049 & 0.0147 & 0.0049 & 0.0147 & 0.0073 & 0.0342 & 0.0488 \\
\hline United Kingdom & 0.0196 & 0.0098 & 0.0196 & 0.0098 & 0.0294 & 0.0098 & 0.0294 & 0.0147 & 0.0686 & 0.0980 \\
\hline United States of America & 0.0402 & 0.0201 & 0.0402 & 0.0201 & 0.0603 & 0.0201 & 0.0603 & 0.0302 & 0.1407 & 0.2010 \\
\hline
\end{tabular}

$14 \mid \mathrm{P}$ a g e 
Table 8 - Morbidity due to Female Workers Losing Productive Time due to caregiving (Proportion of lost days compared to the total workforce working days)

\begin{tabular}{|c|c|c|c|c|c|c|c|c|c|c|}
\hline \multirow{2}{*}{ Country/Region } & \multicolumn{2}{|c|}{ Scenario 01} & \multicolumn{2}{|c|}{ Scenario 02} & \multicolumn{2}{|c|}{ Scenario 03} & \multicolumn{2}{|c|}{ Scenario 04} & \multicolumn{2}{|c|}{ Scenario 05} \\
\hline & Year 01 & Year 02 & Year 01 & Year 02 & Year 01 & Year 02 & Year 01 & Year 02 & Year 01 & Year 02 \\
\hline Argentina & 0.0014 & 0.0007 & 0.0014 & 0.0007 & 0.0021 & 0.0007 & 0.0021 & 0.0011 & 0.0050 & 0.0072 \\
\hline Australia & 0.0004 & 0.0002 & 0.0004 & 0.0002 & 0.0006 & 0.0002 & 0.0006 & 0.0003 & 0.0014 & 0.0019 \\
\hline Brazil & 0.0126 & 0.0063 & 0.0126 & 0.0063 & 0.0188 & 0.0063 & 0.0188 & 0.0094 & 0.0440 & 0.0628 \\
\hline Canada & 0.0034 & 0.0017 & 0.0034 & 0.0017 & 0.0051 & 0.0017 & 0.0051 & 0.0025 & 0.0119 & 0.0170 \\
\hline China & 0.0000 & 0.0000 & 0.0000 & 0.0000 & 0.0001 & 0.0000 & 0.0001 & 0.0000 & 0.0001 & 0.0002 \\
\hline France & 0.0201 & 0.0101 & 0.0201 & 0.0101 & 0.0302 & 0.0101 & 0.0302 & 0.0151 & 0.0705 & 0.1007 \\
\hline Germany & 0.0178 & 0.0089 & 0.0178 & 0.0089 & 0.0266 & 0.0089 & 0.0266 & 0.0133 & 0.0622 & 0.0888 \\
\hline India & 0.0016 & 0.0008 & 0.0016 & 0.0008 & 0.0024 & 0.0008 & 0.0024 & 0.0012 & 0.0056 & 0.0079 \\
\hline Indonesia & 0.0004 & 0.0002 & 0.0004 & 0.0002 & 0.0006 & 0.0002 & 0.0006 & 0.0003 & 0.0014 & 0.0020 \\
\hline Italy & 0.0317 & 0.0159 & 0.0317 & 0.0159 & 0.0476 & 0.0159 & 0.0476 & 0.0238 & 0.1110 & 0.1586 \\
\hline Japan & 0.0002 & 0.0001 & 0.0002 & 0.0001 & 0.0003 & 0.0001 & 0.0003 & 0.0001 & 0.0006 & 0.0009 \\
\hline Mexico & 0.0038 & 0.0019 & 0.0038 & 0.0019 & 0.0056 & 0.0019 & 0.0056 & 0.0028 & 0.0132 & 0.0188 \\
\hline Other Asia & 0.0004 & 0.0002 & 0.0004 & 0.0002 & 0.0007 & 0.0002 & 0.0007 & 0.0003 & 0.0016 & 0.0022 \\
\hline Other oil producing countries & 0.0146 & 0.0073 & 0.0146 & 0.0073 & 0.0219 & 0.0073 & 0.0219 & 0.0109 & 0.0510 & 0.0729 \\
\hline Republic of Korea & 0.0005 & 0.0002 & 0.0005 & 0.0002 & 0.0007 & 0.0002 & 0.0007 & 0.0004 & 0.0017 & 0.0025 \\
\hline Rest of Euro Zone & 0.0199 & 0.0100 & 0.0199 & 0.0100 & 0.0299 & 0.0100 & 0.0299 & 0.0149 & 0.0697 & 0.0995 \\
\hline Rest of OECD & 0.0196 & 0.0098 & 0.0196 & 0.0098 & 0.0294 & 0.0098 & 0.0294 & 0.0147 & 0.0686 & 0.0979 \\
\hline Rest of the World & 0.0017 & 0.0008 & 0.0017 & 0.0008 & 0.0025 & 0.0008 & 0.0025 & 0.0012 & 0.0058 & 0.0083 \\
\hline Russia & 0.0219 & 0.0110 & 0.0219 & 0.0110 & 0.0329 & 0.0110 & 0.0329 & 0.0164 & 0.0767 & 0.1095 \\
\hline Saudi Arabia & 0.0712 & 0.0356 & 0.0712 & 0.0356 & 0.1069 & 0.0356 & 0.1069 & 0.0534 & 0.2493 & 0.3562 \\
\hline South Africa & 0.0372 & 0.0186 & 0.0372 & 0.0186 & 0.0559 & 0.0186 & 0.0559 & 0.0279 & 0.1304 & 0.1862 \\
\hline Turkey & 0.0287 & 0.0143 & 0.0287 & 0.0143 & 0.0430 & 0.0143 & 0.0430 & 0.0215 & 0.1004 & 0.1435 \\
\hline United Kingdom & 0.0020 & 0.0010 & 0.0020 & 0.0010 & 0.0030 & 0.0010 & 0.0030 & 0.0015 & 0.0071 & 0.0101 \\
\hline United States of America & 0.0034 & 0.0017 & 0.0034 & 0.0017 & 0.0050 & 0.0017 & 0.0050 & 0.0025 & 0.0118 & 0.0168 \\
\hline
\end{tabular}

$\mathbf{1 5} \mid \mathrm{P}$ a g e 


\subsubsection{Shock to Total Factor Productivity in each Sector}

The predominant sources of economic impacts with the COVID-19 pandemic have been the change in behaviour of households and firms in responding to the virus and the closure of nonessential economic sectors as means to manage the spread of the pandemic. Some firms in some sectors have been able to utilise technology to implement remote working arrangements. However, firms requiring the physical presence of workers to execute their operations, notably the durable manufacturing and service sectors, have suffered due to the economic shutdowns across the world. To assess the impact of the change in costs of doing business, which is equivalent to a decline in total factor productivity, we applied the estimates from the Australian Bureau of Statistics (2020), data from AUSGRID on electricity use by sector (2020) and del Rio-Chanona et al (2020). Given this data, we estimated the effective proportions of sub-sectors operational during the economic shutdowns. For each country, we estimated what proportion of the broad-sectors could be operational, based on the contribution from sub-sectors to the broad-sectors. We scaled these estimates across countries and scenarios depending on the length of economic shutdowns. Table 9 presents the assumptions on the lengths of shutdowns (in months) in different countries under each scenario. Figure 1 shows the magnitude of the Total Factor Productivity Shock for each sector for all countries for the first year under the first scenario.

\subsubsection{Shock to Consumption}

The changes in the consumption preferences of households have been another significant source of economic impacts during the pandemic. We also attempt to capture the increase in risk, which affects households' discounting of future income.

The change in household behaviour is mainly due to the households getting infected as well as the inability to undertake particular economic activities due to social distancing or concern about the infection. These shifts in consumer preferences are assumed to be exogenous to the model. Other impacts on consumers such as a change in income, employment and wealth as well as shifts in relative prices of different sectors and changes in interest rate etc. are determined by the model. Households partially foresee the long-term impacts on their wealth with the broader economic implications of the pandemic and adjust their current consumption patterns to maximise the expected life-long utility. 
Table 9 - Length of Economic Shutdowns (in months) under each Scenario

\begin{tabular}{|c|c|c|c|c|c|c|c|c|c|c|}
\hline \multirow[b]{2}{*}{ Country/Region } & \multicolumn{2}{|c|}{ Scenario 01} & \multicolumn{2}{|c|}{ Scenario 02} & \multicolumn{2}{|c|}{ Scenario 03} & \multicolumn{2}{|c|}{ Scenario 04} & \multicolumn{2}{|c|}{ Scenario 05} \\
\hline & $\begin{array}{l}1 \text { Year } \\
01\end{array}$ & $\begin{array}{l}1 \text { Year } \\
02\end{array}$ & $\begin{array}{l}2 \text { Year } \\
01\end{array}$ & $\begin{array}{l}2 \text { Year } \\
02\end{array}$ & $\begin{array}{l}3 \text { Year } \\
01\end{array}$ & $\begin{array}{l}3 \text { Year } \\
02\end{array}$ & $\begin{array}{l}4 \text { Year } \\
01\end{array}$ & $\begin{array}{l}4 \text { Year } \\
02\end{array}$ & $\begin{array}{l}5 \text { Year } \\
01\end{array}$ & $\begin{array}{l}5 \text { Year } \\
02\end{array}$ \\
\hline Argentina & 6.07 & 3.04 & 6.07 & 3.03 & 9.10 & 3.03 & 9.10 & 4.55 & 6.07 & - \\
\hline Australia & 5.60 & 2.80 & 5.60 & 2.80 & 8.40 & 2.80 & 8.40 & 4.20 & 5.60 & - \\
\hline Brazil & 7.50 & 3.75 & 7.50 & 3.75 & 11.25 & 3.75 & 11.25 & 5.63 & 7.50 & - \\
\hline Canada & 6.37 & 3.19 & 6.37 & 3.18 & 9.55 & 3.18 & 9.55 & 4.78 & 6.37 & - \\
\hline China & 4.70 & 2.35 & 4.70 & 2.35 & 7.05 & 2.35 & 7.05 & 3.53 & 4.70 & - \\
\hline France & 5.13 & 2.57 & 5.13 & 2.57 & 7.70 & 2.57 & 7.70 & 3.85 & 5.13 & - \\
\hline Germany & 4.97 & 2.49 & 4.97 & 2.48 & 7.45 & 2.48 & 7.45 & 3.73 & 4.97 & - \\
\hline India & 7.60 & 3.80 & 7.60 & 3.80 & 11.40 & 3.80 & 11.40 & 5.70 & 7.60 & - \\
\hline Indonesia & 5.27 & 2.64 & 5.27 & 2.63 & 7.90 & 2.63 & 7.90 & 3.95 & 5.27 & - \\
\hline Italy & 5.63 & 2.82 & 5.63 & 2.82 & 8.45 & 2.82 & 8.45 & 4.23 & 5.63 & - \\
\hline Japan & 5.13 & 2.57 & 5.13 & 2.57 & 7.70 & 2.57 & 7.70 & 3.85 & 5.13 & - \\
\hline Mexico & 6.00 & 3.00 & 6.00 & 3.00 & 9.00 & 3.00 & 9.00 & 4.50 & 6.00 & - \\
\hline Other Asia & 7.30 & 3.65 & 7.30 & 3.65 & 10.95 & 3.65 & 10.95 & 5.48 & 7.30 & - \\
\hline $\begin{array}{l}\text { Other oil producing } \\
\text { countries }\end{array}$ & 8.60 & 4.30 & 8.60 & 4.30 & 12.00 & 4.30 & 12.00 & 6.45 & 8.60 & - \\
\hline Republic of Korea & 4.07 & 2.04 & 4.07 & 2.03 & 6.10 & 2.03 & 6.10 & 3.05 & 4.07 & - \\
\hline Rest of Euro Zone & 5.73 & 2.87 & 5.73 & 2.87 & 8.60 & 2.87 & 8.60 & 4.30 & 5.73 & - \\
\hline Rest of OECD & 5.43 & 2.72 & 5.43 & 2.72 & 8.15 & 2.72 & 8.15 & 4.08 & 5.43 & - \\
\hline Rest of the World & 8.33 & 4.17 & 8.33 & 4.17 & 12.00 & 4.17 & 12.00 & 6.25 & 8.33 & - \\
\hline Russia & 6.60 & 3.30 & 6.60 & 3.30 & 9.90 & 3.30 & 9.90 & 4.95 & 6.60 & - \\
\hline Saudi Arabia & 5.67 & 2.84 & 5.67 & 2.83 & 8.50 & 2.83 & 8.50 & 4.25 & 5.67 & - \\
\hline South Africa & 10.93 & 5.47 & 10.93 & 5.47 & 12.00 & 5.47 & 12.00 & 8.20 & 10.93 & - \\
\hline Turkey & 3.87 & 1.94 & 3.87 & 1.93 & 5.80 & 1.93 & 5.80 & 2.90 & 3.87 & - \\
\hline United Kingdom & 6.37 & 3.19 & 6.37 & 3.18 & 9.55 & 3.18 & 9.55 & 4.78 & 6.37 & - \\
\hline United States of America & 7.30 & 3.65 & 7.30 & 3.65 & 10.95 & 3.65 & 10.95 & 5.48 & 7.30 & - \\
\hline
\end{tabular}

17| P a g e 


\section{Figure 1 - Productivity Shock for the First Year under Scenario 01}

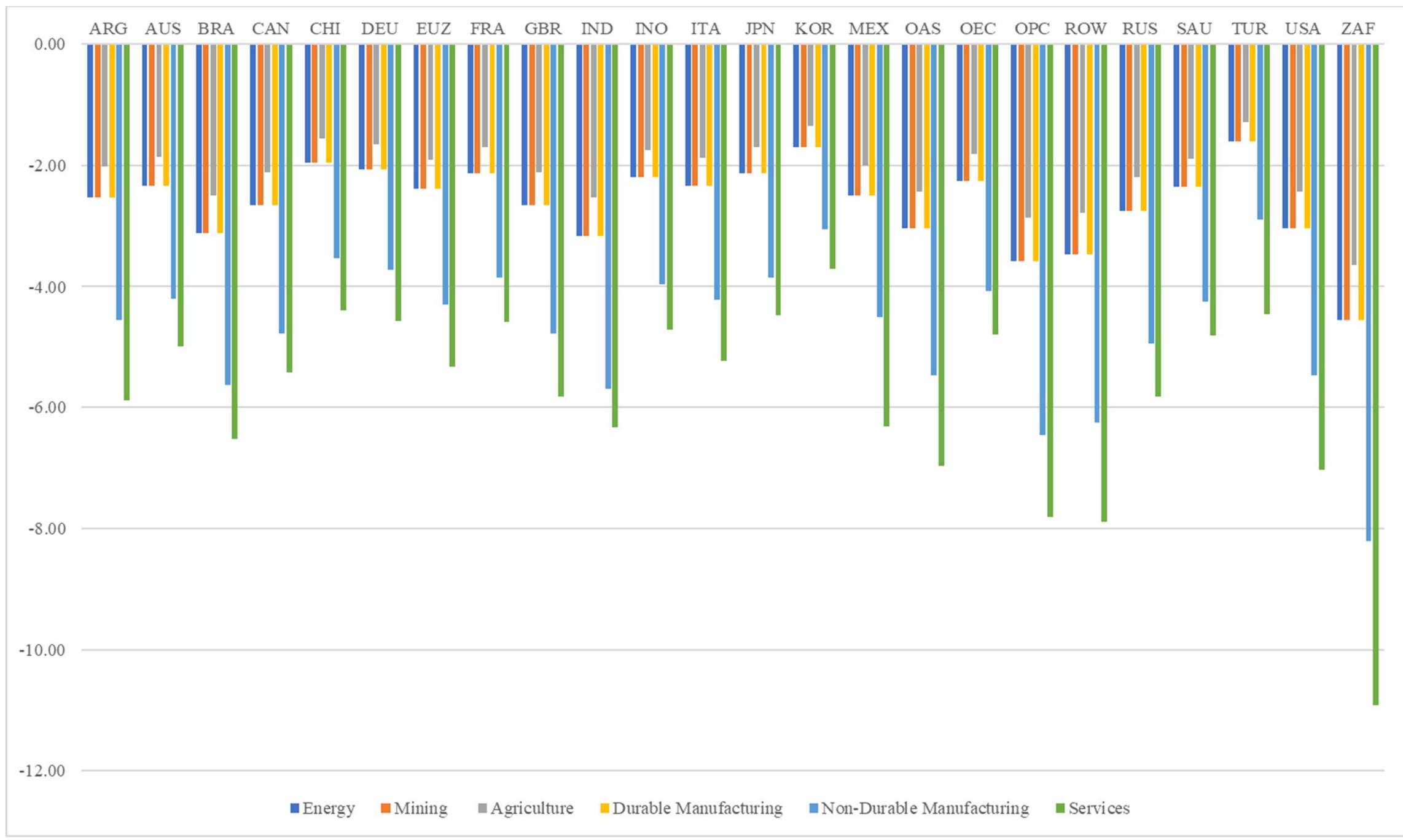

$\mathbf{1 8} \mid \mathrm{P}$ a g e 
As the model endogenously generates some of the above effects due to the other shocks, we only introduced a shift in consumer preferences and a rise in the risk premium in the discount rate households use to discount future labour income in calculating human wealth. We first changed consumer preferences over a large number of subsectors. We started with the proportions of the sub-sectors still operating and aggregated this data to calculate the broad sector change as well as the country-wide amount of consumption that is discontinued during the pandemic. The shock was scaled across the scenarios depending on the length of economic shutdowns in the countries. Figure 2 presents the magnitude of the shock to consumption for the first year under different scenarios.

The change in the risk premium for calculating human wealth is computed using the variation in the Volatility Index (VIX), which is an indicator of changes in market sentiment. We used the movement of the VIX in the US for four months after the outbreak reached the US and calibrated the shock for the US considering its standard deviation and excess variations from the healthy threshold level of 30. We then apply the Risk Aversion Index compiled by Gandelman and Hernández-Murillo (2014), to scale the shock across the different regions in the model. For four countries for which the Risk Aversion Index was unavailable, we used those of their closest peers. The shocks were then scaled across scenarios using scaling factors reflecting the length of shutdowns. Figure 3 presents the Index of Risk Aversion relative to the US for the regions in the model and Figure 4 shows the magnitude of the risk on human wealth for the first year under the different scenarios.

\subsubsection{Shock to the Country \& Sector Risk Premia}

While no country has been immune to the pandemic, the relative attractiveness of economies and economic sectors have changed. This is evident in the changes in financial markets after the outbreak. We attempt to capture this rebalancing in risk via a shock on the country risk premium and equity risk premia of sectors across all countries.

Following the approach in McKibbin and Sidorenko (2006), Lee and McKibbin (2004) and further improved in McKibbin and Fernando (2020), we first constructed a country risk index with three main components: the index of Health, Governance and Financial risks.

The Index of Health Risk is the average of the Index of Health Expenditure per capita and the Index of Health Security. The Health Expenditure per capita data are from the World Health Organization (2019) and the Global Health Security Index, constructed by the Johns Hopkins 
Figure 2 - Consumption Shock for the First Year (\% GDP of Consumption Discontinued)

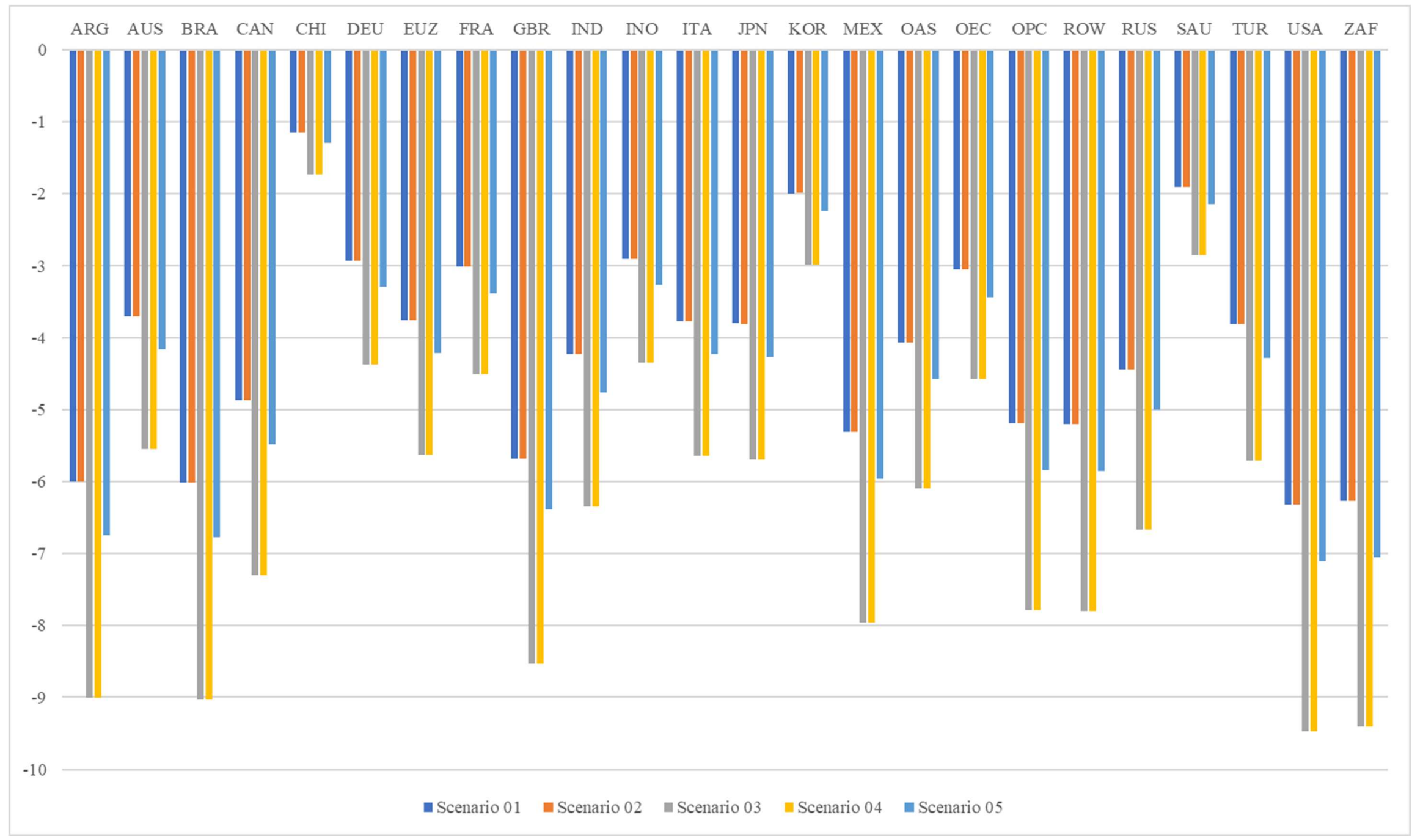

20|P a g e 
Figure 3 - Index of Risk Aversion

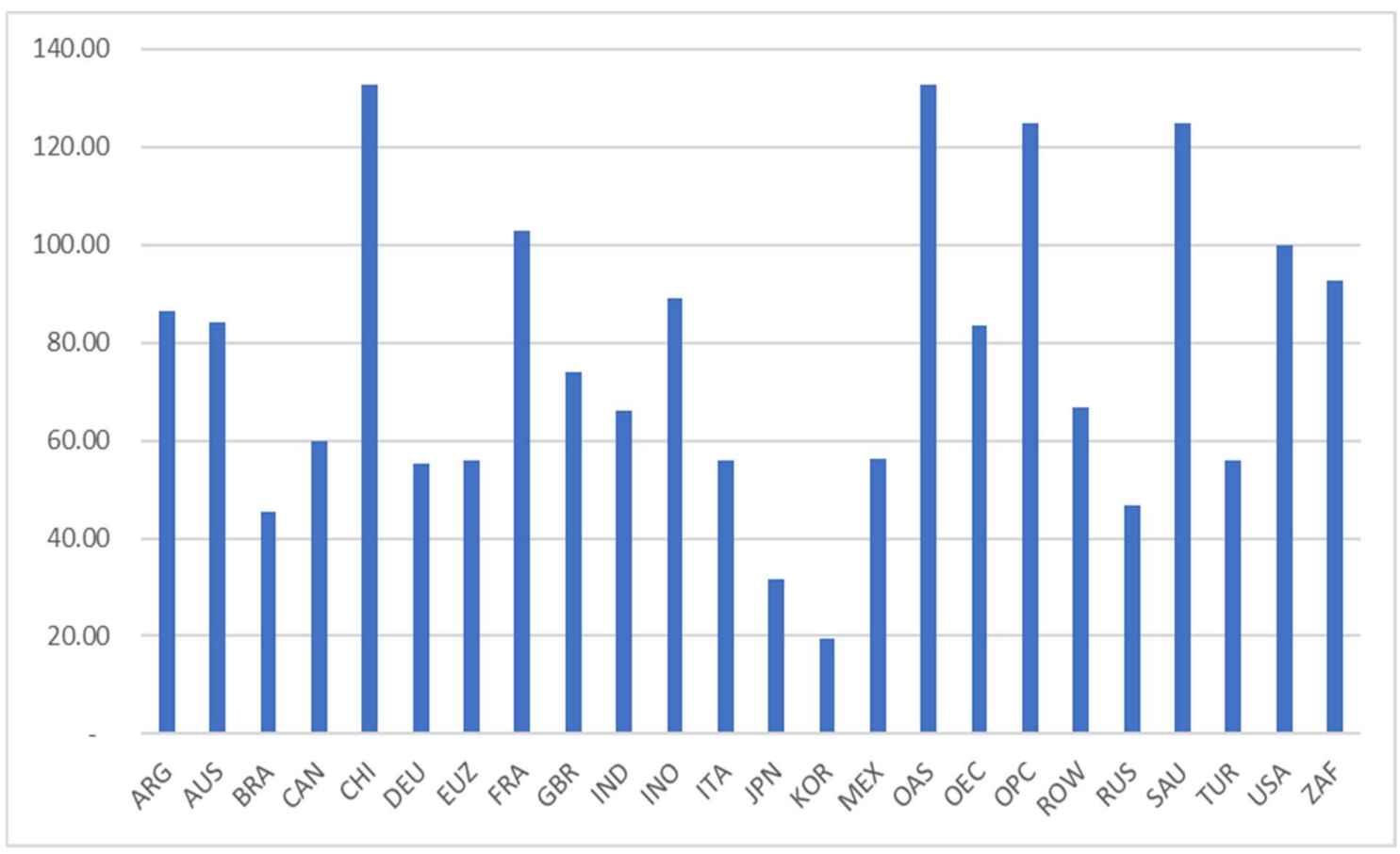

Figure 4 - Increase in Risk Premium on Human Wealth for the First Year under each Scenario

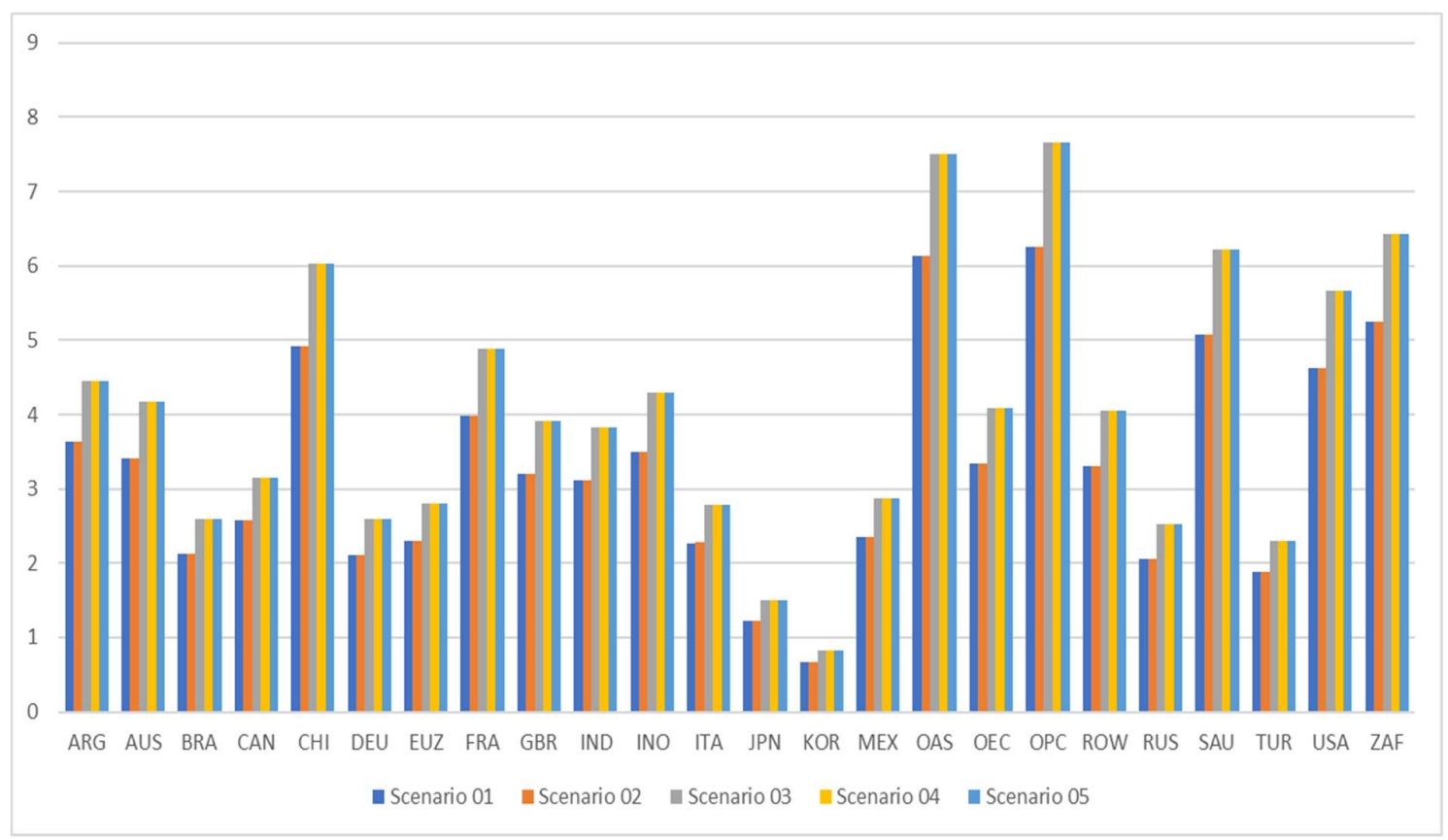


University (2019), was used to develop the Index of Health Security. The Global Health Security Index covers six categories which include the ability to prevent, detect and respond to outbreaks and diseases. It also assesses the health and political systems in a given country and evaluates the country's compliance with international health standards. Figure 5 presents the Index of Health Risk for the regions in the model. A higher value indicates a higher health risk.

The Index of Governance Risk is calculated using the International Country Risk Guide (ICRG) (PRSGroup 2020). The ICRG Index scores countries based on performance in 22 variables categorised under political, economic and financial dimensions. The political dimension accounts for government stability, the rule of law and the prevalence of conflicts. The economic dimension is composed of GDP per capita, real GDP growth and inflation, among others. Exchange rate stability and international liquidity are the two main variables constituting the financial dimension. Figure 6 presents the Index of Governance relative to the US. A higher value indicates a higher governance risk.

The Index of Financial Risk utilises the IMF data on Current Account Balance as a proportion of GDP to demonstrate the financial risk associated with countries. Figure 7 presents the value of the index relative to the US. The Index of Country Risk is the arithmetic average of the three indices and Figure 8 shows the value of the index relative to the US, due to the prevalence of well-developed financial markets there (Fisman \& Love 2004).

We then estimated the average variation of the Nasdaq, Dow Jones and S\&P 500 stock market indices in the US financial markets for four months after the outbreak. After that, using the standard deviation in the US financial markets as a benchmark, we obtained estimates for other countries by scaling for the lengths of lockdowns and the Index of Country Risk. Figure 9 shows the magnitude of the country risk premium shock in the first year for different scenarios.

We then scaled the risk premia for a given country across scenarios by adjusting for changes in the length of lockdowns.

The shock to the sector risk premia is calculated by using the movement of the sector indices in the Australian Stock Exchange (ASX) during the four months following the outbreak. The risk premia shocks are scaled across countries and scenarios according to the length of economic shutdowns. When scaling across sectors, we considered the impact on productivity in different sectors compared to the Australian sectors. Figure 10 presents the magnitude of the sector premium shock for the first year under Scenario 01. 
Figure 5 - Index of Health Risk

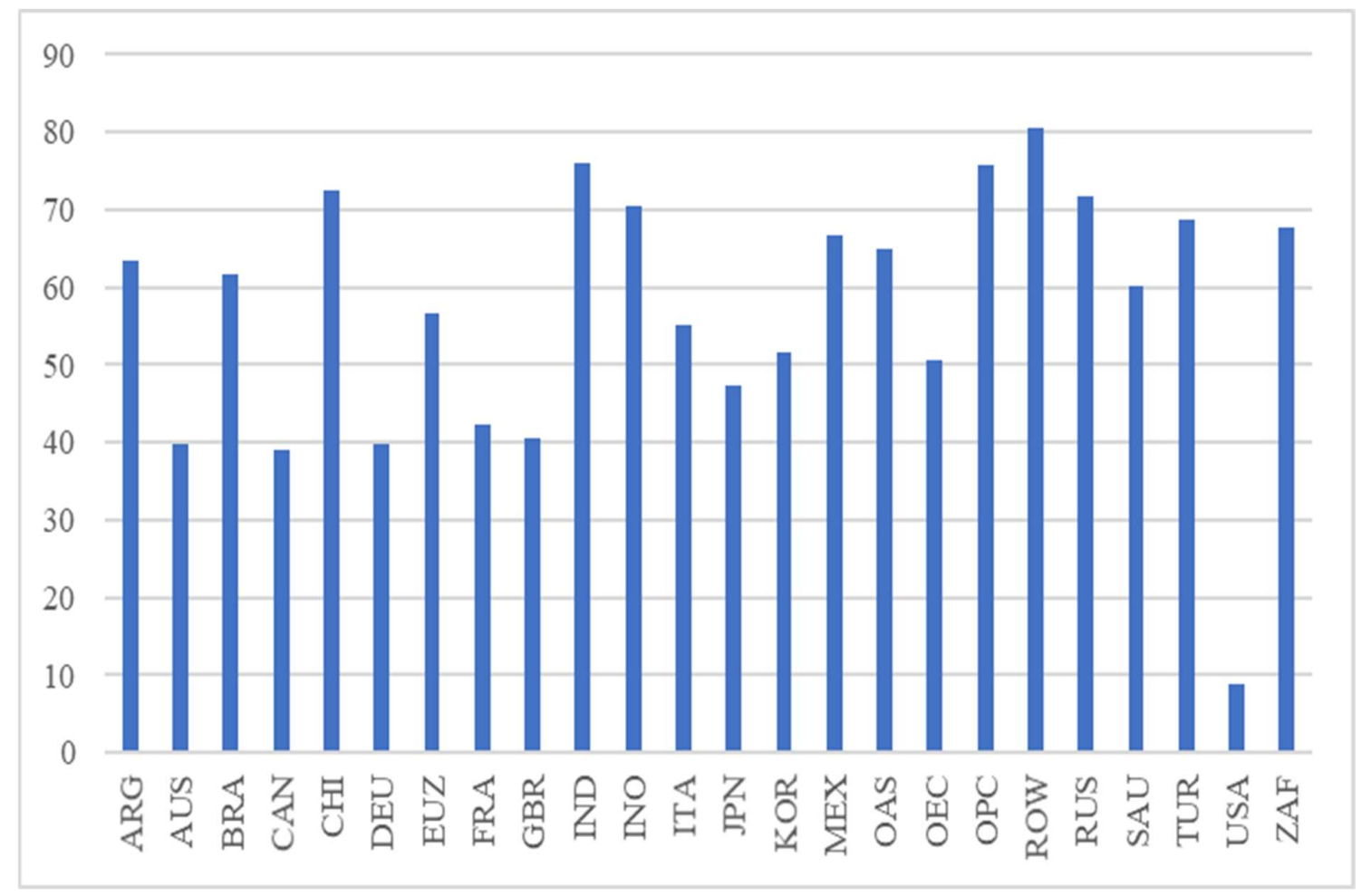

Figure 6 - Index of Governance Risk

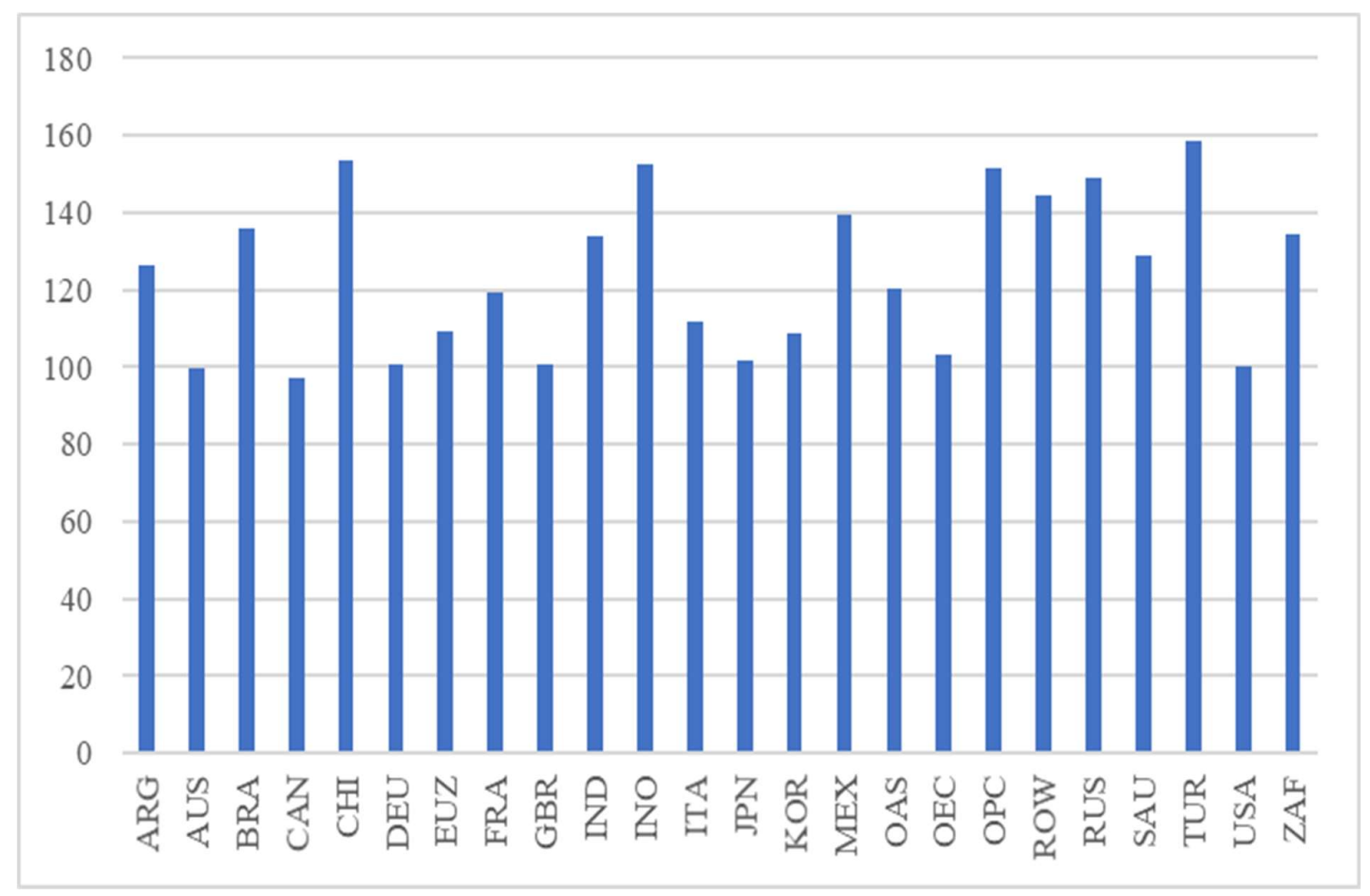


Figure 7 - Index of Financial Risk

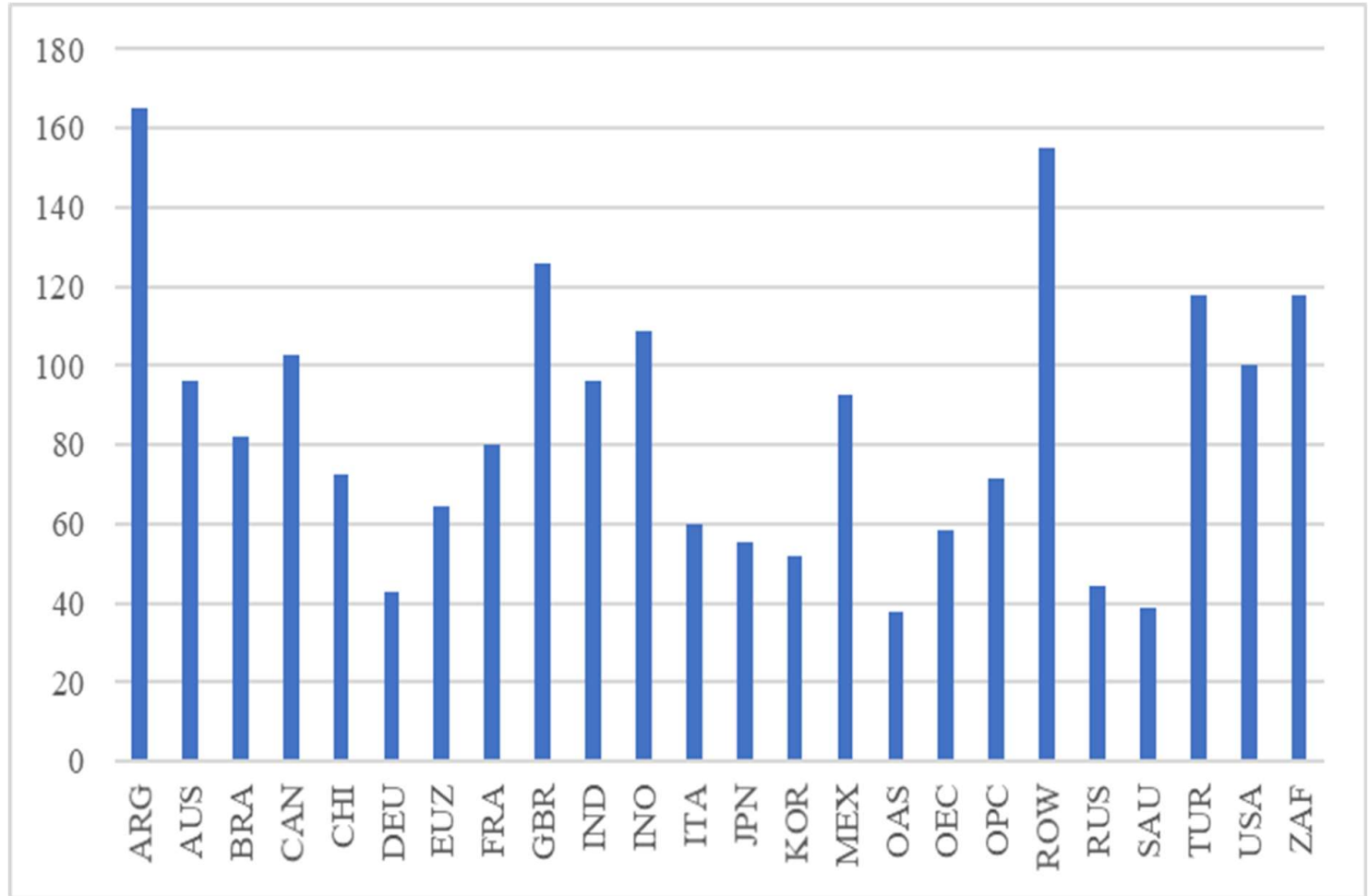

Figure 8 - Net Country Risk Index relative to the US

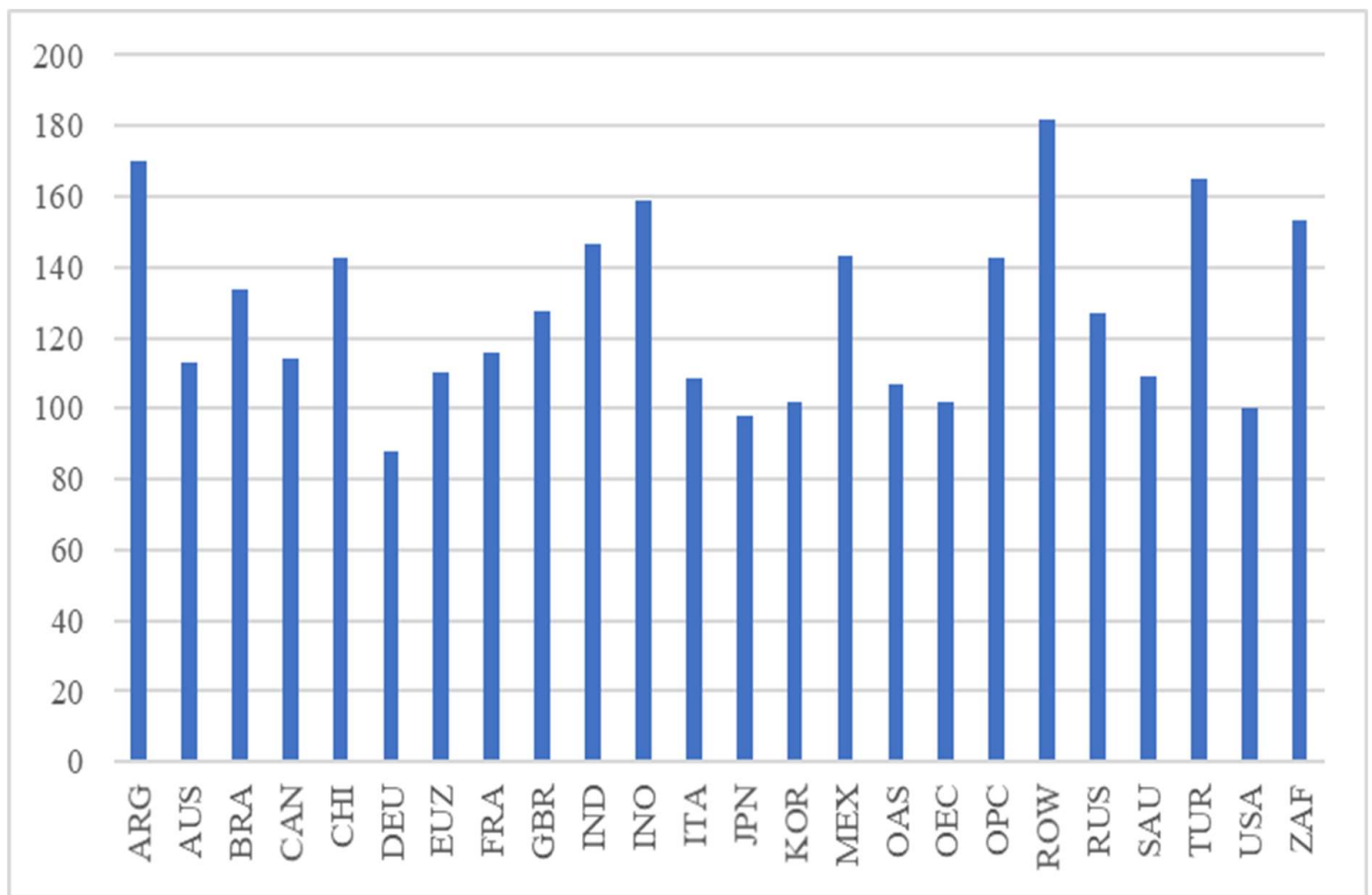


Figure 9 - Country Risk Premium Shock for the First Year under each Scenario

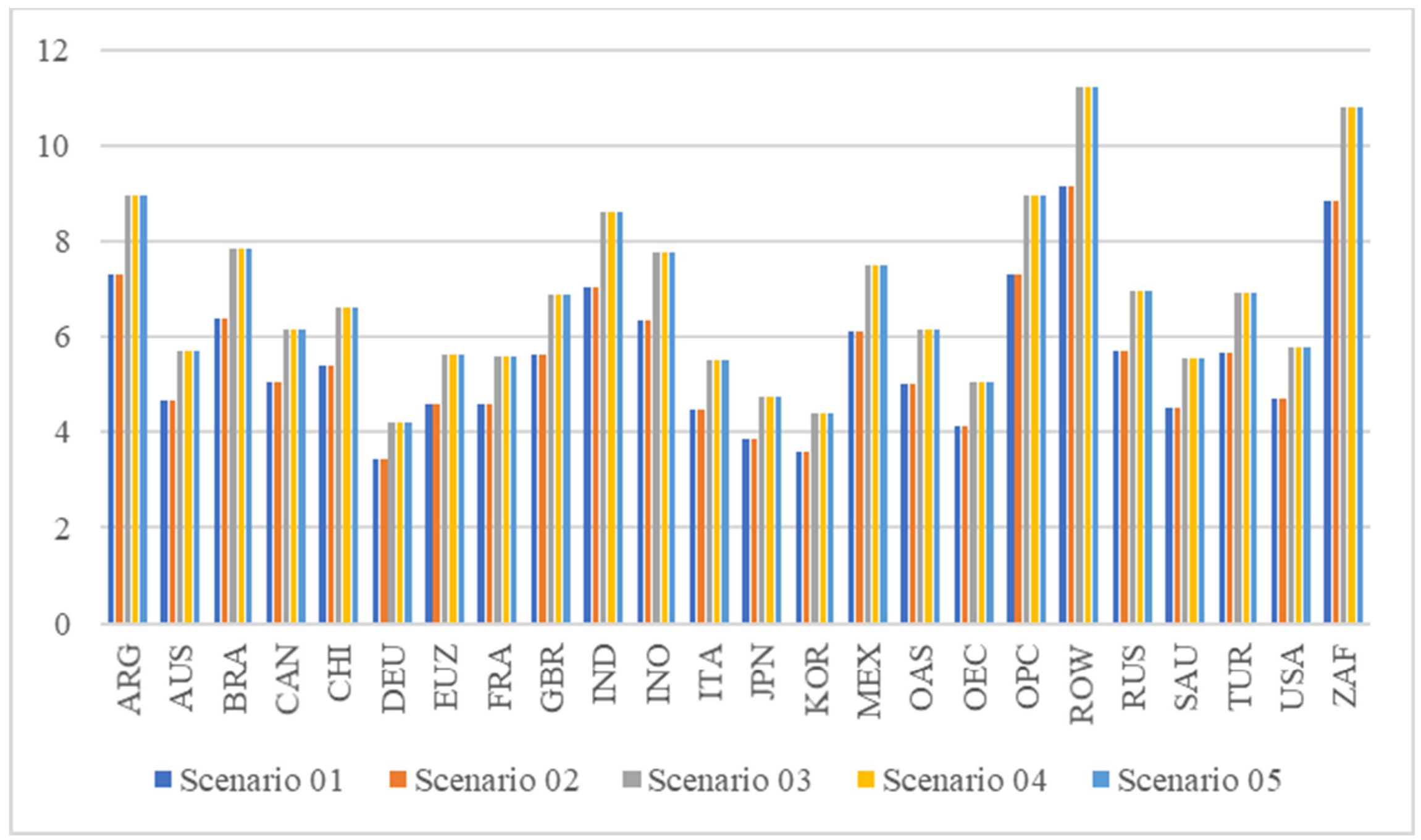

$25 \mid \mathrm{P}$ a g e 
Figure 10 - Sector Equity Risk Premium Shock for the First Year for Scenario 01

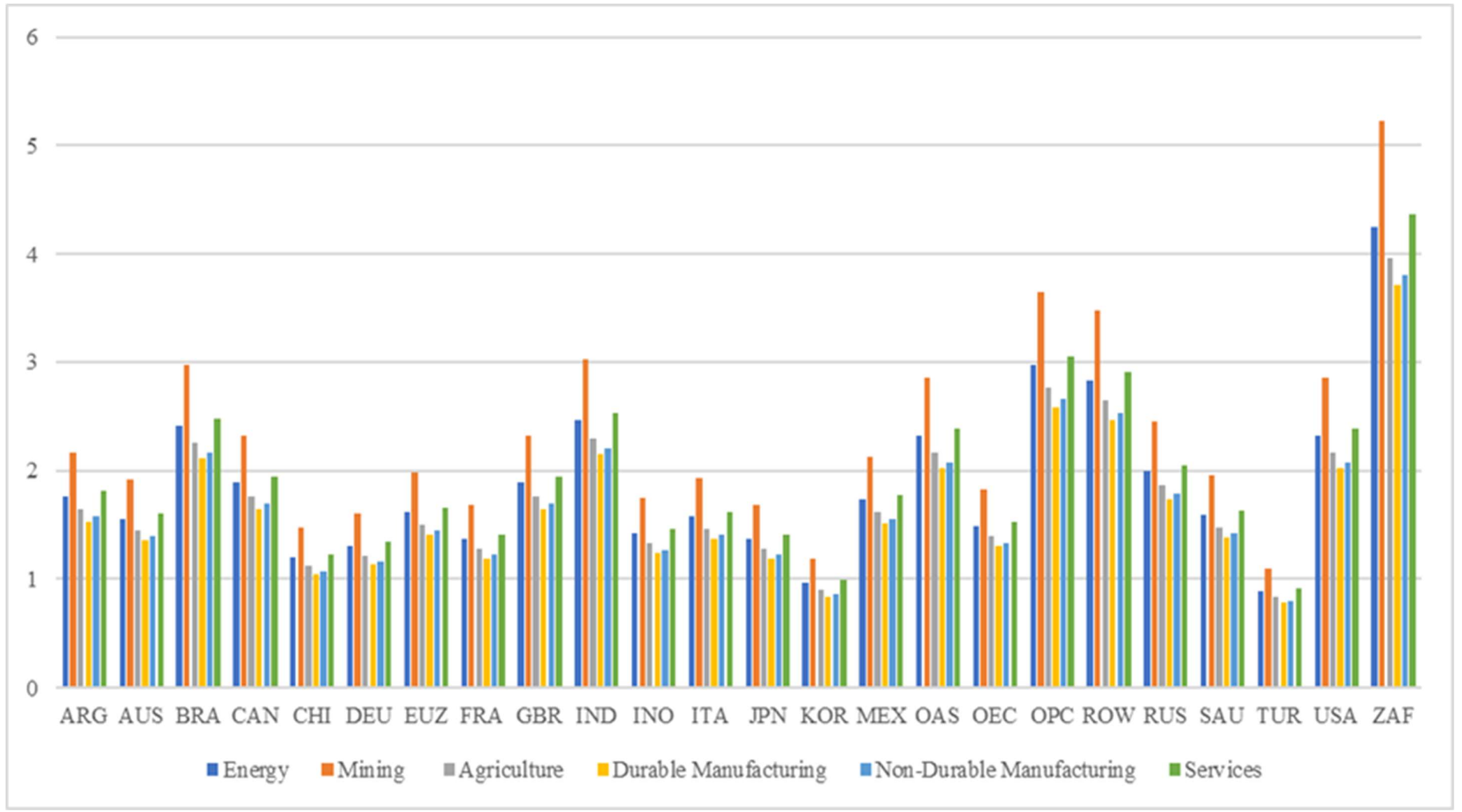




\subsubsection{Shock to Government Expenditure}

In the model, there are endogenous changes in fiscal variables as well as exogenous changes that we impose in the form of shocks. Each country follows the same fiscal rule. The budget deficit is endogenous. The fiscal rule is that a lump sum tax is levied on all households to cover the interest servicing costs of changes in net government debt caused by a change in the fiscal deficit in response to the shocks we impose on the model. Government debt can permanently change after a shock, but debt levels eventually stabilise. National government expenditure is exogenous, while transfers respond to change in economic activity as do tax revenues. There are taxes on household income, corporate income and imports. These fiscal variables all respond when shocks occur in the model. The ultimate change in the budget deficit is a combination of exogenous changes in government spending, transfers and wage subsidies where they occur, and endogenous fiscal stabilisers operating via the fiscal rule.

While imposing the lockdown measures, many governments have implemented a range of fiscal measures to cushion the impact on the economy emanating from the virus, the change in household and firm behaviour and the economic shutdowns. The IMF (2020a) compilation of the policy responses of different countries to COVID-19 reveals that the fiscal measures to support firms include relieving firms from paying tax and social contributions, targeted subsidies to hard-hit sectors, exemptions for paying utility bills and credit guarantees. The fiscal measures to support households include relief from tax payments, exemptions for settling utility bills and direct transfers. Wage subsidies have also been an essential component in the assortment of fiscal measures worldwide. As well as supporting targeted firms and households, governments have also reallocated their current budgets to increase spending on the healthcare sector. Some governments have also increased expenditure on infrastructure projects.

In this paper, we try to capture as much of the difference in policies across countries as possible. We decompose the overall fiscal response into three parts. The first is an increase in general government spending decomposed for the broad sectors. The second is a wage subsidy, and the third is an exogenous increase in transfers to the households. While the data on the rise in general government expenditure was generally available for all the countries, the magnitude of the wage subsidies and transfers were not explicitly apparent for all countries. In this case, we estimated these variables.

Even though the fiscal stimulus packages have been announced, there is uncertainty about what proportion of those packages would actually be spent. Therefore, when calculating the increase 
Figure 11 - Increase in Government Expenditure excluding the Wage Subsidies \& Transfers for Households (\% GDP)

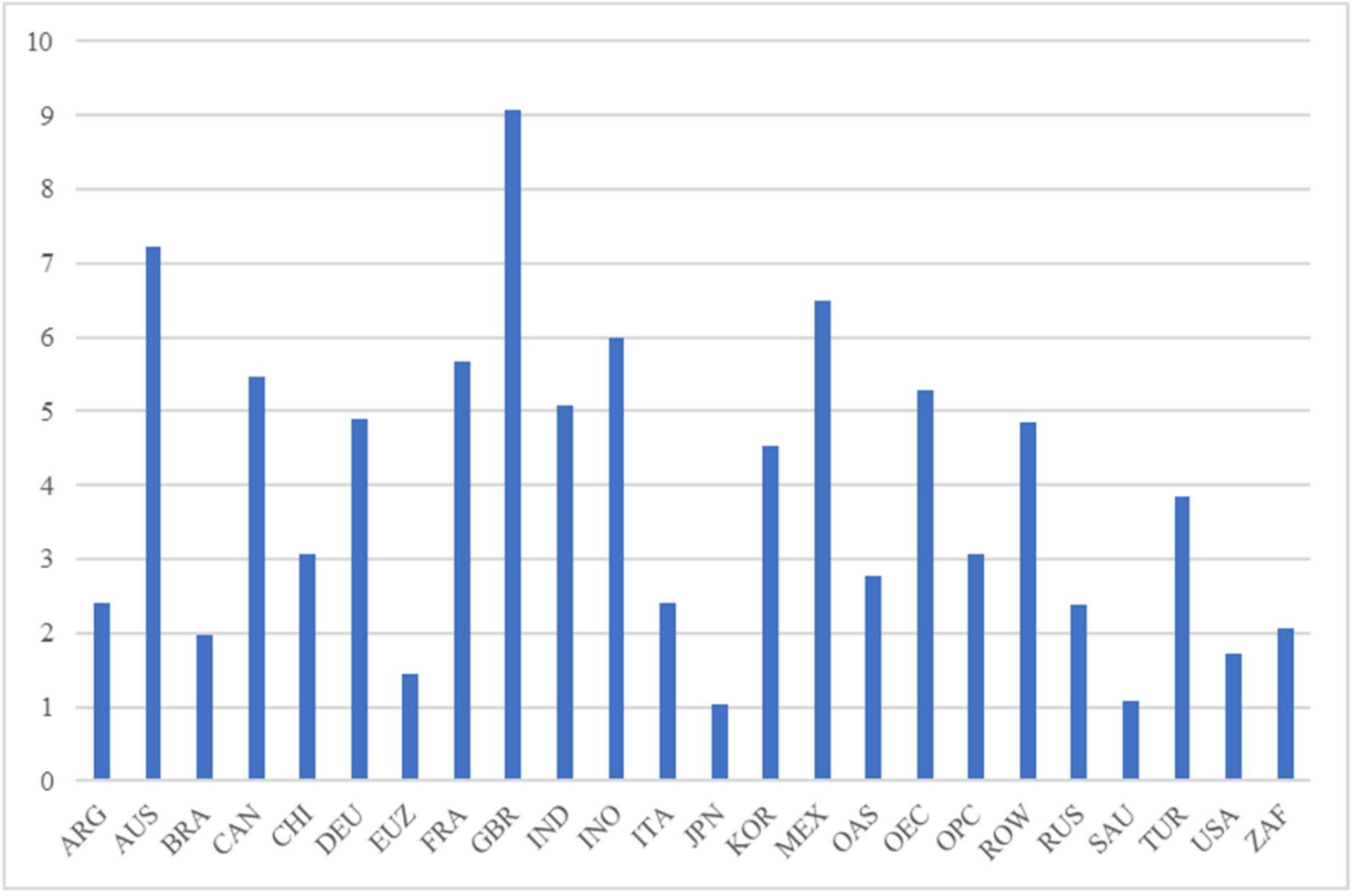

Figure 12 - Wage Subsidies Announced (\% GDP)

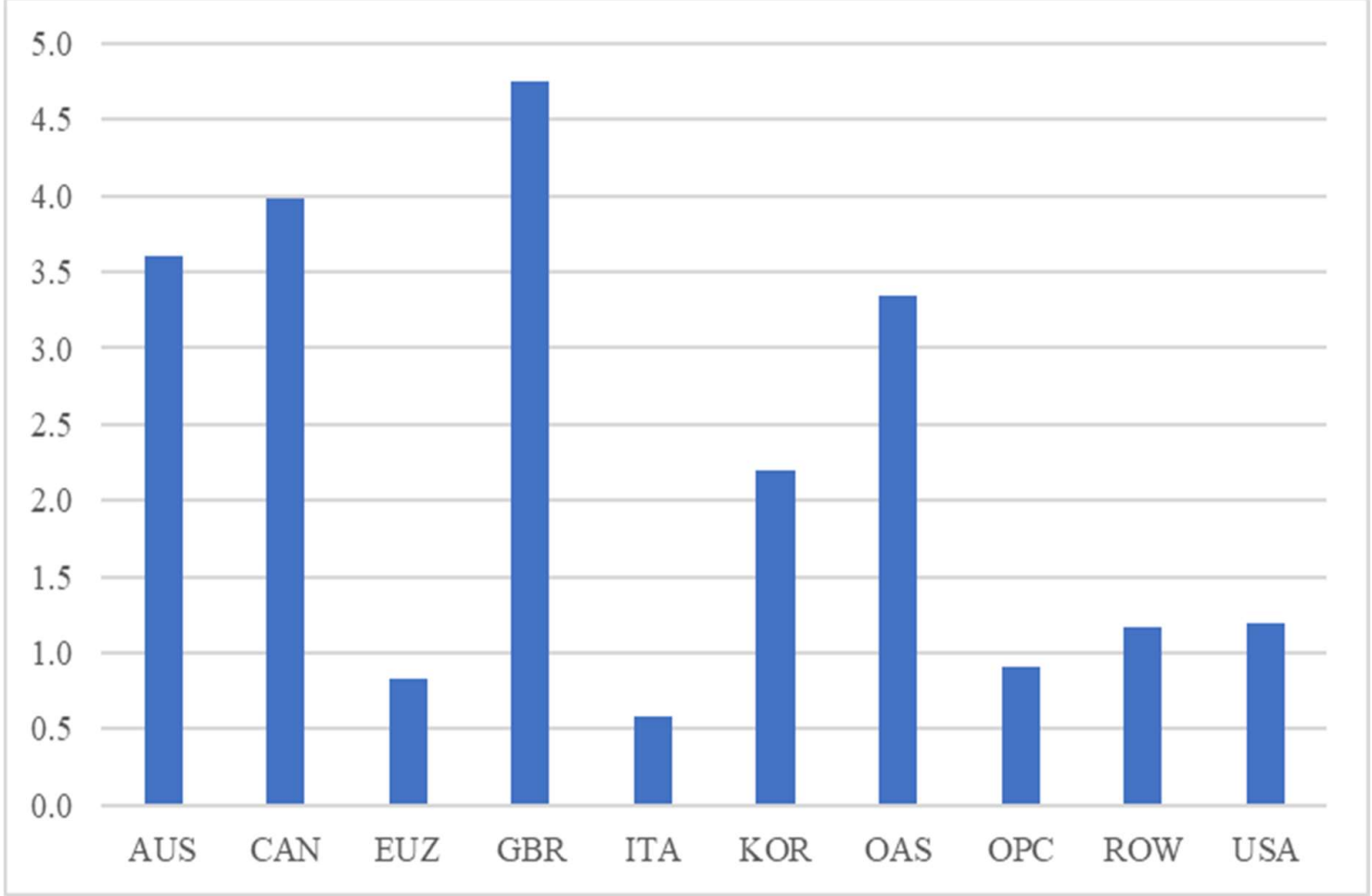




\section{Figure 13 - Household Transfers Announced (\% GDP)}

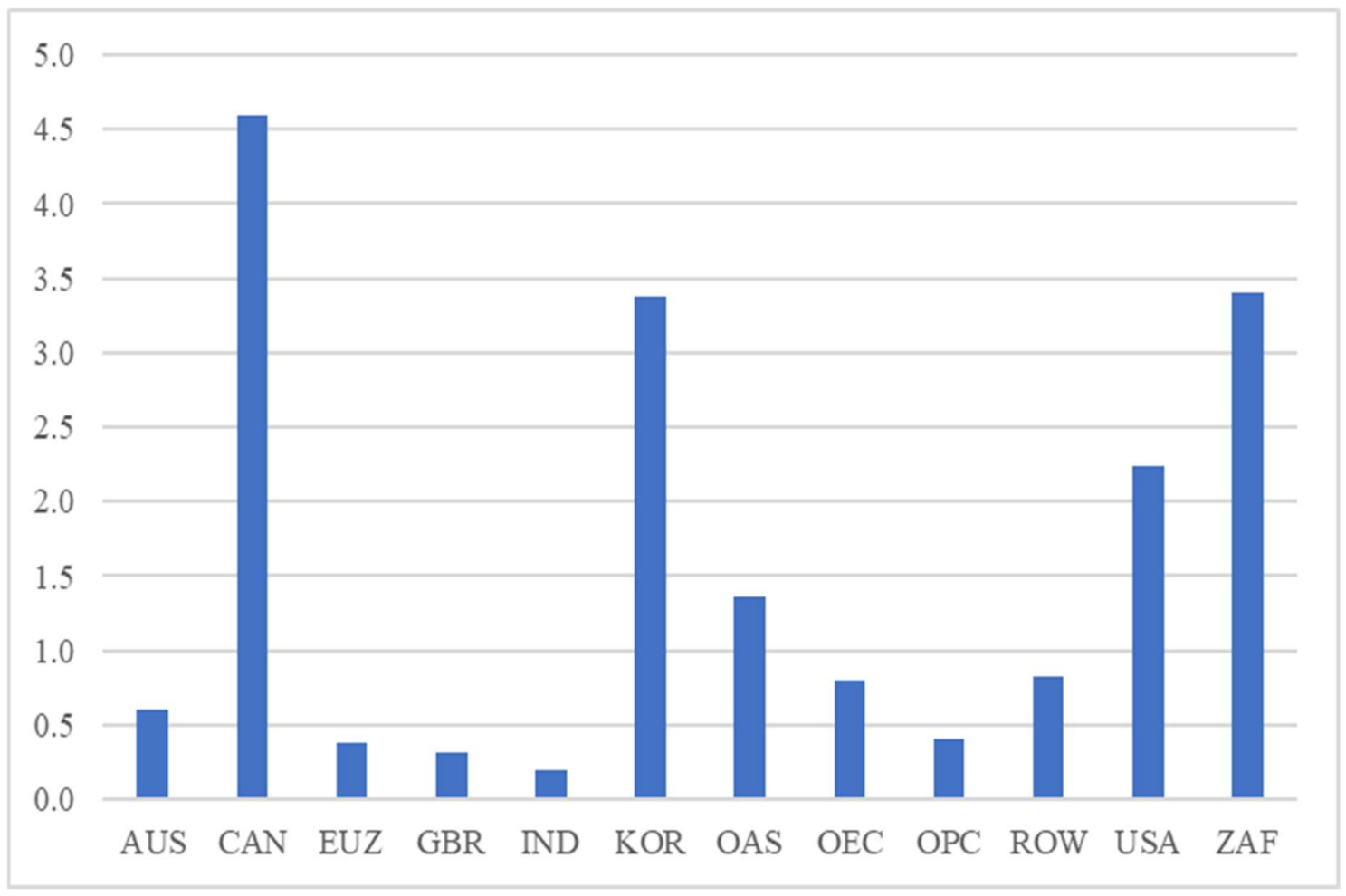

in government expenditure, we utilised the changes in fiscal deficit projected by the IMF in its April 2020 issue of the Fiscal Monitor. Figure 11 presents the increase in government expenditure for different regions in the model in response to the pandemic in early 2020 as a proportion of GDP, excluding wage subsidies and transfers for countries where the explicit data was available. Figure 12 and Figure 13 show the Wage Subsidy and Household Transfers as a proportion of GDP for countries where the data was explicitly available.

Data on the Household Transfers as a proportion of GDP was available for 12 regions in the model. While these details fed into the first scenario, for the subsequent waves and scenarios they were scaled depending on the duration of economic shutdowns compared to the current wave.

The increase in government spending was allocated across sub-sectors depending on the preferences governments would have to support the sub-sectors. We then aggregated this spending to calculate expenditure by government across the broad model sectors. We assume these preferences for spending in different sectors are determined by the expected impact on the sub-sectors during the pandemic. The proportions of government spending on the broad 
sectors were then scaled across scenarios depending on the length of shutdowns. Figure 14 presents the proportions of increased government spending each broad model sector would receive in a given country based on our estimations of government allocation of its expenditure across the sub-sectors. Building on the Figures 11 and 14, Figure 15 presents the increase in government spending for different sectors across different scenarios.

\section{Figure 14 - Government Spending Allocation across Broad-sectors}

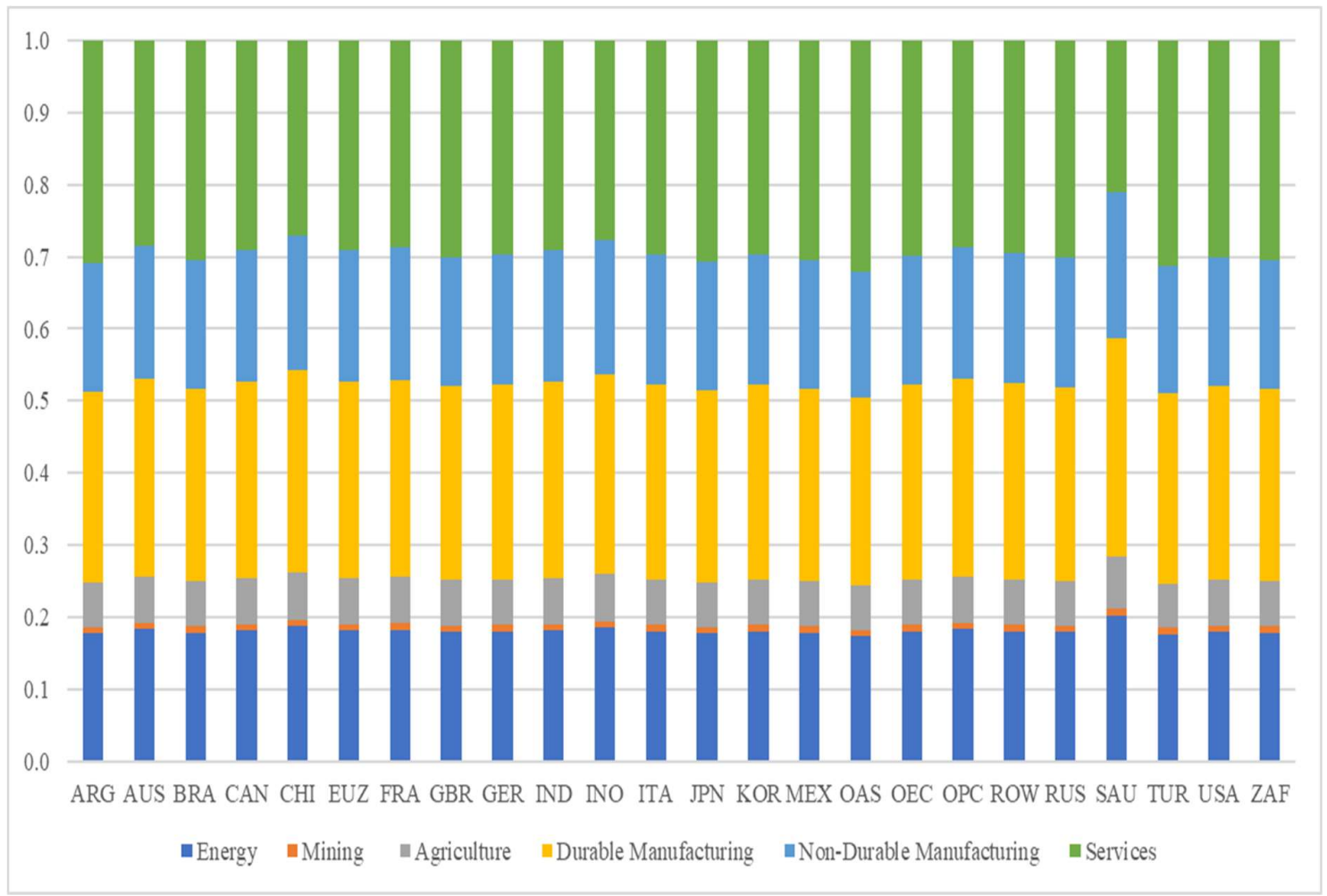

One of the notable elements in the fiscal responses to the pandemic has been the wage subsidies introduced by different governments. Governments in the model can employ workers directly, or they can generate employment in the private sector via demand for goods and services or investments in infrastructure. The motive of the wage subsidies during the pandemic is to directly support workers in jobs while preventing the rise in unemployment. Due to this unprecedented nature of the wage subsidy, we calibrated the wage subsidy shock closely approximating the Australian case and using the estimates by the Australian Treasury for the employment effects of the wage subsidy. 
Figure 15 - Increased Government Spending across Sectors for the First Year in Scenario 01

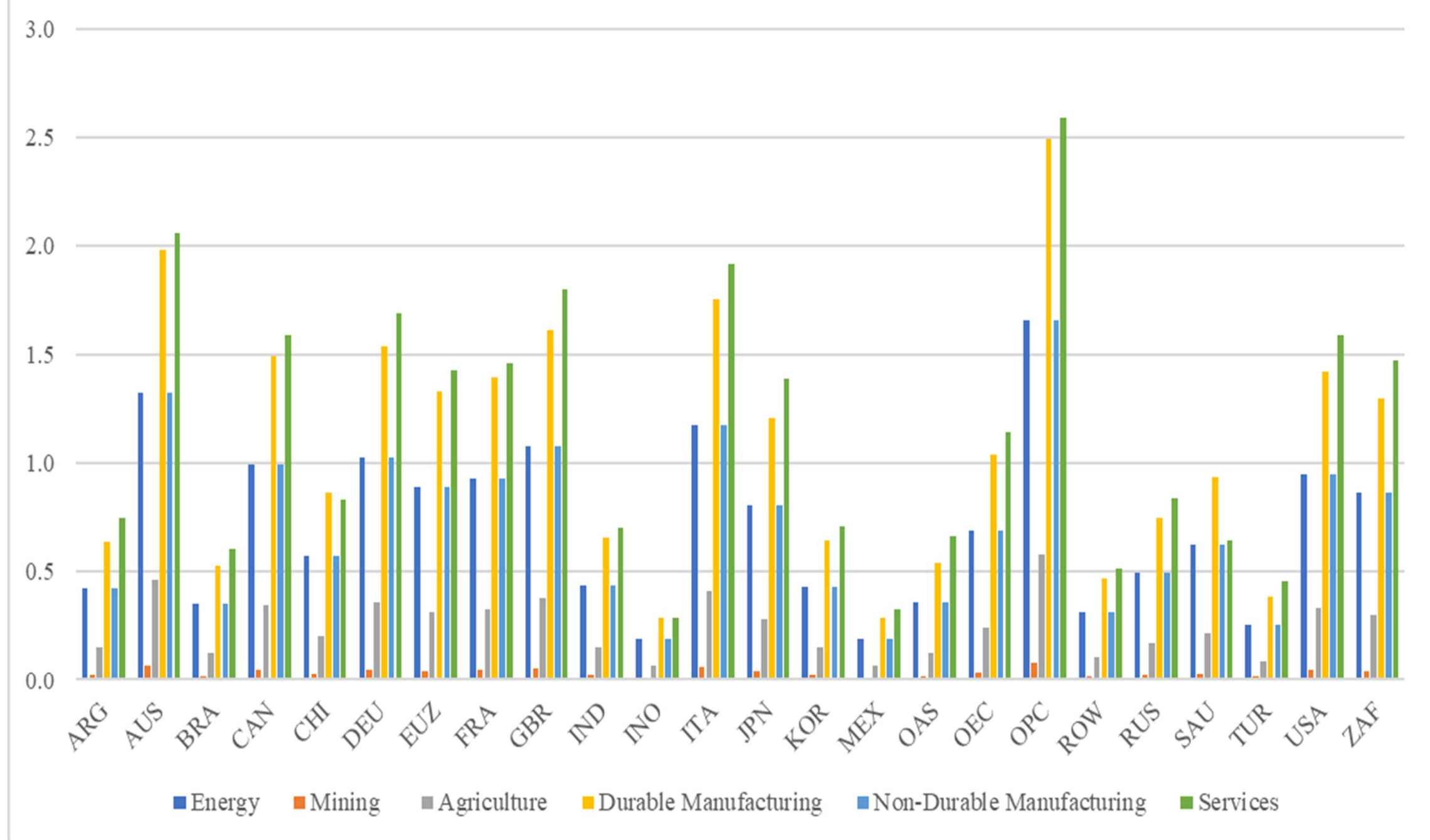

31 P a g e 
Figure 16 - Wage Subsidy Shock for the First Year for Scenario 01

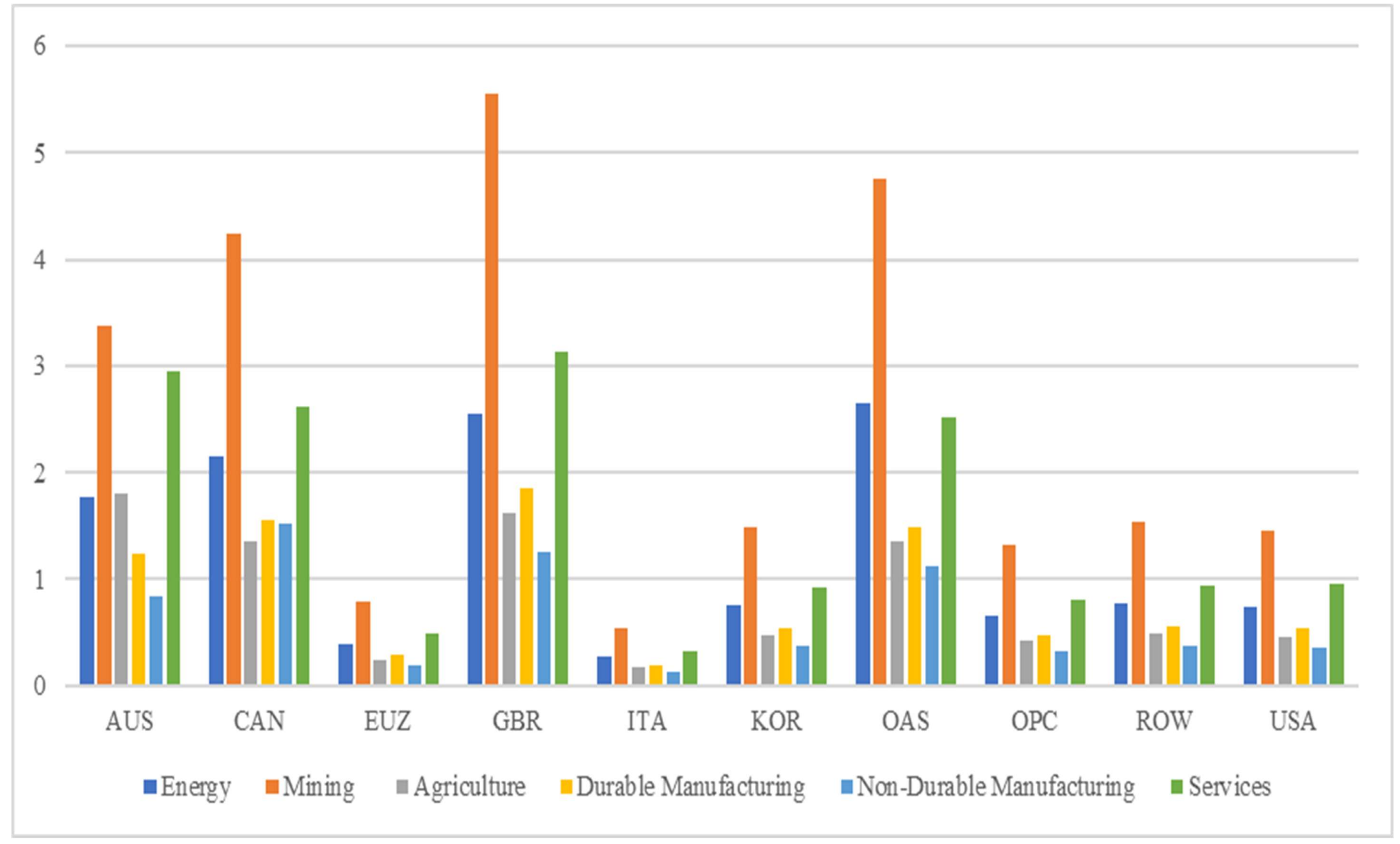

$32 \mid \mathrm{P}$ a g e 
We observed the fall in employment with all the shocks except for the wage subsidy shock in the model and obtained a calibration factor for each sector to achieve the forecasted overall employment benefit given the wage subsidy. We then scaled the shock across countries depending on the respective wage subsidy packages. We also scaled the shock across scenarios depending on the length of the shutdowns. Figure 16 presents the wage subsidy each sector receives for the first year in Scenario 01.

\section{Simulation Results}

\subsection{Baseline scenario}

The baseline of the model is the same as that used in McKibbin and Fernando (2020a \& 2020b). To summarise, the model is solved from 2016 to 2100 with 2015 as the base year for calibrating parameters. The key inputs into the baseline are the initial dynamics from 2015 to 2016 and subsequent projections from 2016 forward for labour-augmenting technological progress by sector and by country. The labour-augmenting technology projections follow the approach of Barro $(1991,2015)$.

In the alternative COVID-19 scenarios, we incorporated the range of shocks discussed above to model the economic consequences of different epidemiological assumptions. All results begin in 2020 and are the difference between the COVID-19 scenario and a baseline of the model in which there is no COVID-19 pandemic. It is important to stress that because the results are either percentage change or per cent of GDP difference from the non-COVID, the interpretation of the numbers can easily be misunderstood. For example, suppose for country X that the change in GDP in 2020 is $-20 \%$. This number means that GDP in 2020 is $20 \%$ lower than it otherwise would have been in 2020 . If the country was growing at $5 \%$ in the baseline, then the change in GDP from 2019 to 2020 is not $-20 \%$ but it is $-15 \%$ relative to 2019 . GDP is $20 \%$ lower than the baseline in 2020 .

A full set of results are presented in the model dashboard available at: https://cama.crawford.anu.edu.au/covid-19-macroeconomic-modelling-results-dashboard.

\subsection{Results for 2020}

Table 10 contains the results for the \$US value of GDP change in 2020 for all countries for all scenarios. The loss to the global economy in 2020 under scenario 01 is \$US14.7 trillion. The more waves are assumed, the larger the loss. By scenario 04 which has four waves, two each in 2020 and 2021 and a replication of the policies seen in the first wave across all countries, the loss rises to \$US 21.8 trillion. In scenario 05 , where lockdowns only occur in the first wave for 
Table 10: Change in Real GDP in 2020 in \$US Billion

\begin{tabular}{lrrrrrr}
\hline \multicolumn{1}{c}{ Country/Region } & \multicolumn{1}{c}{ S01 } & \multicolumn{1}{c}{ S02 } & \multicolumn{1}{c}{ S03 } & \multicolumn{1}{c}{ S04 } & \multicolumn{1}{c}{ S05 } & S06 \\
\hline Argentina & -122.18 & -123.55 & -182.64 & -181.49 & -144.85 & -134.43 \\
Australia & -117.02 & -125.93 & -170.16 & -172.31 & -147.42 & -127.25 \\
Brazil & -607.08 & -620.63 & -908.91 & -905.35 & -723.23 & -631.86 \\
Canada & -134.94 & -145.12 & -200.38 & -200.06 & -178.99 & -151.27 \\
China & $-1,935.94$ & $-2,131.80$ & $-2,787.65$ & $-2,831.90$ & $-2,346.65$ & $-2,046.49$ \\
France & -367.75 & -395.55 & -520.43 & -537.29 & -392.87 & -374.99 \\
Germany & -475.29 & -496.50 & -666.01 & -694.99 & -513.61 & -548.93 \\
India & $-1,075.59$ & $-1,089.88$ & $-1,610.37$ & $-1,605.81$ & $-1,280.35$ & $-1,163.17$ \\
Indonesia & -261.62 & -270.66 & -390.57 & -388.97 & -315.82 & -276.69 \\
Italy & -340.14 & -355.12 & -491.37 & -502.20 & -393.97 & -348.35 \\
Japan & -782.72 & -785.97 & $-1,120.64$ & $-1,160.27$ & -790.03 & -841.37 \\
Mexico & -170.83 & -174.59 & -258.12 & -257.01 & -203.49 & -180.71 \\
Other Asia & -236.56 & -241.84 & -353.60 & -352.88 & -278.88 & -257.08 \\
Other oil producing countries & -305.64 & -317.50 & -449.92 & -454.02 & -382.00 & -350.56 \\
Republic of Korea & -105.45 & -108.42 & -155.91 & -156.91 & -122.45 & -115.91 \\
Rest of Euro Zone & -129.49 & -135.24 & -187.94 & -191.05 & -145.44 & -134.81 \\
Rest of OECD & -260.38 & -270.80 & -373.47 & -383.56 & -295.92 & -296.45 \\
Rest of the World & -292.95 & -296.65 & -442.39 & -440.74 & -352.00 & -309.08 \\
Russia & $-2,830.25$ & $-2,895.40$ & $-4,176.30$ & $-4,211.51$ & $-3,285.58$ & $-2,997.29$ \\
Saudi Arabia & -243.36 & -288.79 & -332.18 & -336.55 & -300.84 & -207.74 \\
South Africa & $-1,377.70$ & $-1,390.12$ & $-2,057.97$ & $-2,063.74$ & $-1,574.52$ & $-1,450.38$ \\
Turkey & -376.00 & -382.80 & -559.15 & -559.10 & -441.04 & -408.64 \\
United Kingdom & -141.19 & -144.79 & -205.47 & -209.07 & -166.19 & -164.55 \\
United States of America & $-2,043.62$ & $-2,149.39$ & $-2,967.76$ & $-2,985.18$ & $-2,490.50$ & $-2,136.57$ \\
Total for the World & $\mathbf{- 1 4 , 7 3 3 . 6 7}$ & $-\mathbf{1 5 , 3 3 7 . 0 4}$ & $-\mathbf{2 1 , 5 6 9 . 3 3}$ & $\mathbf{- 2 1 , 7 8 1 . 9 9}$ & $-\mathbf{1 7 , 2 6 6 . 6 3}$ & $\mathbf{- 1 5 , 6 5 4 . 5 5}$ \\
\hline
\end{tabular}

Table 11: Cumulative Change in Real GDP between 2020 and 2025 in \$US Billion

\begin{tabular}{lrrrrrr}
\hline \multicolumn{1}{c}{ Country/Region } & S01 & \multicolumn{1}{c}{ S02 } & \multicolumn{1}{c}{ S03 } & \multicolumn{1}{c}{ S04 } & \multicolumn{1}{c}{ S05 } & S06 \\
\hline Argentina & -97.90 & -142.96 & -133.20 & -144.15 & -217.77 & -105.23 \\
Australia & -151.62 & -206.04 & -194.11 & -223.98 & -306.63 & -164.96 \\
Brazil & -601.72 & -850.06 & -803.42 & -894.06 & $-1,271.31$ & -629.38 \\
Canada & -157.81 & -235.79 & -199.68 & -232.82 & -397.54 & -169.24 \\
China & $-2,632.94$ & $-3,729.39$ & $-3,335.64$ & $-3,853.41$ & $-4,924.32$ & $-2,712.79$ \\
France & -453.07 & -579.95 & -574.24 & -660.97 & -785.72 & -464.21 \\
Germany & -572.43 & -661.79 & -724.20 & -835.99 & -989.42 & -639.92 \\
India & $-1,305.01$ & $-2,002.01$ & $-1,710.71$ & $-1,919.82$ & $-2,914.95$ & $-1,368.91$ \\
Indonesia & -346.52 & -482.43 & -466.02 & -513.16 & -650.71 & -356.93 \\
Italy & -441.37 & -564.64 & -572.68 & -651.65 & -830.45 & -442.69 \\
Japan & -915.44 & $-1,134.07$ & $-1,171.28$ & $-1,349.83$ & $-1,561.81$ & $-1,000.38$ \\
Mexico & -239.44 & -331.70 & -328.78 & -352.55 & -573.36 & -225.87 \\
Other Asia & -367.02 & -500.63 & -484.77 & -547.04 & -690.66 & -368.81 \\
Other oil producing countries & -515.42 & -755.64 & -672.22 & -752.39 & $-1,046.04$ & -528.27 \\
Republic of Korea & -139.00 & -156.05 & -183.12 & -208.24 & -280.84 & -141.60 \\
Rest of Euro Zone & -159.95 & -215.83 & -205.96 & -234.89 & -339.61 & -162.60 \\
Rest of OECD & -317.50 & -411.33 & -397.68 & -467.34 & -585.80 & -355.28 \\
Rest of the World & -356.24 & -580.25 & -461.47 & -527.31 & -777.83 & -368.28 \\
Russia & $-3,699.76$ & $-5,099.90$ & $-4,830.93$ & $-5,490.82$ & $-6,968.17$ & $-3,868.80$ \\
Saudi Arabia & -535.23 & -630.72 & -681.46 & -749.36 & -845.95 & -438.49 \\
South Africa & $-2,039.51$ & $-3,012.59$ & $-2,609.24$ & $-3,024.52$ & $-3,678.91$ & $-2,068.51$ \\
Turkey & -460.45 & -598.97 & -612.95 & -686.76 & -687.51 & -462.08 \\
United Kingdom & -161.24 & -214.32 & -209.89 & -238.15 & -381.39 & -179.97 \\
United States of America & -901.53 & $-1,106.08$ & $-1,115.56$ & $-1,263.40$ & $-3,653.80$ & $-1,026.25$ \\
Total for the World & $\mathbf{- 1 7 , 5 6 8 . 1 3}$ & $-\mathbf{2 4 , 2 0 3 . 1 4}$ & $-\mathbf{2 2 , 6 7 9 . 1 9}$ & $\mathbf{- 2 5 , 8 2 2 . 6 2}$ & $-\mathbf{3 5 , 3 6 0 . 4 9}$ & $\mathbf{- 1 8 , 2 4 9 . 4 4}$ \\
\hline & & & & & &
\end{tabular}


countries that had lockdowns, the pandemic continues to re-emerge. This continuing emergence of the pandemic causes a permanent increase in global risk. The global loss of GDP in 2020 is \$US17.3 trillion. However, the GDP loss in future years continues to acccumulate, given the permanent risk shock. Table 11 shows the cumulative GDP loss from 2020 to 2025.

Table 12 gives a better indication of the relative decline of economic activity across countries. This table has the change in GDP scaled by the size of GDP for each country measured relative to the baseline in which there is no COVID-19 pandemic. (Note that these results for GDP are not the growth rate of GDP.) The numbers in the tables are results for the percentage change in the level of GDP relative to the baseline. For example, the Australian economy in scenario 01 is estimated to shrink by $8.57 \%$ relative to what would have been the case in 2020 . The change in the growth rate in 2020 would be the growth that would have occurred in 2020 less the number in this table. For example, if Australia's growth rate in 2020 would have been $2.57 \%$, then the new growth rate for Australia for 2020 is estimated to be $-6 \%$.

For all countries, scenario 01, which is optimistic given current data, has a significant contraction in the global economy. The US Congressional Budget Office [CBO] (2020) most recent projection is for GDP over 2020 to be $7.6 \%$ lower than previously forecast. However, CBO estimates that GDP in the second quarter of 2020 is $14.2 \%$ lower than otherwise. Much of this difference to the results in this paper can be attributed to the longer implied persistence of the economic slowdown relative to the $\mathrm{CBO}$ estimates. The current state of all economies is highly uncertain. The results for Scenario 01 are consistent with the estimates from the World Bank and IMF discussed in section 2, although the current results are, on average several percent more negative. Given the current state of uncertainty about the scale of the shock and the evolution of the pandemic, it is unclear which set of estimates are more realistic. However, all the studies predict a dramatic shock to the global economy much larger than the global financial crisis a decade ago.

It is clear from the results that if the waves of the pandemic re-occur the GDP losses mount. This mounting loss from recurring pandemic waves is even in the case where lockdowns are not part of the policy response (in S05). It is also clear from comparing scenario 06 with scenario 01 that even if a country can contain the pandemic within its borders the loss to own GDP continues to rise if the rest of the world loses control. For example, under scenario 01 for all countries, Australia's GDP is $8.6 \%$ lower. If we assume Australia follows scenario 01 but the rest of the world is in scenario 04 (i.e. S06) then Australia GDP is a further $0.7 \%$ lower than when all countries experience scenario 01 . 
Table 12: Percent Change in Real GDP in 2020 relative to baseline

\begin{tabular}{lrrrrrr}
\hline \multicolumn{1}{c}{ Country/Region } & \multicolumn{1}{c}{ S01 } & \multicolumn{1}{c}{ S02 } & \multicolumn{1}{c}{ S03 } & \multicolumn{1}{c}{ S04 } & \multicolumn{1}{c}{ S05 } & \multicolumn{1}{c}{ S06 } \\
\hline Argentina & -11.42 & -11.55 & -17.07 & -16.96 & -13.54 & -12.56 \\
Australia & -8.57 & -9.22 & -12.46 & -12.62 & -10.79 & -9.32 \\
Brazil & -14.99 & -15.32 & -22.44 & -22.35 & -17.85 & -15.60 \\
Canada & -7.09 & -7.62 & -10.52 & -10.51 & -9.40 & -7.94 \\
China & -6.48 & -7.14 & -9.34 & -9.48 & -7.86 & -6.85 \\
France & -11.46 & -12.33 & -16.22 & -16.75 & -12.25 & -11.69 \\
Germany & -10.45 & -10.92 & -14.65 & -15.28 & -11.30 & -12.07 \\
India & -8.02 & -8.13 & -12.01 & -11.97 & -9.55 & -8.67 \\
Indonesia & -6.12 & -6.33 & -9.13 & -9.09 & -7.38 & -6.47 \\
Italy & -12.26 & -12.80 & -17.71 & -18.10 & -14.20 & -12.55 \\
Japan & -13.63 & -13.69 & -19.52 & -20.21 & -13.76 & -14.66 \\
Mexico & -5.56 & -5.68 & -8.40 & -8.37 & -6.62 & -5.88 \\
Other Asia & -9.88 & -10.10 & -14.77 & -14.74 & -11.65 & -10.74 \\
Other oil producing countries & -7.05 & -7.32 & -10.38 & -10.47 & -8.81 & -8.09 \\
Republic of Korea & -5.40 & -5.55 & -7.98 & -8.03 & -6.27 & -5.93 \\
Rest of Euro Zone & -13.21 & -13.80 & -19.17 & -19.49 & -14.84 & -13.75 \\
Rest of OECD & -10.05 & -10.45 & -14.41 & -14.80 & -11.42 & -11.44 \\
Rest of the World & -9.00 & -9.11 & -13.59 & -13.54 & -10.81 & -9.49 \\
Russia & -13.34 & -13.65 & -19.69 & -19.85 & -15.49 & -14.13 \\
Saudi Arabia & -4.26 & -5.05 & -5.81 & -5.89 & -5.26 & -3.64 \\
South Africa & -23.06 & -23.27 & -34.45 & -34.55 & -26.36 & -24.28 \\
Turkey & -6.93 & -7.06 & -10.31 & -10.31 & -8.13 & -7.54 \\
United Kingdom & -6.75 & -6.93 & -9.83 & -10.00 & -7.95 & -7.87 \\
United States of America & -12.10 & -12.73 & -17.58 & -17.68 & -14.75 & -12.65 \\
\hline
\end{tabular}

Table 13: Percent Change in Employment in 2020 relative to baseline

\begin{tabular}{lrrrrrr}
\hline \multicolumn{1}{c}{ Country/Region } & S01 & \multicolumn{1}{c}{ S02 } & \multicolumn{1}{c}{ S03 } & \multicolumn{1}{c}{ S04 } & \multicolumn{1}{c}{ S05 } & \multicolumn{1}{c}{ S06 } \\
\hline Argentina & -15.89 & -16.13 & -23.74 & -23.53 & -19.39 & -18.31 \\
Australia & -6.08 & -7.33 & -8.31 & -8.66 & -8.99 & -7.67 \\
Brazil & -14.64 & -15.31 & -21.80 & -21.70 & -18.29 & -15.93 \\
Canada & -5.25 & -6.30 & -7.62 & -7.64 & -8.66 & -7.06 \\
China & -4.27 & -5.55 & -5.64 & -5.95 & -5.96 & -5.05 \\
France & -12.75 & -14.65 & -17.00 & -18.15 & -12.84 & -13.25 \\
Germany & -11.52 & -12.48 & -15.27 & -16.52 & -12.08 & -14.68 \\
India & -8.35 & -8.59 & -12.46 & -12.40 & -10.50 & -9.65 \\
Indonesia & -6.41 & -6.88 & -9.48 & -9.44 & -8.40 & -7.37 \\
Italy & -12.24 & -13.53 & -16.75 & -17.67 & -14.50 & -12.93 \\
Japan & -13.50 & -13.74 & -18.49 & -19.77 & -12.52 & -15.47 \\
Mexico & -8.32 & -8.67 & -12.57 & -12.53 & -10.44 & -9.41 \\
Other Asia & -6.62 & -7.17 & -9.75 & -9.73 & -8.73 & -8.61 \\
Other oil producing countries & -8.40 & -9.09 & -12.08 & -12.33 & -11.75 & -11.33 \\
Republic of Korea & -3.90 & -4.41 & -5.43 & -5.65 & -4.87 & -5.23 \\
Rest of Euro Zone & -13.89 & -15.23 & -19.37 & -20.10 & -15.53 & -15.09 \\
Rest of OECD & -8.96 & -9.76 & -12.13 & -12.89 & -10.28 & -11.67 \\
Rest of the World & -8.88 & -9.15 & -13.48 & -13.39 & -11.58 & -10.00 \\
Russia & -13.22 & -14.08 & -18.89 & -19.38 & -16.23 & -15.59 \\
Saudi Arabia & -5.97 & -8.97 & -6.87 & -7.14 & -8.52 & -5.16 \\
South Africa & -10.89 & -11.31 & -16.00 & -16.24 & -12.68 & -13.49 \\
Turkey & -8.29 & -8.65 & -12.17 & -12.21 & -10.21 & -9.84 \\
United Kingdom & -8.05 & -8.42 & -11.45 & -11.81 & -9.63 & -10.22 \\
United States of America & -14.46 & -15.49 & -20.75 & -20.93 & -17.96 & -15.35 \\
\hline
\end{tabular}


Table 13 contains results for the employment impacts of the different scenarios. These numbers are the change in hours worked. Employment reductions are significant globally. For some countries, such as Australia, Canada, China, South Korea and Other Asia, that either contained the pandemic or implemented wage subsidies, the employment losses are still substantial. However, for countries such as the United States, the loss of employment is estimated to be $14.5 \%$ in 2020 under the current information. If further waves emerge this rise sharply to $20.9 \%$ in scenario 04 under a repeat of policies or $18 \%$ if lockdowns are discontinued in subsequent waves (S05).

A significant part of the economic shock is the substantial collapse in consumption (Table 14) and Investment (Table 15). The consumption shock is partly due to shifts in preferences for transactions associated with human contact, but falling consumption is also due to the loss of income and wealth caused by the pandemic. Higher risk through the increase in the household risk premium cause private savings to rise and consumption to fall. Loss of employment income reduces consumer spending. In addition, some of the income loss is policy-induced due to the shutdown of specific activities in some countries, but much is caused by the change in the behaviour of households and firms.

Investment (Table 15) also falls sharply reflecting the recessions in many economies. Higher risk and falling output cause the firm's profitability to decline, which reduces the return to capital and therefore, investment drops sharply. As with consumption, the more severe the pandemic, the larger the decline in investment. The more significant the decline in investment, the larger the reduction in future output since firms require capital as an input into production.

Table 16 shows the implications for budget deficits in all countries. For most economies, budget deficits increase significantly because of policy changes in spending, taxes and wage subsidies as well as endogenous changes in tax revenue and unemployment benefits. For some countries which have substantial government debt (such as Argentina and Brazil), the sharp fall in real interest rates and the economy collapses cause the fiscal position to improve.

Table 17 shows the changes in trade balances as a result of the different COVID-19 scenarios. Trade is affected by large swings in exports and imports, and the overall trade balance is driven by changes in savings and investment. Countries that are deeply impacted will tend to have a rise in private savings and fall in private investment. If the government does not respond, then there is likely to be a capital outflow. To the extent that government increase the budget deficit, then some of this capital will flow into the government balance sheet. The net effect is that countries that do well will tend to attract foreign capital. Therefore, these countries will 
Table 14: Percent Change in Real Consumption in 2020 relative to baseline

\begin{tabular}{lllllll}
\hline \multicolumn{1}{c}{ Country/Region } & S01 & S02 & S03 & S04 & S05 & \multicolumn{1}{c}{ S06 } \\
\hline Argentina & -22.08 & -22.50 & -32.99 & -32.66 & -24.00 & -22.83 \\
Australia & -12.36 & -13.18 & -18.69 & -18.24 & -15.47 & -12.86 \\
Brazil & -22.83 & -22.93 & -34.91 & -34.16 & -25.93 & -22.84 \\
Canada & -9.21 & -9.74 & -14.65 & -13.72 & -12.48 & -9.30 \\
China & -11.54 & -12.67 & -16.69 & -16.75 & -12.62 & -12.14 \\
France & -15.14 & -15.68 & -21.55 & -22.09 & -14.70 & -15.96 \\
Germany & -16.09 & -15.62 & -22.48 & -23.57 & -14.69 & -18.69 \\
India & -17.16 & -17.44 & -26.00 & -25.62 & -19.64 & -17.72 \\
Indonesia & -9.80 & -10.18 & -15.07 & -14.49 & -10.90 & -9.02 \\
Italy & -17.20 & -17.30 & -25.28 & -25.50 & -18.44 & -17.79 \\
Japan & -20.00 & -18.63 & -28.63 & -29.67 & -16.73 & -21.52 \\
Mexico & -12.26 & -12.25 & -18.88 & -18.54 & -13.64 & -11.92 \\
Other Asia & -12.38 & -12.54 & -19.74 & -18.63 & -15.65 & -12.10 \\
Other oil producing countries & -21.63 & -23.33 & -31.65 & -31.87 & -27.08 & -25.34 \\
Republic of Korea & -4.44 & -3.97 & -7.51 & -6.87 & -5.41 & -4.54 \\
Rest of Euro Zone & -19.60 & -19.76 & -29.19 & -29.07 & -20.96 & -20.29 \\
Rest of OECD & -15.54 & -15.82 & -21.96 & -22.75 & -15.78 & -17.61 \\
Rest of the World & -15.67 & -16.15 & -23.77 & -23.35 & -18.21 & -15.97 \\
Russia & -26.92 & -27.01 & -40.22 & -40.07 & -29.11 & -27.92 \\
Saudi Arabia & -10.28 & -11.60 & -14.56 & -14.54 & -10.39 & -10.22 \\
South Africa & -32.10 & -33.39 & -47.69 & -47.51 & -35.53 & -33.31 \\
Turkey & -13.78 & -13.69 & -20.92 & -20.53 & -14.33 & -13.67 \\
United Kingdom & -16.63 & -16.83 & -24.40 & -24.60 & -17.54 & -17.84 \\
United States of America & -17.48 & -17.37 & -26.35 & -25.90 & -20.21 & -17.71 \\
\hline
\end{tabular}

Table 15: Percent Change in Real Investment in 2020 relative to baseline

\begin{tabular}{lrrrrrr}
\hline \multicolumn{1}{c}{ Country/Region } & S01 & \multicolumn{1}{c}{ S02 } & \multicolumn{1}{c}{ S03 } & \multicolumn{1}{c}{ S04 } & \multicolumn{1}{c}{ S05 } & \multicolumn{1}{c}{ S06 } \\
\hline Argentina & -17.78 & -21.95 & -24.07 & -25.62 & -20.88 & -14.45 \\
Australia & -18.79 & -19.38 & -27.53 & -27.92 & -25.06 & -15.36 \\
Brazil & -24.04 & -27.10 & -33.55 & -35.22 & -29.70 & -21.18 \\
Canada & -16.31 & -16.65 & -23.61 & -23.62 & -20.77 & -11.92 \\
China & -7.01 & -8.08 & -10.06 & -10.20 & -9.89 & -4.92 \\
France & -38.89 & -43.39 & -54.84 & -57.33 & -38.96 & -31.66 \\
Germany & -25.96 & -26.34 & -36.91 & -38.97 & -27.59 & -23.61 \\
India & -11.54 & -13.18 & -15.98 & -16.56 & -13.92 & -9.75 \\
Indonesia & -7.56 & -8.30 & -10.81 & -10.96 & -8.25 & -5.19 \\
Italy & -33.04 & -35.06 & -47.15 & -49.37 & -41.65 & -26.33 \\
Japan & -34.86 & -36.15 & -49.35 & -52.19 & -37.61 & -32.55 \\
Mexico & -9.09 & -9.99 & -12.55 & -13.00 & -10.75 & -5.35 \\
Other Asia & -21.10 & -22.34 & -30.51 & -31.37 & -26.18 & -17.61 \\
Other oil producing countries & -17.15 & -20.33 & -23.64 & -24.11 & -25.17 & -13.98 \\
Republic of Korea & -4.68 & -2.60 & -8.01 & -7.63 & -7.04 & -1.80 \\
Rest of Euro Zone & -34.98 & -37.43 & -49.93 & -52.02 & -39.45 & -28.29 \\
Rest of OECD & -19.54 & -20.64 & -28.30 & -29.19 & -22.14 & -16.88 \\
Rest of the World & -20.33 & -24.76 & -27.43 & -28.92 & -25.50 & -18.65 \\
Russia & -21.86 & -24.60 & -30.62 & -32.02 & -28.98 & -17.65 \\
Saudi Arabia & -5.36 & -6.32 & -7.61 & -7.16 & -5.97 & -1.03 \\
South Africa & -38.39 & -45.85 & -52.31 & -55.34 & -51.77 & -35.37 \\
Turkey & -7.53 & -7.70 & -11.11 & -11.22 & -5.90 & -4.44 \\
United Kingdom & -25.39 & -28.21 & -35.60 & -37.35 & -28.81 & -23.49 \\
United States of America & -32.70 & -32.41 & -47.88 & -50.01 & -34.80 & -30.94 \\
\hline
\end{tabular}


experience trade deficits while those that are losing private capital, will experience improving trade balances as the exchange rate depreciates and exports rise and imports fall. Countries like Argentina, Brazil, India, Indonesia, Russia and the rest of the world have improving trade positions due to the capital flight. Countries like Australia, Canada and South Korea tend to experience trade deficits due to the capital inflows. The United States has almost no impact on the trade balance because the usual safe-haven status when the increase in global risk is offset by the worse performance of the US in dealing with the virus.

The trade balance adjustment is also consistent with the results in Table 18, which shows the change in real effective exchange rates. A rise in the real effective exchange rate is an appreciation. Those countries losing capital experience a depreciation and those attracting capital experience an appreciation.

Table 19 contains results for inflation defined as the change in the consumer price index. For some countries, the COVID-19 pandemic is mildly inflationary, and for others, it is deflationary. Even more interesting is that for some sectors in some countries, relative prices may rise and in other sectors, relative prices may fall. The key is whether demand falls by more than supply due to the disruptions to production. If demand falls by more than supply in some sectors or some countries the inflation will fall. If supply falls by more than demand, then inflation can initially rise. What matters for inflation over time is the response of central banks. In the model, all central banks follow Henderson-McKibbin-Taylor type monetary rules and inflation eventually returns to baseline. Central banks cut interest rates in response to the pandemic (Table 20). Fiscal deficits are eventually contained through a lumpsum tax on households. In practice countries may not follow these sensible monetary rules or maintain fiscal solvency in which case the results can be very different over time.

Table 20 contains results for short-term real interest rates across all countries and Table 21 shows the change in the real return on ten-year bonds for all countries. The short-term interest rate falls sharply. This sharp drop in interest rates is mostly due to the response of monetary authorities that loosen monetary policy quickly. We do not impose a zero-lower bound on the nominal policy interest rate. We treat negative nominal rates as if they are shadow policy rates becoming negative to reflect the range of policies, including loan guarantees that different central banks follow to stabilise the economy. Note that the real rate on ten-year bonds (Table 21) falls by much less than short-term real interest rates, so there is a steepening of the real yield curve. Short interest rates recover over time. The long-term real interest rate encompasses the expected future path of short real interest rates. 
Table 16: Percent of GDP Change in Fiscal Deficit in 2020 relative to baseline

\begin{tabular}{lrrrrrr}
\hline \multicolumn{1}{c}{ Country/Region } & \multicolumn{1}{c}{ S01 } & \multicolumn{1}{c}{ S02 } & \multicolumn{1}{c}{ S03 } & \multicolumn{1}{c}{ S04 } & \multicolumn{1}{c}{ S05 } & \multicolumn{1}{c}{ S06 } \\
\hline Argentina & -0.69 & -0.72 & -1.03 & -1.03 & -1.00 & -0.72 \\
Australia & 6.95 & 7.08 & 10.28 & 10.38 & 6.64 & 7.28 \\
Brazil & -3.38 & -3.33 & -5.16 & -5.08 & -3.85 & -3.24 \\
Canada & 9.22 & 9.27 & 13.77 & 13.83 & 8.99 & 9.38 \\
China & 0.99 & 1.05 & 1.44 & 1.48 & 0.83 & 1.04 \\
France & 2.87 & 3.01 & 4.18 & 4.25 & 2.58 & 2.77 \\
Germany & 2.82 & 2.82 & 4.16 & 4.19 & 2.40 & 2.75 \\
India & -0.90 & -0.91 & -1.37 & -1.35 & -1.20 & -0.88 \\
Indonesia & -1.11 & -1.12 & -1.72 & -1.66 & -1.29 & -0.95 \\
Italy & 5.27 & 5.39 & 7.76 & 7.84 & 5.26 & 5.19 \\
Japan & 0.31 & 0.45 & 0.40 & 0.41 & -0.11 & 0.42 \\
Mexico & 0.79 & 0.85 & 1.16 & 1.19 & 0.94 & 0.98 \\
Other Asia & 3.69 & 3.81 & 5.47 & 5.50 & 3.81 & 3.89 \\
Other oil producing countries & 7.83 & 7.87 & 11.68 & 11.71 & 8.01 & 8.12 \\
Republic of Korea & 5.15 & 5.46 & 7.46 & 7.61 & 5.09 & 5.51 \\
Rest of Euro Zone & 3.42 & 3.56 & 4.98 & 5.05 & 3.21 & 3.32 \\
Rest of OECD & 2.72 & 2.81 & 3.95 & 4.03 & 2.54 & 2.89 \\
Rest of the World & 1.20 & 1.23 & 1.80 & 1.81 & 1.14 & 1.24 \\
Russia & 0.52 & 0.60 & 0.67 & 0.74 & 0.48 & 0.94 \\
Saudi Arabia & 3.20 & 3.59 & 4.54 & 4.58 & 3.55 & 3.57 \\
South Africa & 2.71 & 2.65 & 4.06 & 4.10 & 2.25 & 2.97 \\
Turkey & 0.43 & 0.50 & 0.57 & 0.61 & 0.58 & 0.61 \\
United Kingdom & 5.80 & 5.82 & 8.65 & 8.67 & 5.53 & 5.78 \\
United States of America & 1.59 & 1.60 & 2.39 & 2.42 & 0.66 & 1.49 \\
\hline
\end{tabular}

Table 17: Percent of GDP Change in Trade Balance in 2020 relative to baseline

\begin{tabular}{lrrrrrr}
\hline \multicolumn{1}{c}{ Country/Region } & S01 & \multicolumn{1}{c}{ S02 } & \multicolumn{1}{c}{ S03 } & \multicolumn{1}{c}{ S04 } & \multicolumn{1}{c}{ S05 } & \multicolumn{1}{c}{ S06 } \\
\hline Argentina & 4.64 & 5.65 & 6.39 & 6.61 & 4.39 & 3.24 \\
Australia & -3.85 & -3.91 & -5.40 & -5.76 & -2.79 & -5.26 \\
Brazil & 2.96 & 3.40 & 4.30 & 4.32 & 3.25 & 1.56 \\
Canada & -3.86 & -4.04 & -5.34 & -5.88 & -3.49 & -5.65 \\
China & -2.12 & -1.92 & -3.21 & -3.29 & -1.94 & -3.15 \\
France & -1.15 & -0.94 & -2.01 & -1.80 & -2.22 & -2.23 \\
Germany & -2.62 & -3.29 & -4.15 & -3.83 & -3.96 & -3.29 \\
India & 3.13 & 3.68 & 4.46 & 4.45 & 3.71 & 2.23 \\
Indonesia & 0.76 & 1.01 & 1.22 & 0.99 & 0.28 & -0.90 \\
Italy & -1.61 & -1.73 & -2.51 & -2.35 & -1.21 & -2.85 \\
Japan & 1.30 & 0.68 & 1.45 & 1.99 & -0.23 & 0.63 \\
Mexico & 3.80 & 3.88 & 5.72 & 5.63 & 4.02 & 2.29 \\
Other Asia & 0.05 & 0.17 & 0.62 & 0.15 & 1.30 & -1.72 \\
Other oil producing countries & 0.96 & 2.32 & 0.78 & 0.91 & 4.00 & 1.50 \\
Republic of Korea & -4.29 & -5.35 & -5.53 & -6.05 & -4.05 & -5.70 \\
Rest of Euro Zone & -1.78 & -1.91 & -2.53 & -2.58 & -2.00 & -3.10 \\
Rest of OECD & -2.51 & -2.60 & -3.95 & -3.79 & -3.33 & -3.42 \\
Rest of the World & 6.07 & 7.34 & 8.52 & 8.59 & 7.38 & 5.42 \\
Russia & 2.60 & 2.85 & 3.73 & 3.75 & 2.94 & 1.38 \\
Saudi Arabia & -2.02 & -2.12 & -2.85 & -3.06 & -2.98 & -2.94 \\
South Africa & 0.57 & 2.89 & -0.50 & -0.01 & 2.39 & -0.68 \\
Turkey & 2.28 & 2.11 & 3.66 & 3.41 & 1.08 & 0.99 \\
United Kingdom & 2.07 & 2.45 & 2.69 & 2.92 & 1.97 & 1.41 \\
United States of America & -0.13 & -0.91 & 0.31 & 0.23 & -0.61 & -0.82 \\
\hline
\end{tabular}


Table 18: Percent Change in Real Exchange Rate in 2020 relative to baseline

\begin{tabular}{lrrrrrr}
\hline \multicolumn{1}{c}{ Country/Region } & \multicolumn{1}{c}{ S01 } & \multicolumn{1}{c}{ S02 } & \multicolumn{1}{c}{ S03 } & \multicolumn{1}{c}{ S04 } & \multicolumn{1}{c}{ S05 } & \multicolumn{1}{c}{ S06 } \\
\hline Argentina & -11.44 & -13.40 & -16.06 & -16.36 & -11.45 & -11.27 \\
Australia & 2.83 & 2.78 & 3.86 & 4.32 & 1.27 & 3.13 \\
Brazil & -4.28 & -5.24 & -6.13 & -6.10 & -4.51 & -2.97 \\
Canada & 2.53 & 2.35 & 3.60 & 4.14 & 1.73 & 3.05 \\
China & 1.84 & 1.40 & 2.96 & 2.94 & 1.32 & 1.60 \\
France & 1.95 & 1.92 & 2.97 & 2.89 & 2.68 & 1.20 \\
Germany & 0.76 & 1.17 & 1.31 & 1.05 & 1.31 & -0.73 \\
India & -5.32 & -6.27 & -7.53 & -7.58 & -6.25 & -5.38 \\
Indonesia & -2.83 & -3.28 & -4.24 & -3.95 & -2.13 & -2.23 \\
Italy & 1.76 & 1.91 & 2.64 & 2.53 & 1.52 & 1.00 \\
Japan & -2.93 & -2.03 & -3.51 & -4.44 & -0.81 & -3.47 \\
Mexico & -8.75 & -9.42 & -12.73 & -12.77 & -10.09 & -8.66 \\
Other Asia & -0.14 & -0.37 & -0.42 & -0.19 & -0.85 & -0.98 \\
Other oil producing countries & -1.41 & -2.92 & -1.36 & -1.50 & -4.55 & -3.40 \\
Republic of Korea & 2.11 & 2.72 & 2.57 & 2.92 & 1.27 & 1.88 \\
Rest of Euro Zone & 1.21 & 1.32 & 1.69 & 1.76 & 1.21 & 0.18 \\
Rest of OECD & 1.52 & 1.57 & 2.39 & 2.30 & 2.03 & 0.81 \\
Rest of the World & -4.80 & -6.41 & -6.40 & -6.48 & -5.89 & -4.83 \\
Russia & -2.58 & -2.80 & -3.70 & -3.70 & -2.95 & -3.07 \\
Saudi Arabia & -1.25 & -1.49 & -1.87 & -1.75 & -1.20 & -3.17 \\
South Africa & 3.19 & 0.87 & 6.13 & 5.67 & 1.99 & 2.68 \\
Turkey & -3.59 & -3.62 & -5.55 & -5.28 & -2.51 & -3.47 \\
United Kingdom & -2.65 & -3.04 & -3.59 & -3.76 & -2.31 & -3.39 \\
United States of America & 3.90 & 6.20 & 4.20 & 4.57 & 6.16 & 4.77 \\
\hline
\end{tabular}

Table 19: Percentage point Change in Inflation in 2020 relative to baseline

\begin{tabular}{lrrrrrr}
\hline \multicolumn{1}{c}{ Country/Region } & S01 & \multicolumn{1}{c}{ S02 } & \multicolumn{1}{c}{ S03 } & \multicolumn{1}{c}{ S04 } & \multicolumn{1}{c}{ S05 } & \multicolumn{1}{c}{ S06 } \\
\hline Argentina & -3.11 & -3.00 & -4.76 & -4.53 & -4.58 & -4.65 \\
Australia & 0.44 & -0.48 & 1.19 & 1.00 & -0.43 & -0.91 \\
Brazil & -0.54 & -0.70 & -0.97 & -0.71 & -1.64 & -1.52 \\
Canada & 1.88 & 1.14 & 2.86 & 2.91 & 0.54 & 0.64 \\
China & 0.47 & -1.12 & 1.68 & 1.34 & -0.34 & -0.62 \\
France & -2.88 & -3.98 & -2.88 & -3.58 & -1.96 & -3.28 \\
Germany & -4.09 & -4.58 & -4.44 & -5.43 & -2.97 & -6.40 \\
India & -0.07 & 0.02 & -0.31 & -0.11 & -1.18 & -1.60 \\
Indonesia & -1.01 & -1.36 & -1.57 & -1.38 & -2.37 & -2.06 \\
Italy & -2.70 & -3.62 & -2.84 & -3.43 & -3.04 & -3.17 \\
Japan & -2.66 & -2.58 & -2.88 & -3.60 & -0.53 & -4.08 \\
Mexico & -3.85 & -4.15 & -6.22 & -5.98 & -5.71 & -5.21 \\
Other Asia & 0.69 & 0.15 & 1.03 & 1.27 & -0.46 & -0.98 \\
Other oil producing countries & -1.16 & -1.37 & -1.46 & -1.67 & -2.66 & -4.23 \\
Republic of Korea & 0.03 & -0.96 & 0.68 & 0.41 & -0.09 & -1.53 \\
Rest of Euro Zone & -2.78 & -3.62 & -3.23 & -3.60 & -2.81 & -3.42 \\
Rest of OECD & -1.15 & -1.69 & -0.61 & -1.23 & -1.10 & -3.18 \\
Rest of the World & 2.61 & 3.02 & 3.28 & 3.57 & 1.65 & 1.54 \\
Russia & -0.53 & -0.93 & -0.30 & -0.55 & -1.27 & -2.51 \\
Saudi Arabia & -4.90 & -8.49 & -4.83 & -5.21 & -7.17 & -4.27 \\
South Africa & 7.85 & 8.13 & 11.62 & 11.66 & 9.10 & 5.87 \\
Turkey & -1.00 & -1.36 & -1.23 & -1.31 & -2.54 & -2.59 \\
United Kingdom & -1.26 & -1.39 & -1.49 & -1.68 & -1.41 & -2.94 \\
United States of America & -1.32 & -2.20 & -1.30 & -1.27 & -2.77 & -1.96 \\
\hline & & & & & & \\
\hline
\end{tabular}


Table 20: Percentage point Change in Real interest rate in 2020 relative to baseline

\begin{tabular}{lccrrrr}
\hline \multicolumn{1}{c}{ Country/Region } & S01 & S02 & \multicolumn{1}{c}{ S03 } & \multicolumn{1}{c}{ S04 } & \multicolumn{1}{c}{ S05 } & \multicolumn{1}{c}{ S06 } \\
\hline Argentina & -8.05 & -8.29 & -12.68 & -11.86 & -10.04 & -10.05 \\
Australia & -2.35 & -2.61 & -1.55 & -3.14 & -0.42 & -4.19 \\
Brazil & -5.38 & -5.74 & -7.34 & -7.85 & -6.07 & -6.68 \\
Canada & -2.23 & -2.64 & -1.77 & -3.15 & -1.08 & -4.11 \\
China & -1.99 & -1.80 & -0.86 & -2.75 & 1.17 & -4.30 \\
France & -2.04 & -1.65 & -0.82 & -2.82 & 1.50 & -4.36 \\
Germany & -3.58 & -3.09 & -3.12 & -4.89 & 0.25 & -5.91 \\
India & -4.64 & -4.87 & -6.35 & -6.85 & -4.47 & -6.61 \\
Indonesia & -3.82 & -4.12 & -5.08 & -5.57 & -4.03 & -5.69 \\
Italy & -3.56 & -3.41 & -2.97 & -4.98 & -0.26 & -6.13 \\
Japan & -4.58 & -3.86 & -4.81 & -6.53 & 0.11 & -6.00 \\
Mexico & -8.66 & -9.31 & -13.53 & -12.95 & -12.34 & -11.05 \\
Other Asia & -4.01 & -4.34 & -4.38 & -5.69 & -2.93 & -6.68 \\
Other oil producing countries & -3.66 & -3.70 & -3.59 & -5.33 & -0.11 & -7.23 \\
Republic of Korea & -3.77 & -3.90 & -3.76 & -5.15 & -2.20 & -6.24 \\
Rest of Euro Zone & -3.27 & -3.18 & -2.95 & -4.59 & -0.74 & -6.04 \\
Rest of OECD & -3.16 & -2.81 & -2.40 & -4.34 & 0.51 & -5.25 \\
Rest of the World & -3.29 & -3.72 & -4.19 & -5.14 & -2.35 & -4.76 \\
Russia & -5.75 & -5.82 & -7.29 & -8.27 & -4.39 & -8.46 \\
Saudi Arabia & -4.95 & -4.76 & -6.06 & -7.08 & -3.73 & -8.77 \\
South Africa & -0.62 & -0.80 & 2.55 & -0.93 & 4.81 & -3.02 \\
Turkey & -5.04 & -5.13 & -7.07 & -7.33 & -5.19 & -7.01 \\
United Kingdom & -3.69 & -3.55 & -4.09 & -5.36 & -0.89 & -5.47 \\
United States of America & -4.68 & -4.64 & -5.13 & -6.39 & -3.59 & -5.43 \\
\hline
\end{tabular}

Table 21: Percentage point Change in real 10-year interest rate in 2020 relative to baseline

\begin{tabular}{lccrrrr}
\hline \multicolumn{1}{c}{ Country/Region } & S01 & S02 & \multicolumn{1}{c}{ S03 } & \multicolumn{1}{c}{ S04 } & \multicolumn{1}{c}{ S05 } & \multicolumn{1}{c}{ S06 } \\
\hline Argentina & -1.33 & -1.64 & -1.87 & -2.00 & -2.39 & -1.71 \\
Australia & -0.02 & -0.52 & 0.14 & 0.04 & -1.06 & -0.29 \\
Brazil & -0.62 & -0.98 & -0.80 & -0.92 & -1.67 & -0.81 \\
Canada & 0.13 & -0.19 & 0.26 & 0.20 & -0.91 & -0.11 \\
China & -0.06 & -0.49 & 0.10 & -0.03 & -0.98 & -0.41 \\
France & -0.19 & -0.73 & -0.04 & -0.20 & -1.13 & -0.55 \\
Germany & -0.54 & -1.23 & -0.48 & -0.68 & -1.43 & -1.01 \\
India & -0.53 & -0.79 & -0.68 & -0.80 & -1.75 & -0.82 \\
Indonesia & -0.39 & -0.69 & -0.47 & -0.56 & -1.26 & -0.62 \\
Italy & -0.28 & -0.82 & -0.16 & -0.34 & -1.37 & -0.68 \\
Japan & -0.74 & -1.23 & -0.77 & -1.02 & -1.36 & -1.05 \\
Mexico & -0.89 & -1.10 & -1.30 & -1.41 & -2.04 & -1.17 \\
Other Asia & -0.28 & -0.75 & -0.25 & -0.37 & -1.44 & -0.66 \\
Other oil producing countries & -0.07 & -0.33 & 0.02 & -0.11 & -1.66 & -0.64 \\
Republic of Korea & -0.34 & -0.95 & -0.28 & -0.42 & -1.38 & -0.69 \\
Rest of Euro Zone & -0.30 & -0.82 & -0.23 & -0.38 & -1.34 & -0.73 \\
Rest of OECD & -0.30 & -0.89 & -0.18 & -0.36 & -1.29 & -0.69 \\
Rest of the World & -0.10 & -0.09 & -0.14 & -0.23 & -1.30 & -0.29 \\
Russia & -0.55 & -0.95 & -0.63 & -0.78 & -1.67 & -0.94 \\
Saudi Arabia & -0.56 & -1.12 & -0.60 & -0.75 & -1.73 & -1.09 \\
South Africa & 0.70 & 0.61 & 1.15 & 1.03 & -0.62 & 0.30 \\
Turkey & -0.63 & -1.00 & -0.79 & -0.90 & -1.69 & -0.94 \\
United Kingdom & -0.45 & -0.84 & -0.48 & -0.64 & -1.49 & -0.80 \\
United States of America & -0.88 & -1.87 & -0.97 & -1.16 & -1.90 & -1.01 \\
\hline
\end{tabular}




\subsection{Dynamic Results}

The results for all countries exhibit similar patterns because of the nature of the economic shocks we have imposed. It is possible that the COVID-19 pandemic has caused a major structural change to the world economy and that the pattern of recovery in the scenarios considered in this paper does not ensue. Scenarios 1-4 imply an eventual recovery of the global economy, whereas scenario 5 implies the persistence of higher risk, which causes the countries to have a permanent output loss. In this paper, we do not consider any major benefits of the implementation of new technologies that may follow the recovery to the COVID-19 pandemic. McKibbin and Triggs (2018) use the same model as in this paper to consider a range of global productivity scenarios unrelated to the COVID-19 pandemic but which is illustrative of how different the world evolves depending on productivity changes due to technology.

In this section, we will focus on results for Australia to explain the economic adjustments over time. The economic story is similar for all countries given the initial differences for 2020 discussed above. A complete set of all dynamic results for all countries are available on the Dashboard.

Figure 17 shows the dynamic path of Real GDP, real consumption, real investment and the trade balance. It is clear, that as the pandemic worsens across the scenarios, the falls in year 1 GDP, consumption and investment increase. It takes three years on average for real GDP to return to the pre COVID-19 baseline under most scenarios. Under scenario 5, in which there is a permanent change in risk, Australian GDP (and that of all other countries) never returns to baseline. One exception to the more substantial falls across scenarios is the Australian trade balance, which worsens by less as the pandemic worsens. This result is not surprising as the world economy is increasingly negatively impacted; the impact on the Australian economy, which is exposed to global trade becomes less attractive as an investment destination. Figure 18 contains results for the other key macroeconomic variables: employment, inflation, the real short-term interest rate and the real effective exchange rate.

Figures 19 and 20 show the sectoral output and employment results for energy, mining, agriculture, durable manufacturing, non-durable manufacturing and services. All sectors are negatively impacted by the sharp reduction in demand and supply except for energy output because the fall in energy prices causes a rise in energy use. Services and Non-Durable manufacturing have larger output and employment losses. In the case of a permanent rise in global risk (S05), there is a permanent structural change induced by the pandemic. Higher risk means a lower global capital stock and those sectors that feed heavily into investment activities such as durable manufacturing and mining experience permanent relative contractions. 
Figure 17: Dynamic Results for Australia

Change in Real GDP

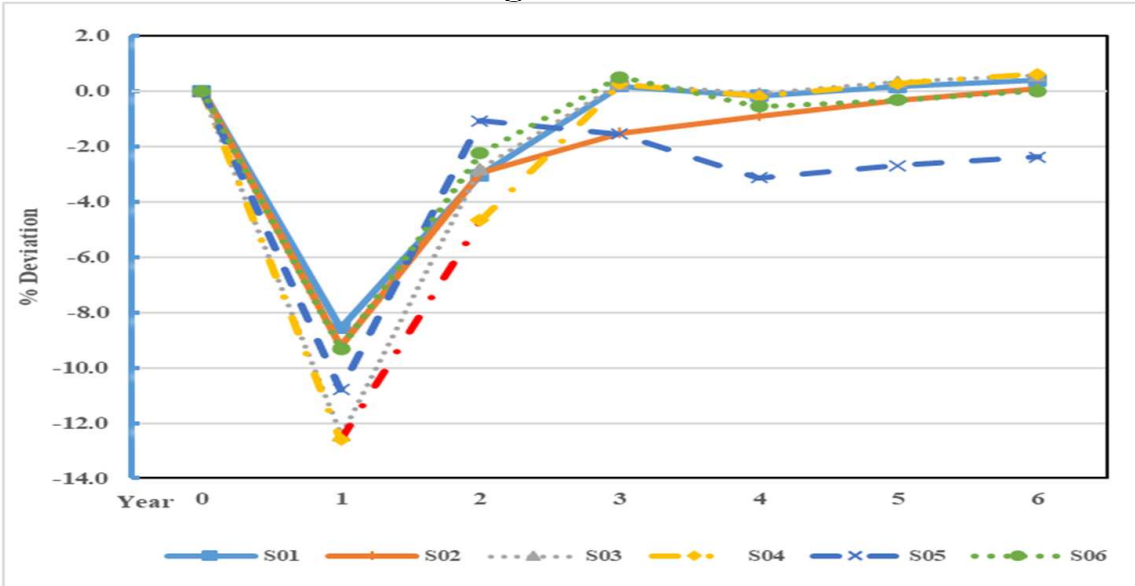

Change in Real Investment

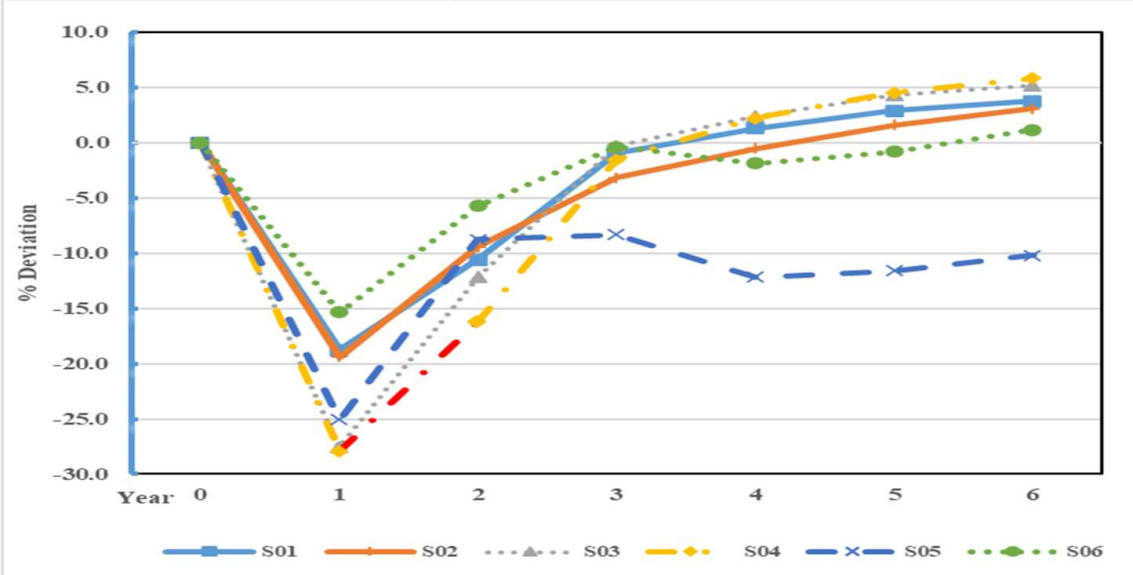

Change in Real Consumption

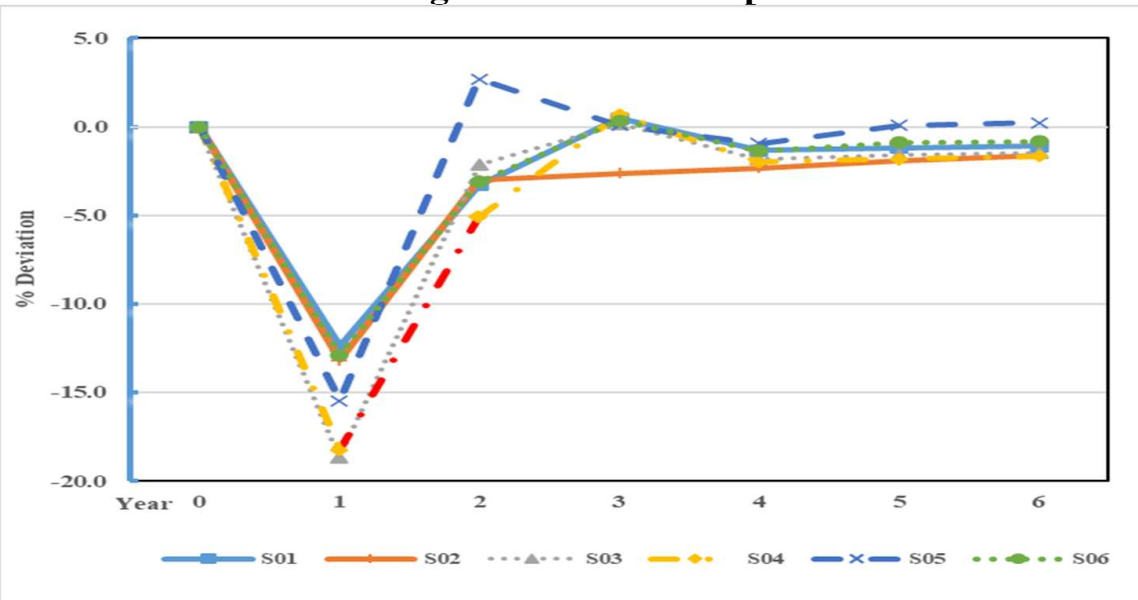

Change in Trade Balance (\% GDP)

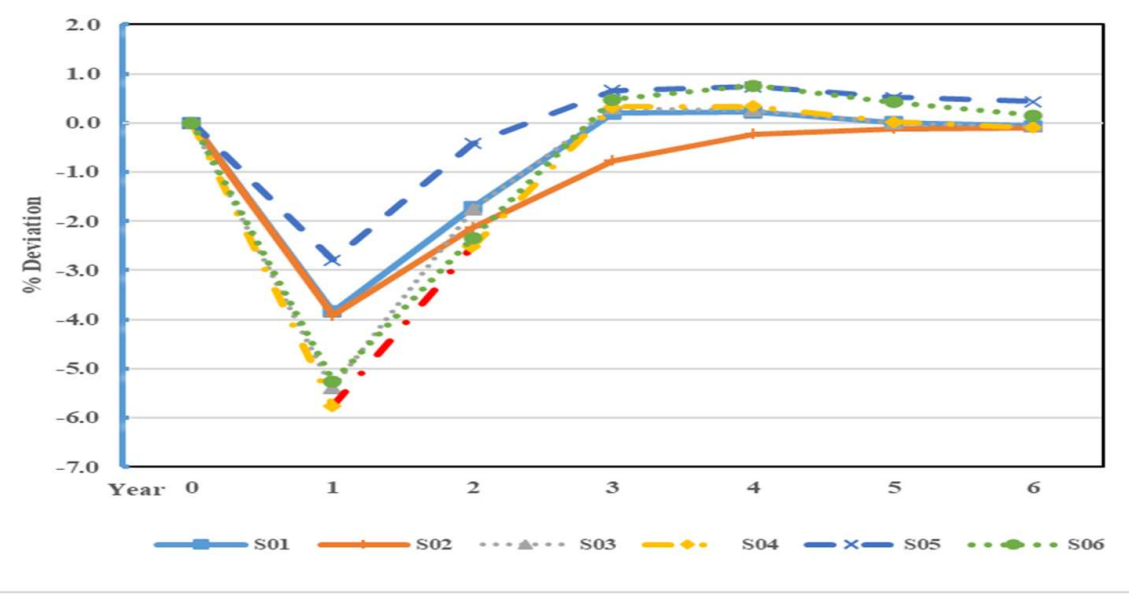


Figure 18: Dynamic Results for Australia (Contd.)

Change in Employment

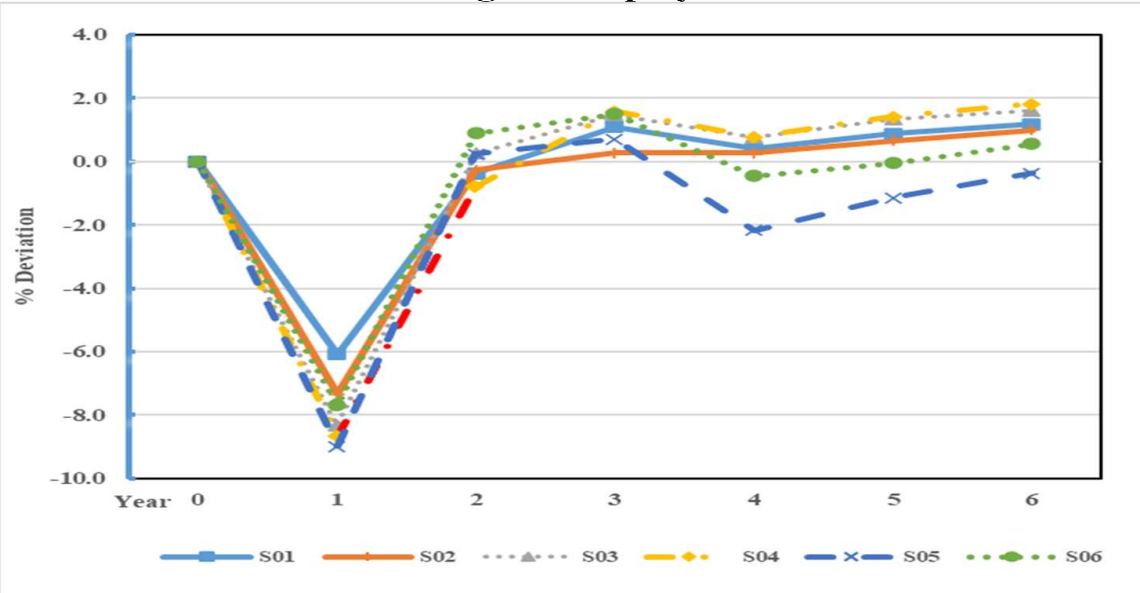

Change in Real Short-term Interest Rate

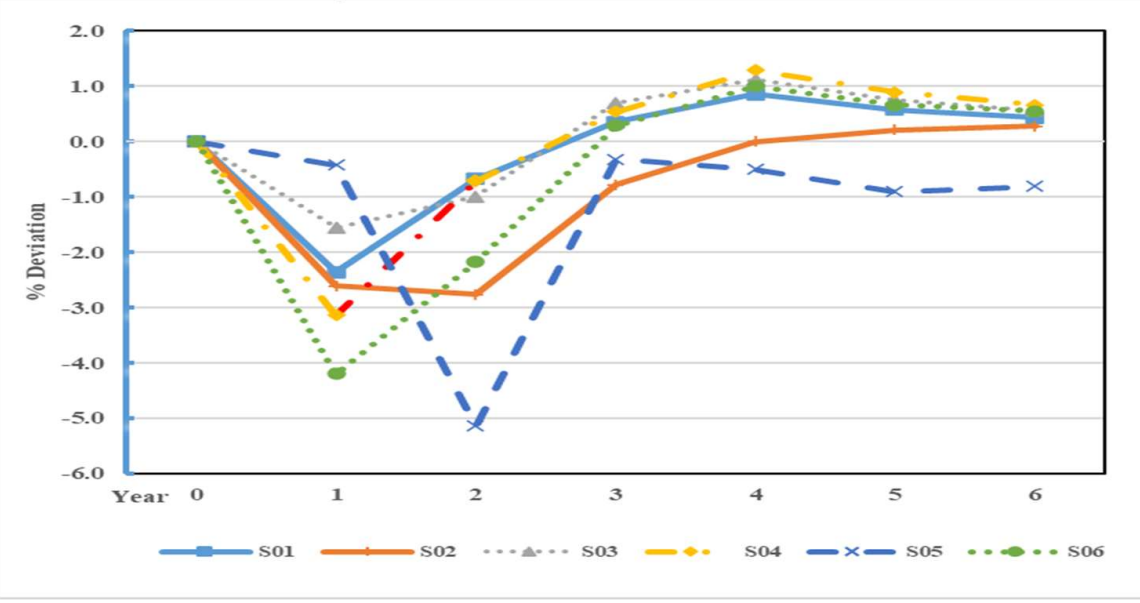

\section{Change in Inflation}

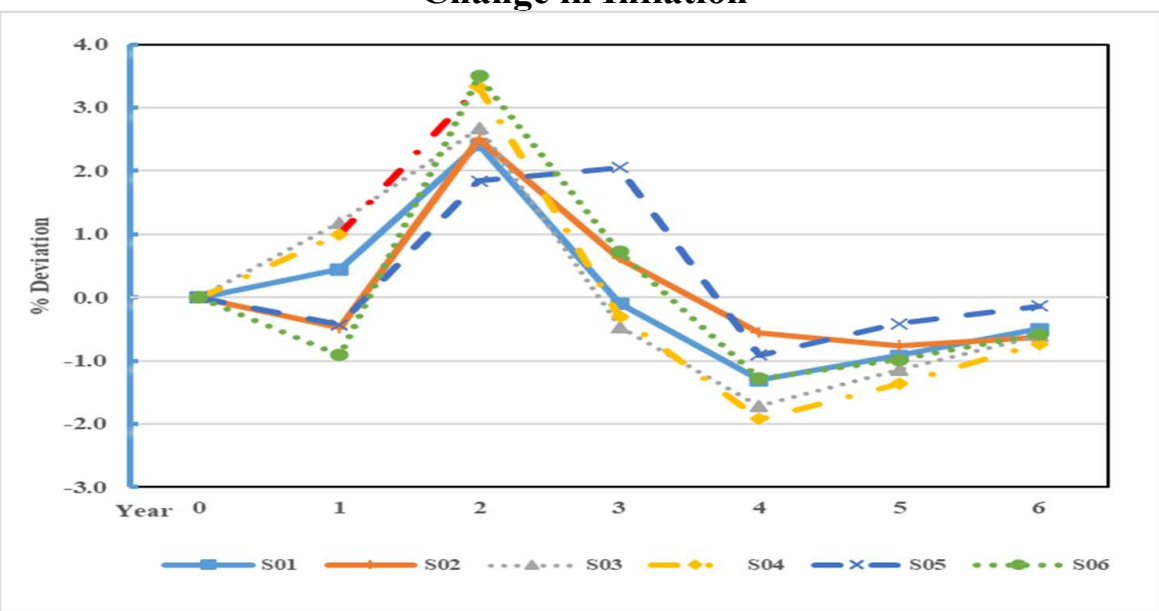

Change in Real Effective Exchange Rate

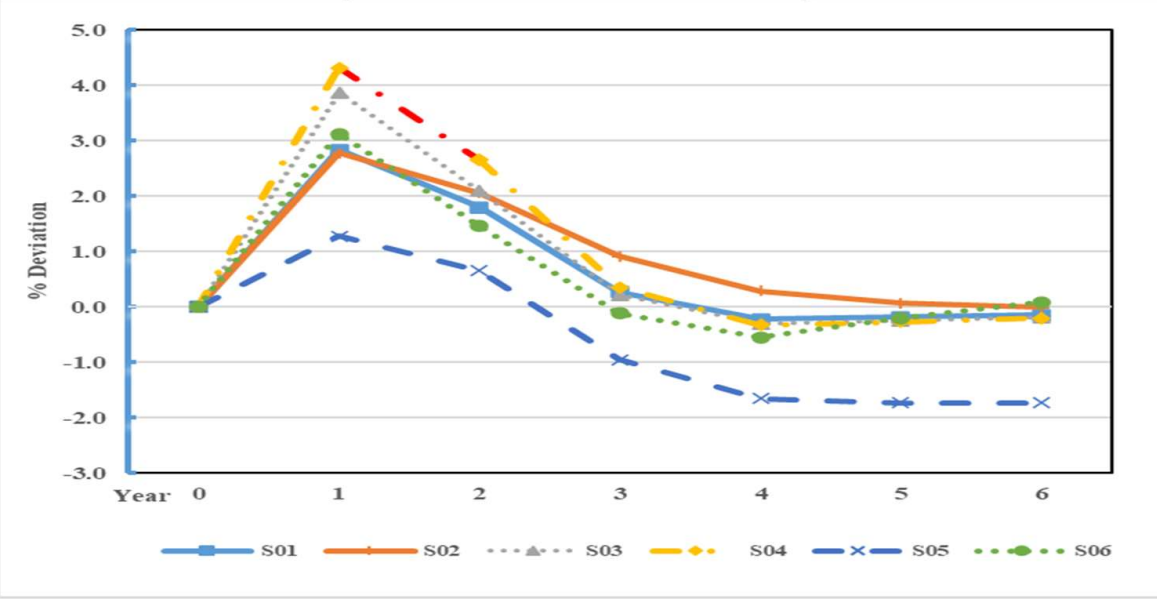


Figure 19: Dynamic Results for Australia (Contd.)

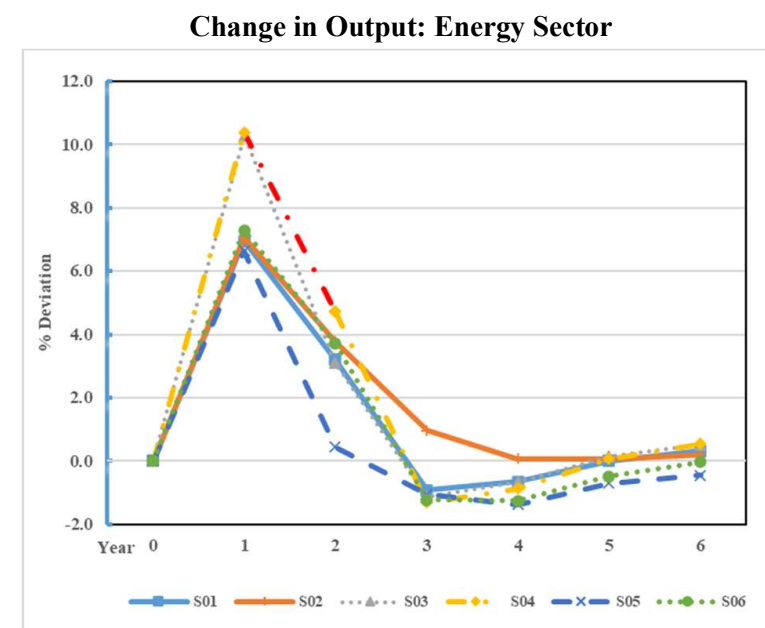

Change in Output: Durable Manufacturing Sector

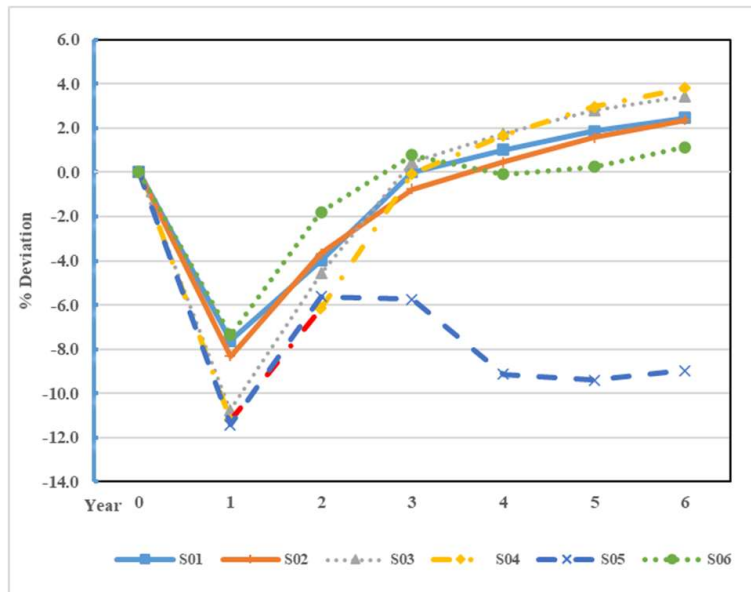

Change in Output: Mining Sector

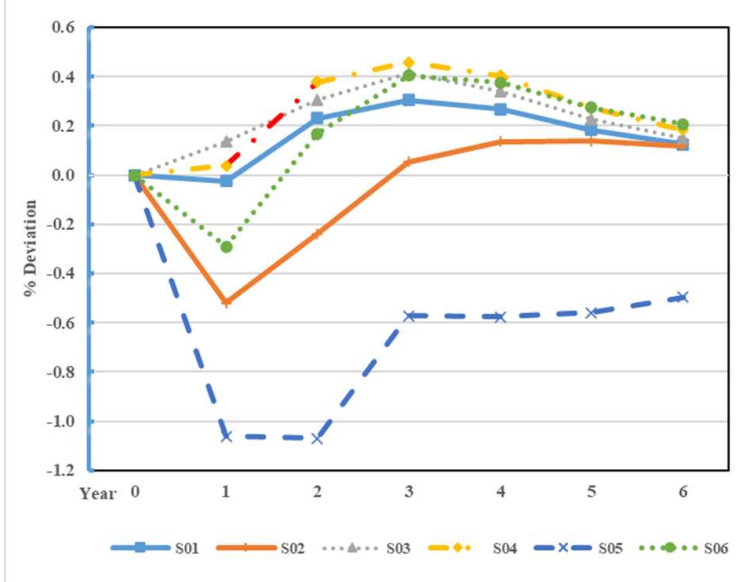

Change in Output: Non-Durable Manufacturing Sector

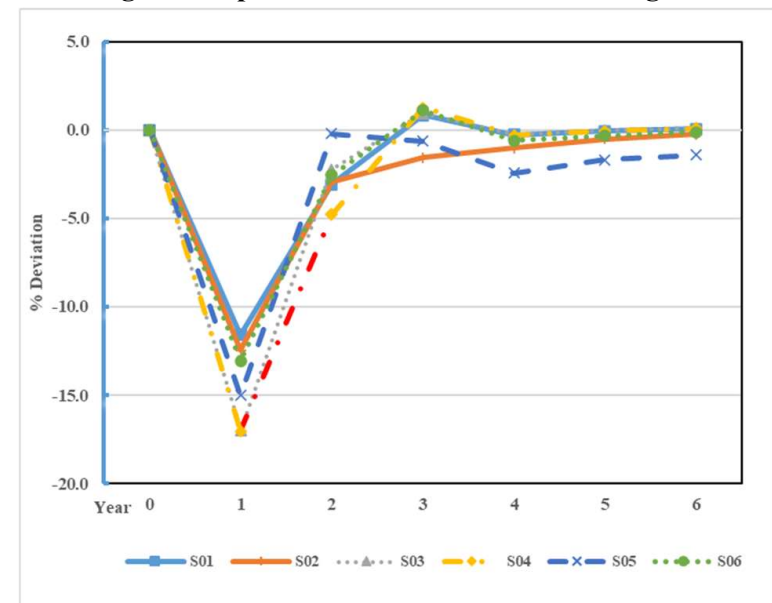

Change in Output: Agriculture Sector

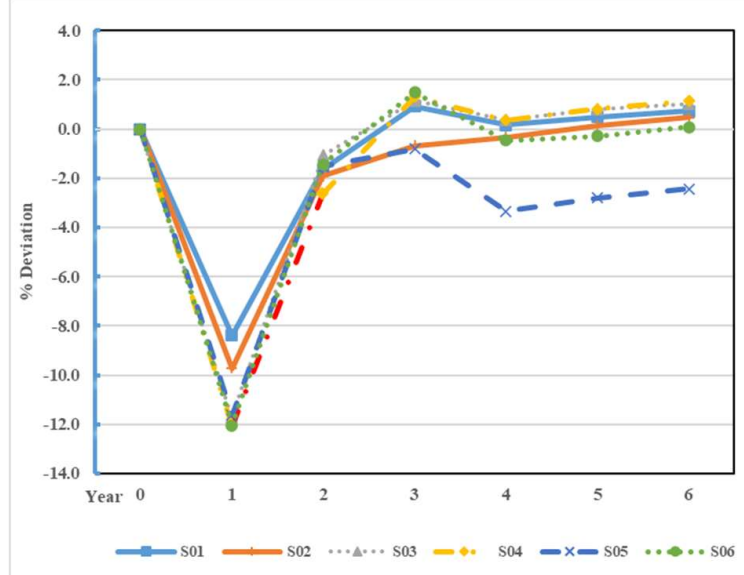

Change in Output: Services Sector

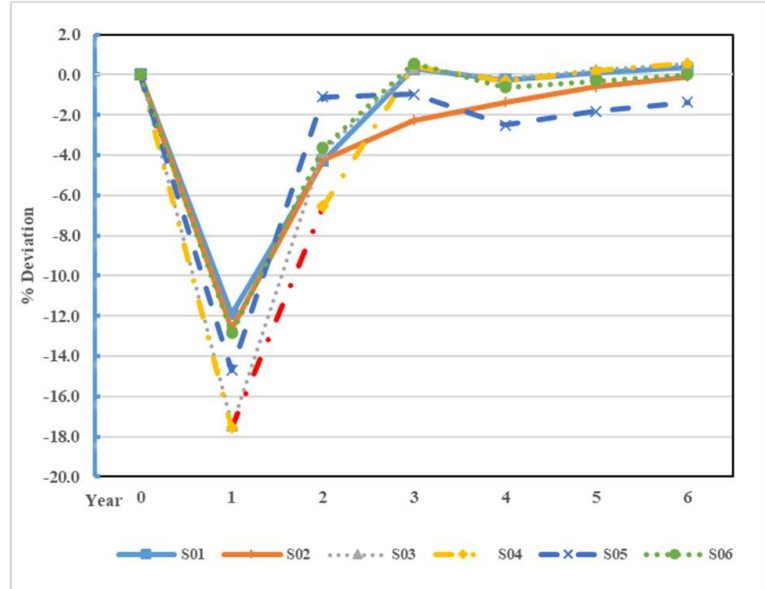


Figure 20: Dynamic Results for Australia (Contd.)

Change in Employment: Energy Sector

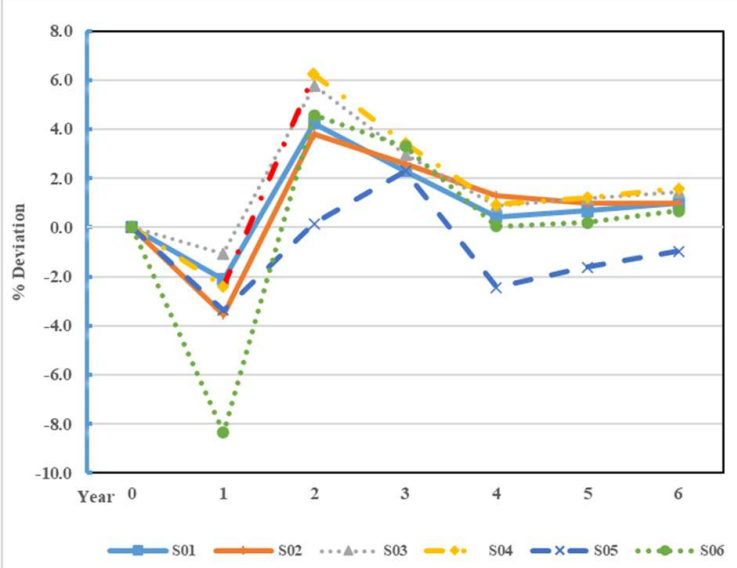

Change in Employment: Durable Manufacturing Sector

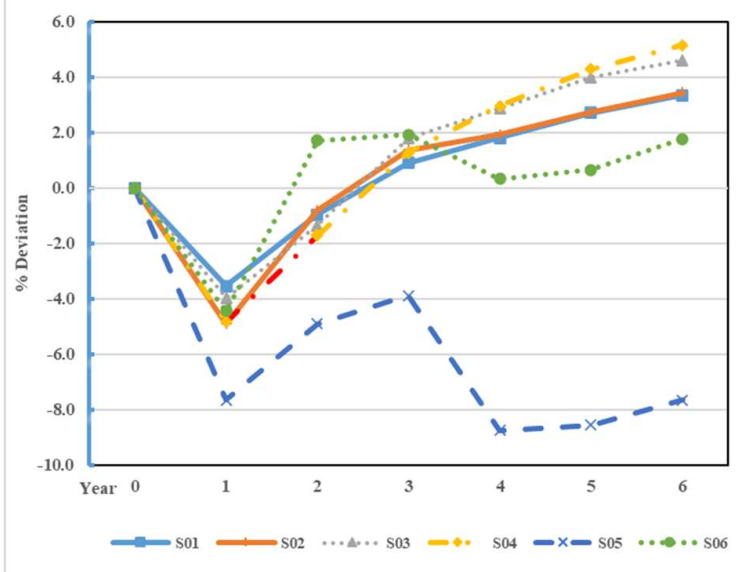

Change in Employment: Mining Sector

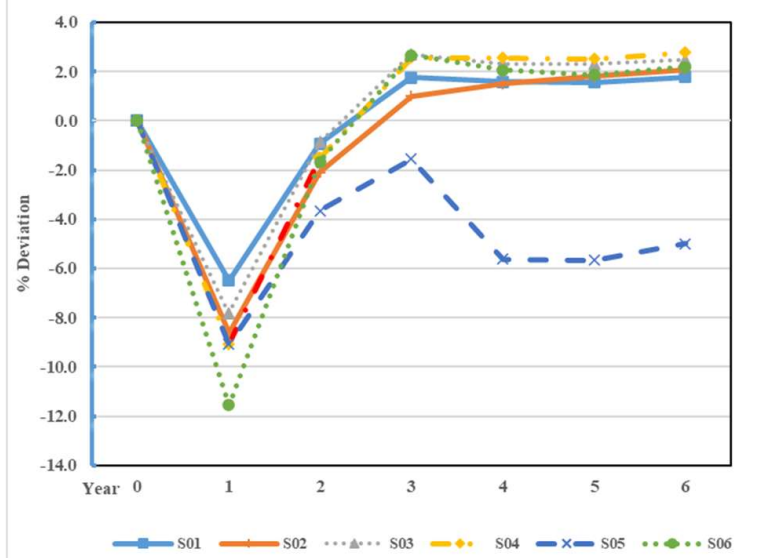

Change in Employment: Non-Durable Manufacturing Sector

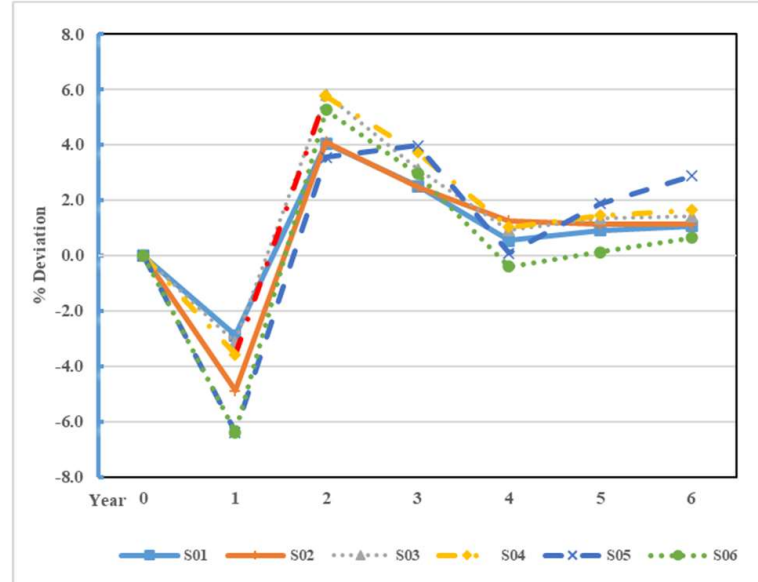

Change in Employment: Agriculture Sector

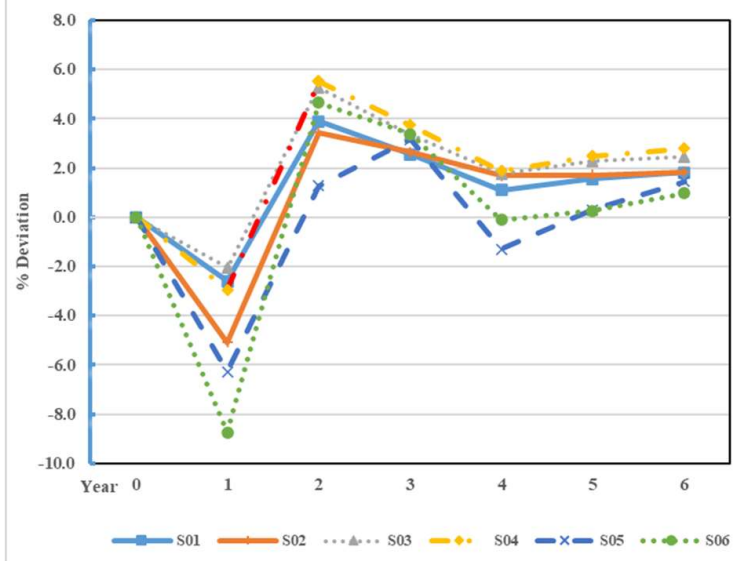

Change in Employment: Services Sector

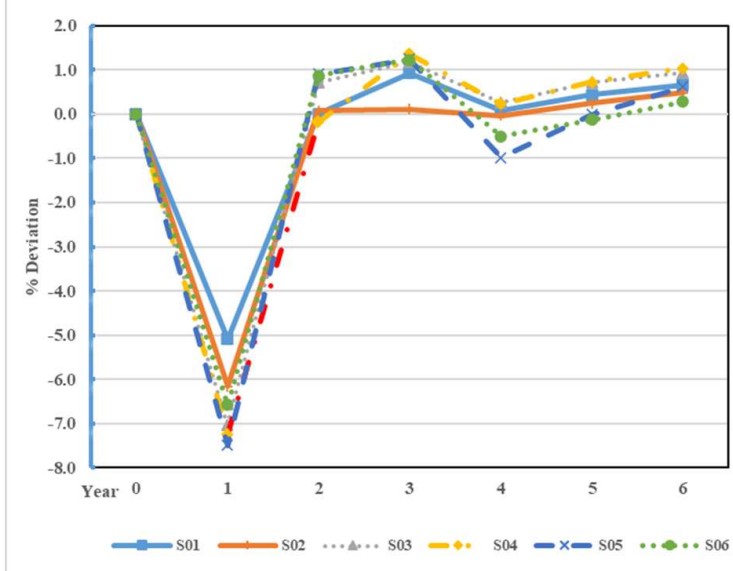




\section{Conclusion \& Policy Implications}

This paper applies recent data on the different epidemiological experiences of COVID-19 and recent observations on the extent of economic shocks in early 2020 across countries to explore six different scenarios for the evolution of the world economy over the next few years. There is still enormous uncertainty about the future course of the pandemic, whether a vaccine will be available and effective in the near term, and whether countries will change their policies in response to the economic adjustments already experienced, if new waves of the pandemic emerged. There is no doubt that COVID-19 is a significant negative shock to the world economy. The health policy responses and the economic policy responses have been very different across countries. As a result, some countries have done much better in responding to the pandemic. It is also very likely that there will be future waves of COVID-19 just as there were waves of the 1918/19 flu pandemic. The basis of the scenarios explored in this paper revolve around how many future waves there might be and how countries will respond to those outbreaks in terms of public health responses and changes in economic policies.

Even under the first scenario, which assumes that the worst of COVID-19 is over by mid-2020, the global economy experiences a major recession in 2020. Some countries are impacted far more than others. The results from this paper and recent IMF and World Bank forecasts make it clear that health and economic policies will have to be carefully designed and adapted to get through the current phase of the pandemic. Withdrawing macroeconomic support and creating 'fiscal cliffs' through setting expiration dates on critical fiscal support policies in economies is likely to worsen the uncertainty and increase the economic costs. Preventing countries from undertaking more substantial fiscal stimulus measures either through institutional arrangements or by lack of access to financing also increase the cost of the pandemic. In McKibbin and Vines (2020), we explore the benefits of an additional globally coordinated fiscal response for constrained countries through G20 policy cooperation in the case of scenario 5 from this paper. The gains (or avoided losses) are significant for the global economy.

While the short-term public health and macroeconomic policy responses are critical to the shape of the world economy in 2020, the evolution of the global economy over future decades will depend on longer-term policy decisions. As argued in McKibbin and Fernando (2020a \& 2020b), investment in global public health, particularly in developing economies is a crucial ingredient in avoiding future devastation from pandemics. The experience of pandemic emergence over the past two decades shows that COVID-19 is not an isolated event. Given the scientific knowledge about zoonotic diseases and emerging spillovers of viruses from current hosts to humans, there is a strong case for investment in pandemic preparedness at the national 
and global levels. Global cooperation is fundamental since pandemics do not respect borders. Therefore, the institutional design at the global level is critical to success. A World Health Organization, in some form, is vital to a cooperative global public health response. Also, the role of the G20, as it was in the global financial crisis a decade ago, is critical. Design and financing of macroeconomic policy responses will need to be better coordinated over the coming years.

COVID-19 is one amongst many challenges that the world will face in the coming decades. These problems include ongoing pandemics, the increasing prevalence of antimicrobial resistance and the need to deal with the impacts of climate change and the impact of transitional policies to address climate change. The current experience with the COVID-19 pandemic has revealed deep problems in existing institutions at the supernational level and within countries. While policies need to be designed and implemented at the national level, for most foreseeable problems, there needs to be greater cooperation across countries. COVID-19 shows the folly of isolationist politics and policies when the natural world ignores artificial boundaries. 


\section{References}

Aguiar, A., Chepeliev, M., Corong, E., McDougall, R., \& van der Mensbrugghe, D. (2019). The GTAP Data Base: Version 10. Journal of Global Economic Analysis. vol. 4 no. 1. pp. 1-27.

Almeshal, AM., Almazrouee, AI., Alenizi, MR. and Alhajeri, SN. (2020). Forecasting the spread of COVID-19 in Kuwait using compartmental and logistic regression models. Applied Sciences. vol. 10, doi:10.3390/app10103402.

Australian Bureau of Statistics. ABS graphic showing proportion of Australian Business Population operating during COVID-19 shutdown. Australian Bureau of Statistics. https://www.abc.net.au/news/2020-04-08/abs-graphic:-proportion-of-australianbusiness-population-opera/12130566? $\mathrm{nw}=0$.

Australian Stock Exchange. (2020). Sector Indices. Australian Stock Exchange. https://www.asx.com.au/products/sector-indices.htm\#consumerdiscretionary.

Barro, RJ. (1991). Economic Growth in a Cross-Section of Countries. The Quarterly Journal of Economics. vol. 106, no. 2. pp. 407-443.

Barro, RJ. (2015). Convergence and Modernisation. Economic Journal. vol. 125, no. 585, pp. 911-942.

Batista, M. (2020). Estimation of the final size of the coronavirus epidemic by the logistic model. medRxviv. https://www.medrxiv.org/content/10.1101/2020.03.11.20024901v2.

Congressional Budget Office (2020) 'Comparison of CBO's May 2020 Interim Projections of Gross Domestic Product and Its January 2020 Baseline Projections'

del Rio-Chanona, RM., Mealy, P., Pichler, A., Lafond, F. and Farmer, JD. (2020). Supply and demand shocks in the COVID-19 pandemic: an industry and occupation perspective. Covid Economics. vol. 6. pp. 66-103.

European Centre for Disease Prevention and Control (2020). Download today's data on the geographic distribution of COVID-19 cases worldwide. European Centre for Disease Prevention and Control. https://www.ecdc.europa.eu/en/publications-data/download-todays-data-geographicdistribution-covid-19-cases-worldwide.

Federal Reserve Bank of St. Louis. (2020a). CBOE Volatility Index. Federal Reserve Bank of St. Louis. https://fred.stlouisfed.org/series/VIXCLS.

Federal Reserve Bank of St. Louis. (2020b). Stock Market Indexes. Federal Reserve Bank of St. Louis. https://fred.stlouisfed.org/categories/32255.

Fisman, R. and Love, I. (2004). Financial Development and Growth in the Short and Long Run. Policy Research Working Paper 3319. World Bank. Washington DC. 
Gandelman, N. and Hernandez-Murillo, R. (2014). Risk aversion at the country level. Working Paper 2014-005B. Federal Reserve Bank of St. Louis. St. Louis.

GHSIndex. (2020). Global Health Security Index 2019. Nuclear Threat Initiative, Washington DC; Johns Hopkins Center for Health Security, Maryland; and The Economist Intelligence Unit, London. https://www.ghsindex.org/.

Henderson, DW. and McKibbin, W. (1993). A Comparison of Some Basic Monetary Policy Regimes for Open Economies: Implications of Different Degrees of Instrument Adjustment and Wage Persistence. Carnegie-Rochester Conference Series on Public Policy. vol. 39. no. 1. pp. 221-317.

International Monetary Fund. (2020a). Policy Responses to COVID-19. International Monetary Fund. Washington DC. https://www.imf.org/en/Topics/imf-and-covid19/Policy-Responses-to-COVID-19.

International Monetary Fund. (2020b). Tracking the \$9 Trillion Global Fiscal Support to Fight COVID-19. IMF Blog. https://blogs.imf.org/2020/05/20/tracking-the-9-trillion-global-fiscal-support-to-fightcovid-19/.

International Monetary Fund. (2020c). World Economic Outlook: The Great Lockdown. International Monetary Fund. Washington DC. April.

Lee, J-W and McKibbin, W. (2004). Globalisation and Disease: The Case of SARS. Asian Economic Papers. vol. 3. no. 1. MIT Press. Cambridge USA. pp. 113-131 (ISSN 1535-3516).

Lee, J-W and McKibbin, W. (2004). 'Estimating the Global Economic Costs of SARS' in S. Knobler, A. Mahmoud, S. Lemon, A. Mack, L. Sivitz, and K. Oberholtzer (Editors), Learning from SARS: Preparing for the Next Outbreak, The National Academies Press, Washington DC (0-309-09154-3).

Levine, DI and McKibbin, W. (2020). Simple steps to reduce the odds of a global catastrophe. The Brookings Institution. https://www.brookings.edu/opinions/simple-steps-to-reduce-the-odds-of-a-globalcatastrophe/

Maliszewska, M., Mattoo, A. and van der Mensbrugghe, A. (2020). The Potential Impact of COVID-19 on GDP and Trade: A Preliminary Assessment. Policy Research Working Paper 9211. World Bank. Washington DC.

McKibbin, WJ. and Fernando, R. (2020a). The Global Macroeconomic Impacts of COVID19: Seven Scenarios. Centre for Applied Macroeconomic Analysis. Working Paper 19/2020. Australian National University. March.

SSRN: https://ssrn.com/abstract=3547729 or http://dx.doi.org/10.2139/ssrn.3547729.

McKibbin, WJ. and Fernando, R. (2020b). The economic impact of COVID-19 in R. Baldwin and BW di Mauro (Editors), Economics in the time of COVID-19, Centre for Economic Policy Research, London. March. https://voxeu.org/system/files/epublication/COVID-19.pdf 
McKibbin, W. and Sachs, J. (1991). Global Linkages: Macroeconomic Interdependence and Cooperation in the World Economy. Brookings Institution. Washington DC. June. https://www.brookings.edu/book/global-linkages/.

McKibbin, W. and Sidorenko, A. (2006). Global Macroeconomic Consequences of Pandemic Influenza" Lowy Institute Analysis, February. 100 pages.

McKibbin, W. and Sidorenko, A. (2009). What a Flu Pandemic Could Cost the World", Foreign Policy, April.

https://foreignpolicy.com/2009/04/28/what-a-flu-pandemic-could-cost-the-world/

McKibbin, W. and Triggs, A. (2018). Modelling the G20. Centre for Applied Macroeconomic Analysis. Working paper 17/2018. Australian National University. April. https:/cama.crawford.anu.edu.au/publication/cama-working-paperseries/12470/modelling-g20.

McKibbin, W. and Vines, D. (2020). Global Macroeconomic Cooperation in response to the Covid-19 Pandemic: A roadmap for the G20 and the IMF.

McKibbin, W. and Wilcoxen P. (1999). The Theoretical and Empirical Structure of the GCubed Model” Economic Modelling, 16, 1, pp 123-148 (ISSN 0264-9993).

McKibbin, W. and Wilcoxen P. (2013). A Global Approach to Energy and the Environment: The G-cubed Model" Handbook of CGE Modelling, Chapter 17, North-Holland, pp 995-1068.

Organisation for Economic Cooperation and Development (2020). Global Economic Outlook. Organisation for Economic Cooperation and Development. Paris. June.

PRS Group, (2012). The International Country Risk Guide Methodology (ICRG). PRSGroup. https://www.prsgroup.com/wp-content/uploads/2012/11/icrgmethodology.pdf.

Roser, M., Ritchie, H., Ortiz-Ospina, E. and Hasell, J. (2020). Coronavirus pandemic (COVID-19). OurWorldInData.org. https://ourworldindata.org/coronavirus.

Taylor, JB (1993). Discretion versus policy rules in practice. Carnegie-Rochester Conference Series on Public Policy. vol. 39. pp. 195-214.

World Bank. (2020a). East Asia and Pacific Economic Update: East Asia and Pacific in the Time of COVID-19. World Bank. Washington DC. April.

World Bank. (2020b). Global Economic Prospects June 2020. World Bank Group. https://www.worldbank.org/en/publication/global-economic-prospects.

World Bank. (2020c). World Bank Open Data. World Bank. https://data.worldbank.org/.

World Health Organization. (2019). Global Health Expenditure Database. World Health Organization. https://apps.who.int/nha/database.

World Trade Organization. (2020). Methodology for the WTO Trade Forecast as of April 2, 2020. World Trade Organization. Geneva. 
Appendix A: Flowcharts for formulating shocks

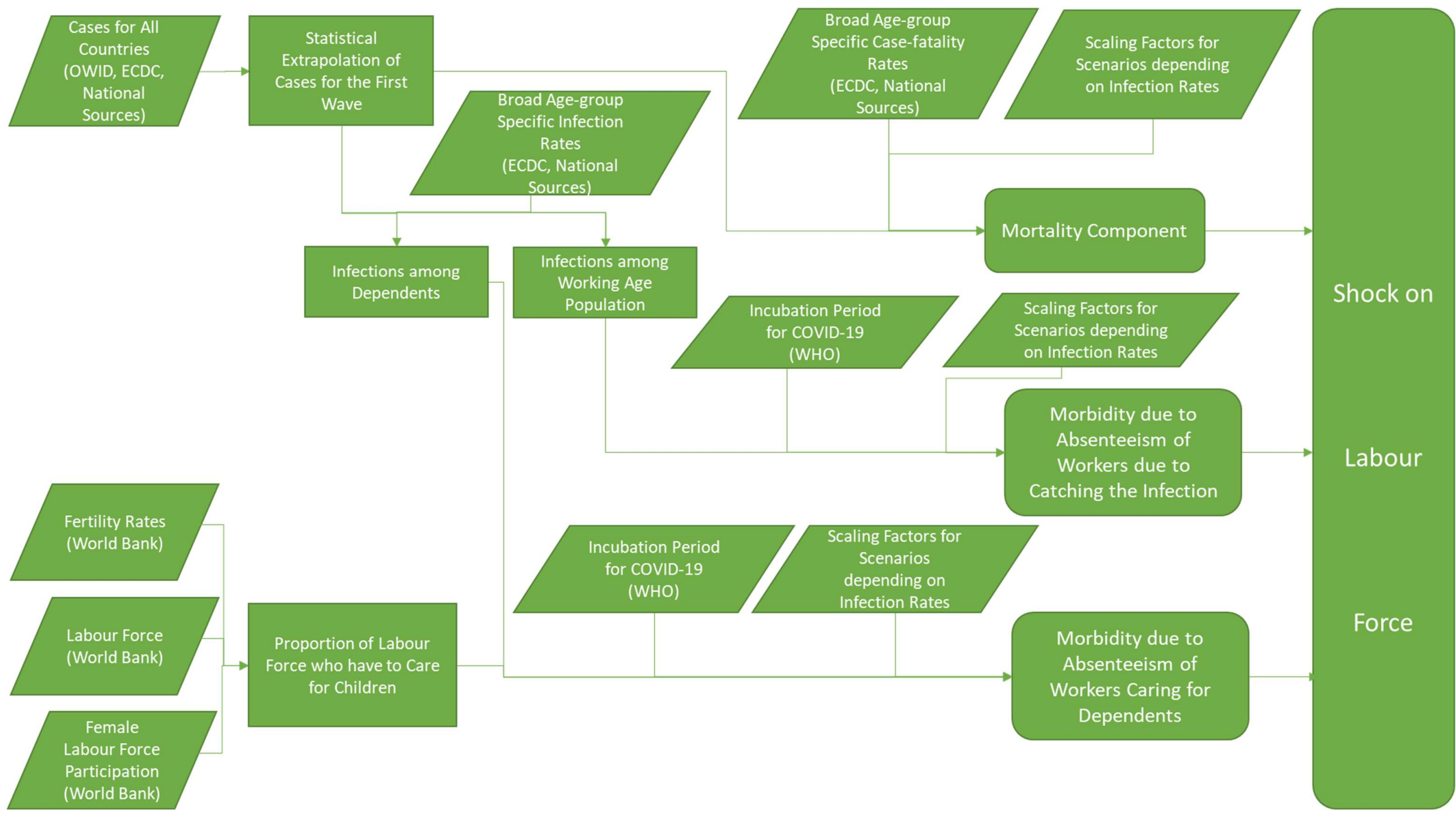

i|P a g e 

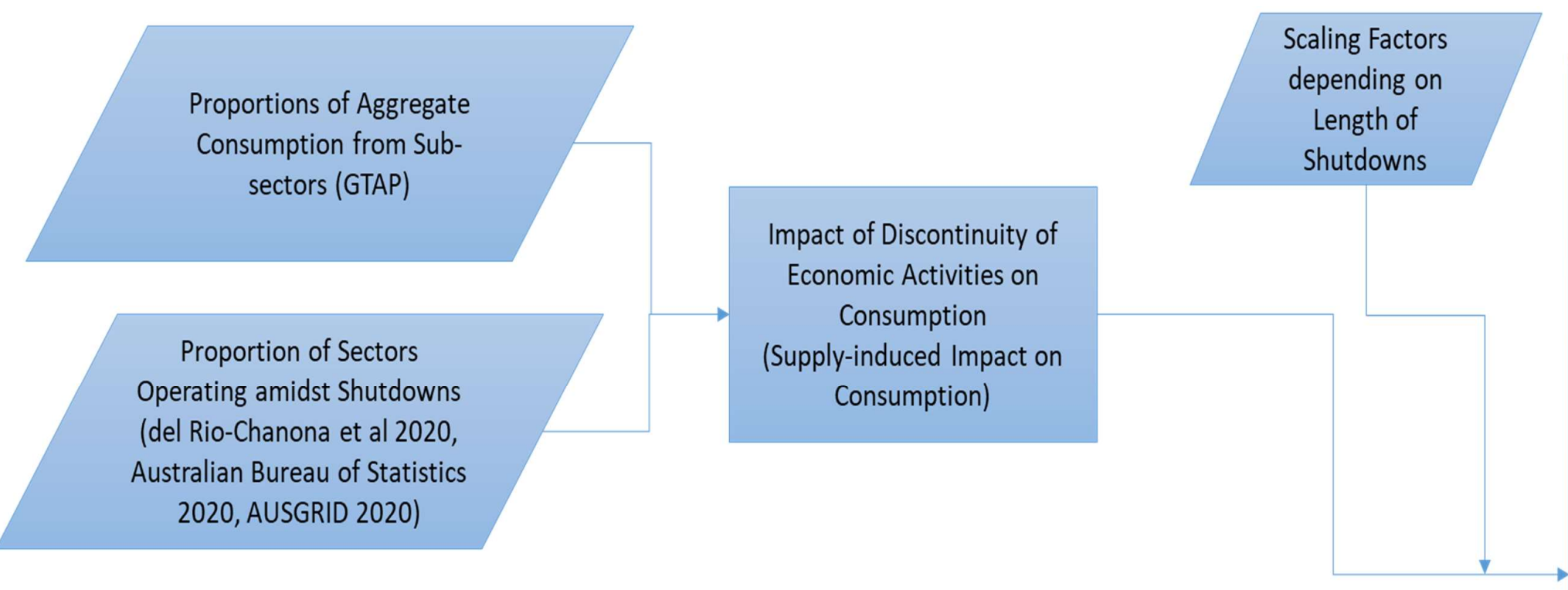

Shock

on

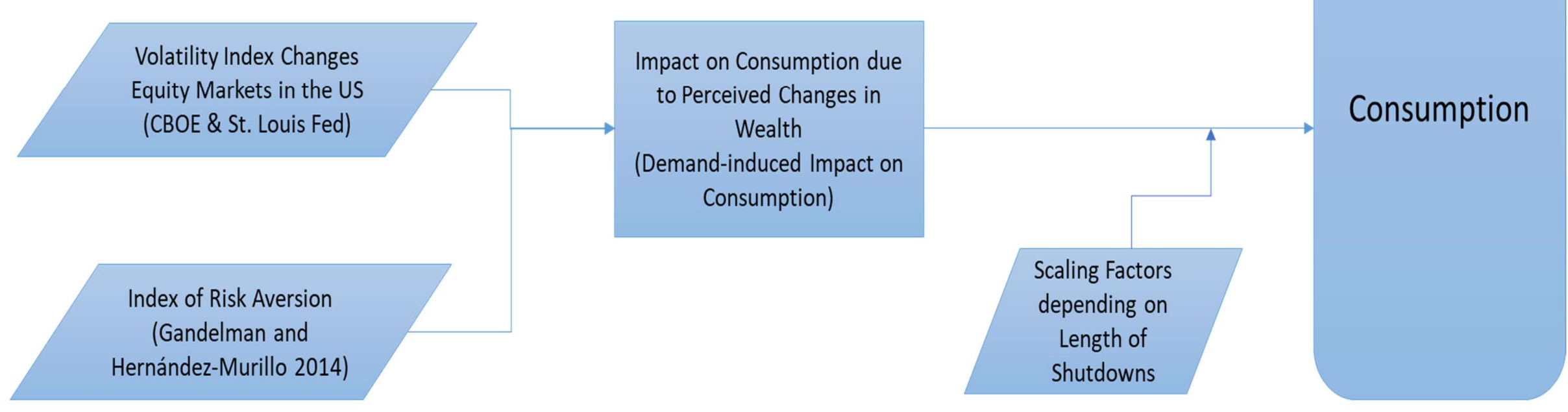

ii | P a g e 


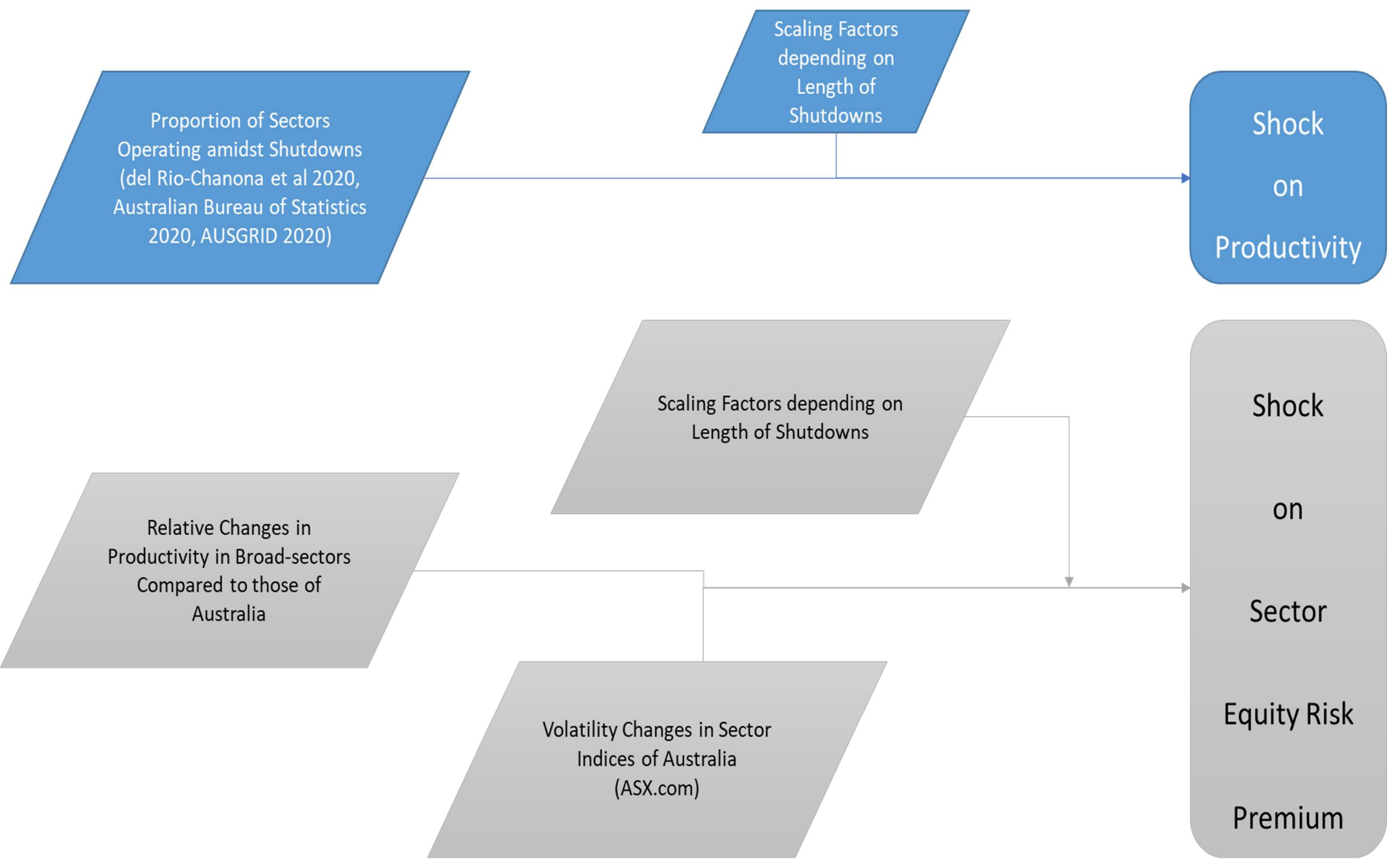

iii | P a g e 


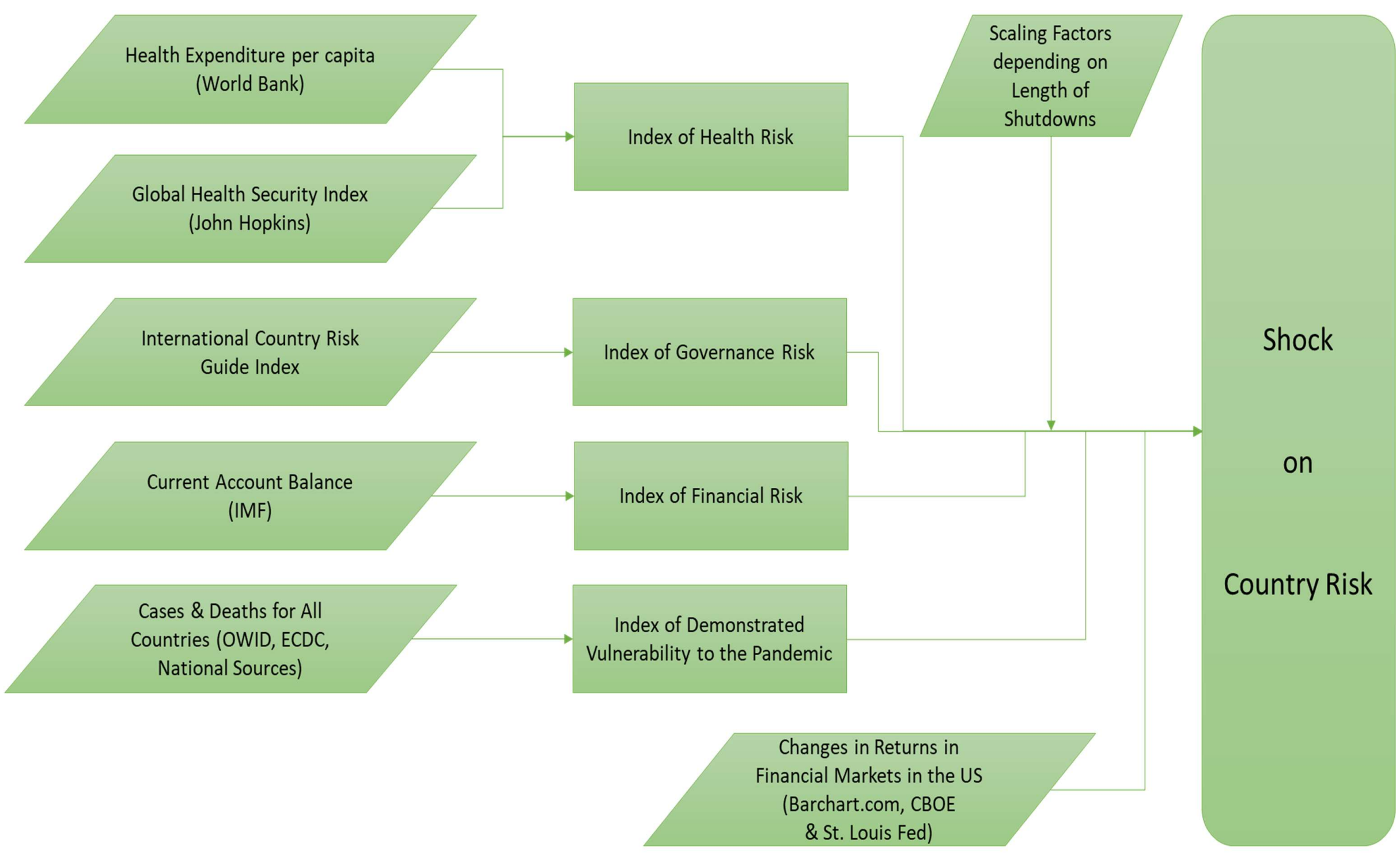

iv $\mathrm{P}$ a $\mathrm{g} \mathrm{e}$ 


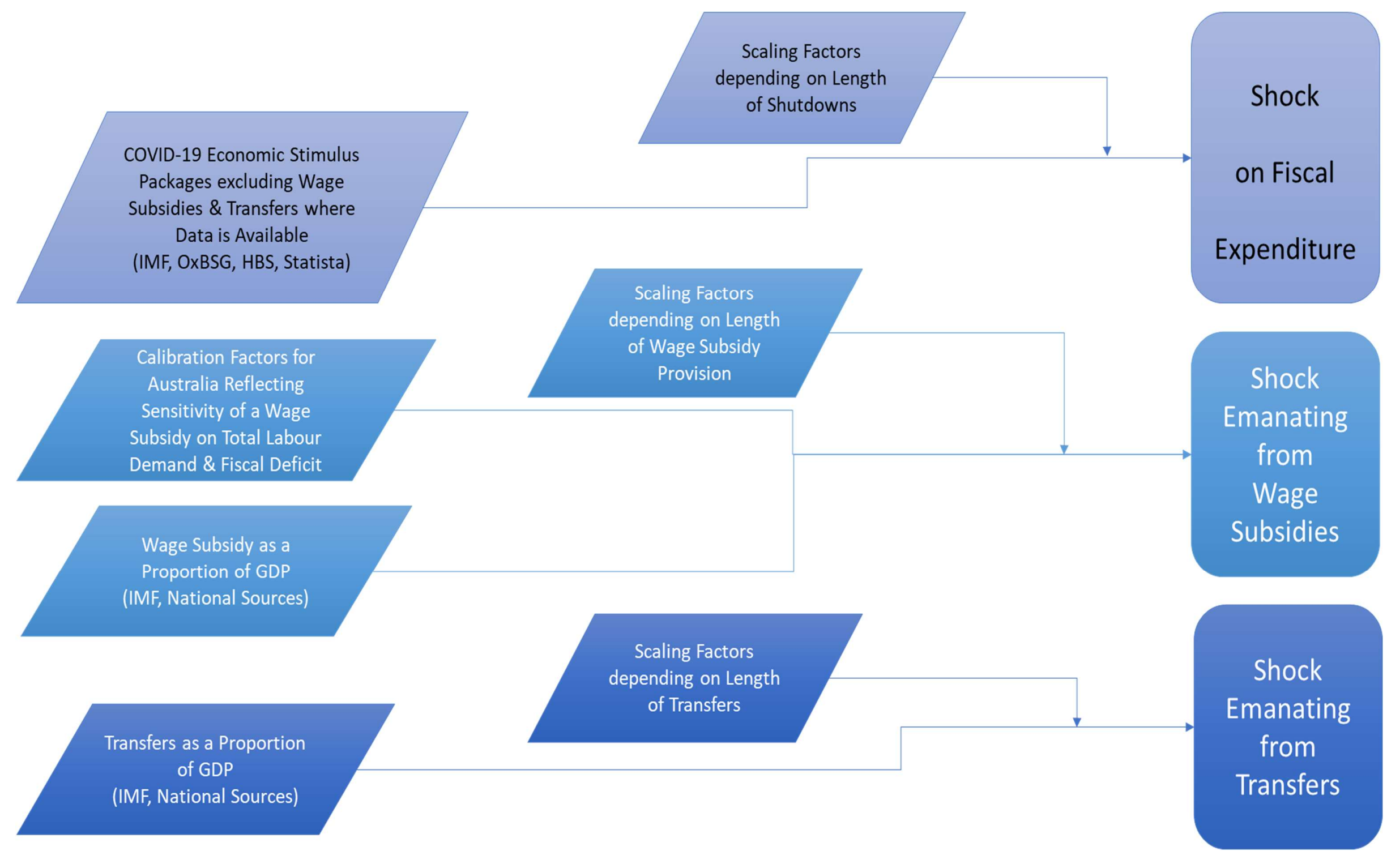

$\mathbf{v} \mid \mathrm{P}$ a g e 